\title{
Characterization of Optically Sensitive Polymer and Application to Microwave Antenna by
}

\section{Tosin Morolari, B.Tech.}

A thesis submitted to the Faculty of Graduate Studies and Research in partial fulfillment of the requirements for the degree of

\author{
Master of Applied Science \\ In \\ Electrical Engineering
}

Ottawa-Carleton Institute for Electrical Engineering

Department of Electronics, Carleton University

Ottawa, Canada

January 2010

(C) Copyright

2010, Tosin Morolari 
Library and Archives

Canada

Published Heritage

Branch

395 Wellington Street

Ottawa ON K1A ON4

Canada
Bibliothèque et

Archives Canada

Direction du

Patrimoine de l'édition

395 , rue Wellington

Ottawa ON K1A ON4

Canada
Your file Votre référence

ISBN: 978-0-494-68646-1

Our file Notre référence

ISBN: 978-0-494-68646-1
NOTICE:

The author has granted a nonexclusive license allowing Library and Archives Canada to reproduce, publish, archive, preserve, conserve, communicate to the public by telecommunication or on the Internet, loan, distribute and sell theses worldwide, for commercial or noncommercial purposes, in microform, paper, electronic and/or any other formats.

The author retains copyright ownership and moral rights in this thesis. Neither the thesis nor substantial extracts from it may be printed or otherwise reproduced without the author's permission.
AVIS:

L'auteur a accordé une licence non exclusive permettant à la Bibliothèque et Archives Canada de reproduire, publier, archiver, sauvegarder, conserver, transmettre au public par télécommunication ou par l'Internet, prêter, distribuer et vendre des thèses partout dans le monde, à des fins commerciales ou autres, sur support microforme, papier, électronique et/ou autres formats.

L'auteur conserve la propriété du droit d'auteur et des droits moraux qui protège cette thèse. Ni la thèse ni des extraits substantiels de celle-ci ne doivent être imprimés ou autrement reproduits sans son autorisation.
In compliance with the Canadian Privacy Act some supporting forms may have been removed from this thesis.

While these forms may be included in the document page count, their removal does not represent any loss of content from the thesis.
Conformément à la loi canadienne sur la protection de la vie privée, quelques formulaires secondaires ont été enlevés de cette thèse.

Bien que ces formulaires aient inclus dans la pagination, il n'y aura aucun contenu manquant. 
The undersigned recommended to the faculty of Graduate Studies and Research acceptance of Thesis

\title{
Characterization of Optically Sensitive Polymer and Application to Microwave Antenna
}

\author{
Submitted by Tosin Morolari, B. TECH \\ In partial fulfillment of the requirement for the degree of \\ Master of Applied Science in Electrical Engineering
}

Thesis Supervisor

Chair, Department of Electronics

Ottawa-Carleton Institute for Electrical Engineering

Carleton University

2010 


\section{ABSTRACT}

Due to the rapid growth in wireless networks in recent years, there is a need for a tunable microwave device to be able to effectively switch between different networks and wireless technologies. This thesis investigates the use of a photoconductive polymer to optically tune a microwave device or antenna.

The dielectric properties of a hybrid (Polymer + Cadmium Sulphide) photoconductive polymer are extracted using microwave reflection measurements on a coplanar waveguide test structure. The material under test was overlaid on an interdigitated capacitor that was fabricated on a transparent glass substrate. The material characterization was done with and without broadband optical illumination. The material parameters were obtained by fitting measured reflection coefficient data to an equivalent lumped element circuit or HFSS model in ADS. The results obtained from the characterization show that the polymer was photoconductive. The extracted dielectric constant $\left(\varepsilon_{\mathrm{r}}\right)$ of 4 and loss tangent $(\tan \delta)$ of 0.004 were obtained without illumination, while the loss tangent increased to 0.11 with illumination but the $\varepsilon_{\mathrm{r}}$ value had no measureable change.

The properties of the novel photoconductive polymer were used in the theoretical design of an optically tunable dipole antenna. The antenna was designed for GSM band (1900MHz to $2100 \mathrm{MHz}$ ). The tunability in the antenna was achieved by applying the characterized polymer along a slotted segment of the dipole arm, and effectively changing the dipole length by optical illumination. 


\section{ACKNOWLEDGEMENTS}

Firstly, I am my grateful to my supervisors, Dr Langis Roy and Dr Barry Syrett for the continuous technical support and guidance through the program. I also want to appreciate my project group members, Atiff, Bashir, Greg, Arsalan, Popi for their priceless contributions and ideas. Many thanks to the departmental staff, Blazenka, Peggy, Sylvie and Anna for the moral support and care during the whole program.

Special thanks to Funmilayo Lawal for the time spent in editing, reference writing and moral support. I am also extending my appreciations to Rhoda, Walefeips, Fola and Femi, John for the moral and constant support

I would especially appreciate the Ogini`s family who has made the whole program a huge convenience.

My heartfelt gratitude goes to God, the author of wisdom, Who has held my hand tightly throughout the ups and downs of this program. 


\section{TABLE OF CONTENTS}

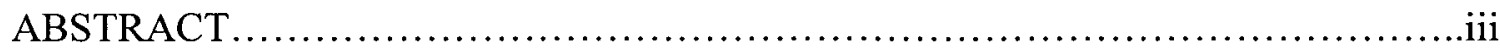

ACKNOWLEDGEMENT .........................................................

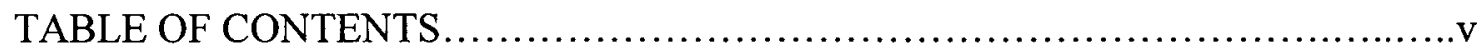

LIST OF FIGURES...........................................................

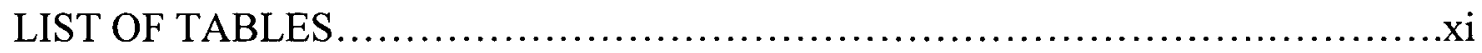

LIST OF ABBREVIATIONS AND SYMBOLS................................

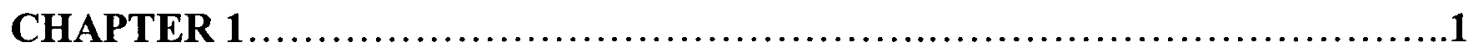

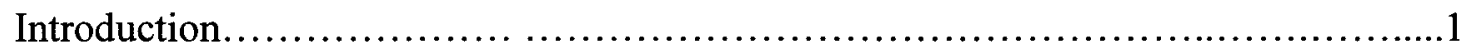

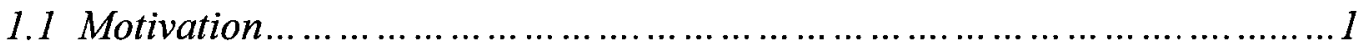

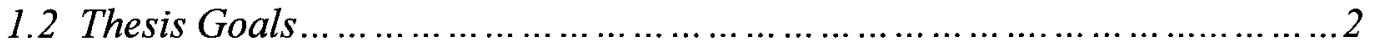

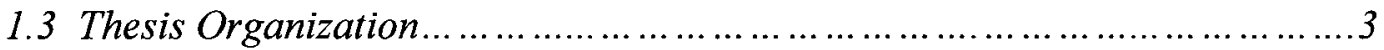

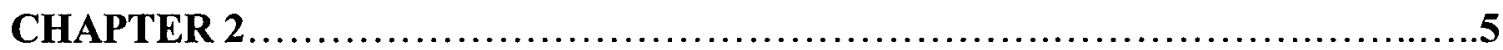

Material Properties of Polymers and Applications to Tuning Microwave Devices........5

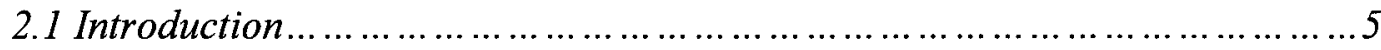

2.2 Dielectric Properties of Materials ................................................. 5

2.3 Optically Controllable Polymer ............................................. 10

2.4 Tunable Microwave Device ....................................................... 15

2.5 Proposed Optical Tuning of Microwave components ..........................22

2.6 Chapter Summary and Conclusion ...........................................24

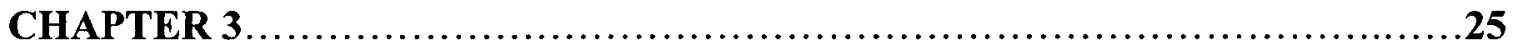

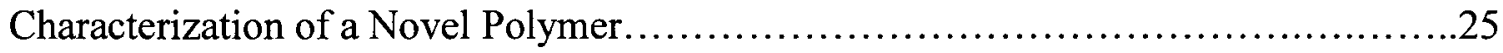

3.1 Introduction: Techniques and Proposed Method of Characterization.........25

3.2 Monolithic Metal Insulator Metal (MIM) Capacitor ..........................26 


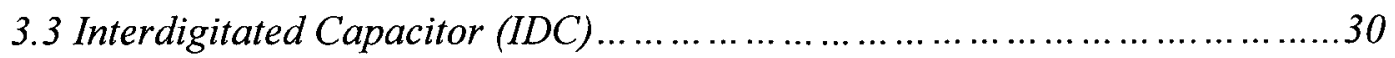

3.4 Development of Interdigitated Structure for Polymer Characterization.........32

3.5 Experimental Characterization of Novel Polymer ................................... 39

3.6 Extraction and Modeling of Material Properties...................................4 47

3.7 Chapter Summary and Conclusion ..............................................55

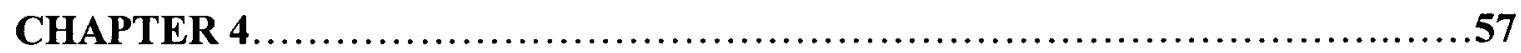

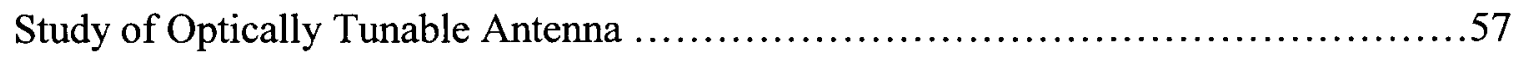

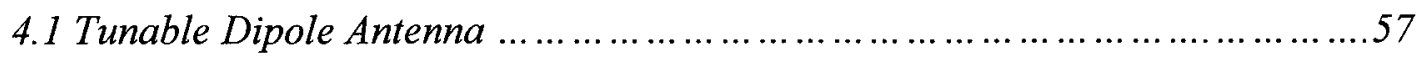

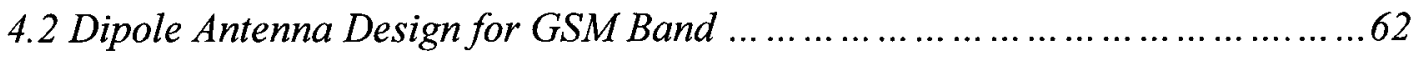

4.3 Estimation of the Required Polymer Properties ....................................... 72

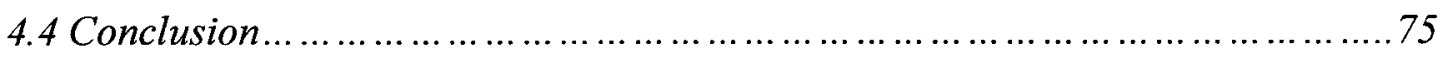

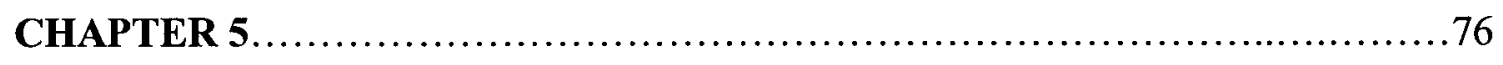

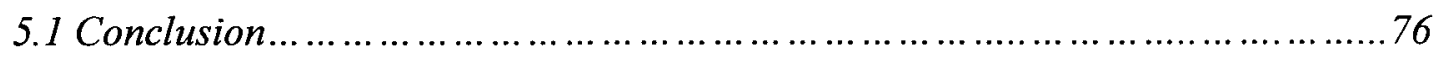

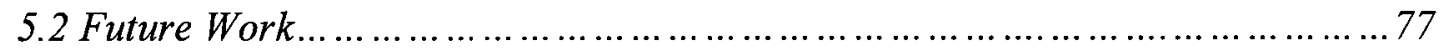

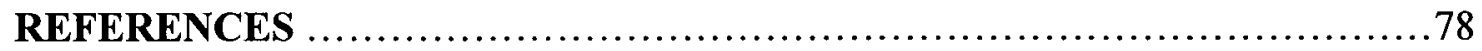




\section{LIST OF FIGURES}

Figure 2.1 Frequency dependence of permittivity for a hypothetical dielectric

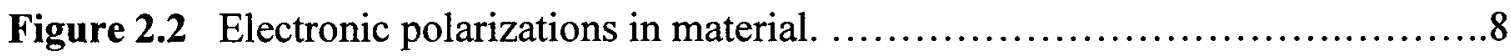

Figure 2.3 Ionic polarizations showing the application of E-Field ...................9

Figure 2.4 Dipolar polarization................................................

Figure 2.5 Conductivities of various polymeric materials covering the conductivity span.

Figure 2.6 PVK with the fullerene PCBM, 4F-TCNQ, TCNP ......................13

Figure 2.7 (a)-(e) Eplanation of photorefractive effect (a) The absorption of the light. (b) Transport of the charge carriers. (c) Trapping of the carriers. (d) and (e) Dephasing ..............15

Figure 2.8 Common wireless usages for different applications. .16

Figure 2.9 Configuration for the electrically controllable antenna with the voltage applied perpendicularly to the direction

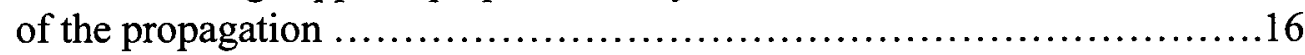

Figure 2.10 Measured antenna pattern at $7.8 \mathrm{GHz}$ as a result of bias voltage ...........18

Figure 2.11 A single pole double throw RF MEMS switch........................ 20

Figure 2.12 Dipole antenna with RF MEMS along the length of the arm .............21

Figure 2.13 Antenna pattern of the RF MEMS tunable dipole antenna.................21

Figure 2.14 Tunable bandpass filter with its response overlaid with optically sensitive polymer.

Figure 2.15 Tunable bandpass filter with its response overlaid with optically sensitive polymer upon illumination.........................23

Figure 3.1 Metal Insulator Metal (MIM) Capacitor..............................26

Figure 3.2 Equivalent lumped element model MIM..............................27

Figure 3.3 (a)The top view of HFSS model of CPW feed MIM capacitor.............29

Figure 3.3 (b) The side view of the model showing the "step"....................29

Figure 3.4 A two port interdigitated capacitor...................................3 
Figure 3.5 A lumped equivalent model of IDC. Rs, Ls and Cs are the series resistor, inductor and capacitor respectively. The $\mathrm{Cp}$ is the parallel capacitor.

Figure 3.6 HFSS model of interdigitated capacitor with the zoomed section showing the $10 \mu \mathrm{m}$ spacing between each fingers, where $L F$ is the length of the Finger, $W F$ is the width of the finger, $W F B$ is the width of the feedbar CPW, $W$ is the width of the CPW, $L$ is the length of CPW, $L F B$ is the length of the feed bar, and $G$ gap between ground and signal line $(0.32 \mu \mathrm{m})$

Figure 3.7 HFSS model of the material under test placed on interdigitated capacitor with $1 \mathrm{~mm}$ finger length

Figure 3.8 (a) and (b). The Simulated S11 on Smith chart for $1 \mathrm{~mm}$ finger length interdigitated capacitor with lossy dielectric overlay having $\varepsilon_{\mathrm{r}}=5$ over frequency range of $100 \mathrm{MHz}$ to $5 \mathrm{GHz}$ with $\tan \delta$ as a parameter .36

Figure 3.9 The Simulated $\mathrm{S} 11$ for the $1 \mathrm{~mm}$ finger length interdigitated capacitor with lossy dielectric overlay having $\varepsilon_{\mathrm{r}}=5$ over frequency range of $100 \mathrm{MHz}$ to $5 \mathrm{GHz}$ with $\tan \delta$ as a parameter.

Figure 3.10 (a) and (b) The Simulated Phase of S11 for the $1 \mathrm{~mm}$ finger length interdigitated capacitor with lossy dielectric overlay having $\tan \delta=0.05$ over frequency range of $100 \mathrm{MHz}$ to $5 \mathrm{GHz}$ with $\varepsilon_{r}$ as a parameter.

Figure 3.11 Fabricated IDC on a circular glass substrate 40

Figure 3.12 IDC with the new dimensions after fabrication. 40

Figure 3.13 Characterization Setup showing the VNA, LAMP and the MUT.

Figure 3.14 S11 measurements of the interdigitated from $100 \mathrm{MHz}$ to $5 \mathrm{GHz}$ with no overlay material. A) Shows the Return loss, as the frequency increase less reflection occurs. B) Phase. C) The capacitance with resonance at $1.6 \mathrm{GHz}$. D) S11 on Smith Chart

Figure 3.15 Mixture of CdS and polymer overlaid on the interdigitated capacitor with SMA connector mounted with silver epoxy 
Figure 3.16 Measured results for IDC having a nominal finger length of $\approx 1 \mathrm{~mm}$ having $\mathrm{CdS} /$ polymer overlay coating with and without broadband optical illumination, with illumination over the frequency range of $100 \mathrm{MHz}$ to $5 \mathrm{GHz}$.

a) Return loss, b) Impedance on Smith chart, c) Phase of S11 .45

Figure 3.17 Lumped element equivalent circuits for the connector, CPW and IDC.

Figure 3.18 HFSS model for the fabricated model with MUT overlaid on the IDC

Figure 3.19 Equivalent lumped/HFF model with s-parameter (SP) data from HFSS

Figure 3.20 Return loss comparison of the measured result, lumped element equivalent model and lumped/HFSS model without polymer overlay

Figure 3.21 Reflection phase comparison of the measured result, lumped element equivalent model and lumped/HFSS model without polymer overlay

Figure 3.22 Return loss comparison of the measured result, lumped element equivalent model and lumped/HFSS model with polymer overlay having $\varepsilon_{r}=4$ and $\tan \delta=0.004$ - No illumination

Figure 3.23 Reflection phase comparison of the measured result, lumped element equivalent model and lumped/HFSS model with polymer overlay having $\varepsilon_{r}=4$ and $\tan \delta=0.004$ - No illumination

Figure 3.24 Return loss comparison of the measured result, lumped element equivalent model and lumped/HFSS model with polymer overlay having $\varepsilon_{r}=4$ and $\tan \delta=0.004$ - With illumination .54

Figure 3.25 Reflection phase comparison of the measured result, lumped element equivalent model and lumped/HFSS model with polymer overlay having $\varepsilon_{r}=4$ and $\tan \delta=0.004$ - With illumination

Figure 4.1 Dipole arm with two diodes on each arm .58

Figure 4.2 Measured return loss of multi-frequency dipole for, all the diodes are $\mathrm{OFF}$, inner diodes are $\mathrm{ON}$, all diodes are $\mathrm{ON}$ 
Figure 4.3 Silicon switch controlled dipole antenna............................60

Figure 4.4 Return loss of the dipole antenna as a function of light intensity ...........61

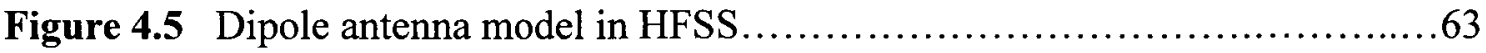

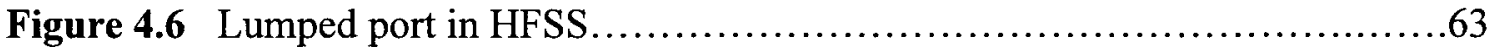

Figure 4.7 $\mathrm{S} 11$ at $1.9 \mathrm{GHz}$ for $26.6 \mathrm{~mm}$ dipole arm..............................65

Figure 4.8 Real and imaginary impedances at $1.9 \mathrm{GHz}$

for the $26.6 \mathrm{~mm}$ dipole arm........................................66

Figure 4.9 The distribution of E-fields for the $26.6 \mathrm{~mm}$ dipole arm at $1.9 \mathrm{GHz}$ dipole with high coupling at the feed....................66

Figure 4.10 Simulated return loss $\mathrm{S} 11$ at $2.1 \mathrm{GHz}$

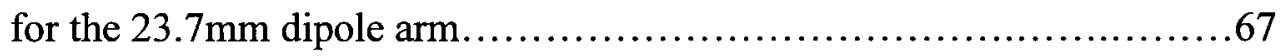

Figure 4.11 Simulated radiation pattern at $2.1 \mathrm{GHz}$

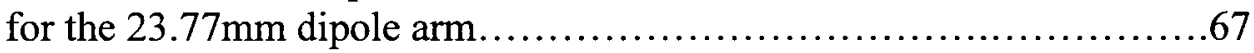

Figure 4.12 Simulated real and imaginary impedances for

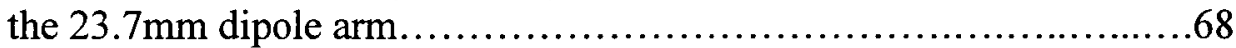

Figure 4.13 The new dipole antenna structure with the gap placed along the dipole arm

Figure 4.14 Simulated S11 of the segmented dipole arm at $2.1 \mathrm{GHz}$ with $0.4 \mathrm{~mm}$ gap. 70

Figure 4.15 E-field plot of the segmented dipole arm

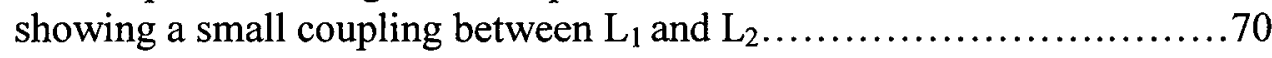

Figure 4.16 Antenna structure with the photoconductive material placed along the segmented gap

Figure 4.17 Resonance frequency of the antenna with different conductivity values of the hybrid polymer. 


\section{LIST OF TABLES}

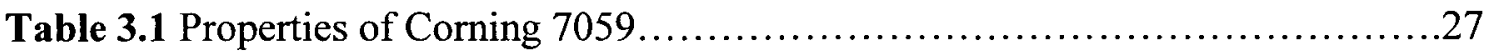

Table 3.2 Different geometry of IDC with the corresponding Capacitance and SRF....34

Table 3.3 Results of optically-sensitive polymer material characterization using the IDC test structure developed in this thesis......................55

Table 4.1 The optimized length and spacing for the dipole antenna...................64

Table 4.2 Resonance frequency with conductivity and the material type ...........74 


\section{LIST OF ABBREVIATIONS}

GSM Group Special Mobile

VNA Vector network analyzer

ADS Agilent Advance Design System

PVC Poly(vinyl chloride)

PVK Poly-N-vinylcarbozole

PCBM Phenyl-C61-Butyric-Acid-Methyl-Ester

TCNP Tetracyanopyrazinide Dimer Dianion

CdS Cadmium Sulphide

MEMS Micro Electro Mechanical Systems

MIM Metal-Insulator-Metal

IDC Interdigitated Capacitor

MUT Material Under Test

CPW Co-Planar Wave guide

ITO Indium tin oxide

SDR Software Define Radio

CR Cognitive Radio 


\section{Chapter 1}

\section{Introduction}

\subsection{Motivation}

Many mobile devices that are used today, such as global positioning systems (GPS), cellular phone, personal digital assistants (PDA) operate on multiple wireless networks, so there is a need for the devices to be able to effectively switch between these different networks. This need has led to the development of tunable microwave devices. The deployment of optically tunable microwave devices has become more attractive due to its advantages over existing approaches such as tuning by temperature or applied dc bias. Optical control offers advantages such as high isolation between the controlling optical beam and controlled microwave signal, fast response, and high-power handling capability. Immunity to electromagnetic interference and absence of mechanical controls, which usually lead to noise, wear and tear, are the other advantages of optically controlled devices. Passive microwave devices such as phase shifters, filters, attenuators, antennas, switches can be controlled optically [1] [2] [3].

The principle behind the optical tunability of these devices is photo-excitation of a photosensitive dielectric material. The photo-carriers in the dielectric material modulate the complex dielectric constant changing the propagation characteristics of the microwave signal. At low microwave frequencies the photo-carriers essentially modify the conductance of the material keeping the dielectric constant of the medium practically 
unaltered. However, at millimeter wavelengths, both the real and imaginary part of the dielectric constant is modified due to photo-excitation. This effect makes it possible to develop optically controlled microwave devices [2]. In some resonance circuit of

inductance (L) and capacitance (C), optical tunability is easily achieved because the capacitance of a material is a function of the dielectric constant which can be altered as a function of light illumination.

Polymers are organic materials. They are light in weight, cheap, non toxic, and easy to manipulate. The material properties of some polymers can be altered by applying external forces (applied dc field, excitation by light, pressure etc). The effect of the change in the material properties can be used to tune or reconfigure microwave devices. As part of the ongoing research Prof W.Wang of the chemistry department and Prof. S. McGarry are currently developing new optically sensitive polymers at Carleton University.

\subsection{Thesis Goals}

The major goal of this thesis research is to characterize a novel optically sensitive polymer in the microwave region. That is, by the use of microwave measurements to extract the basic physical properties of the polymer, namely dielectric constant, loss tangent and the conductivity as a function of optical illumination. The second main goal is to use this information to design an optically tunable dipole antenna at the GSM band (1900MHz to $2100 \mathrm{MHz}$ ). 
The specific goals of this thesis are as follows.

1. Develop a suitable test structure for microwave characterization of optically sensitive polymers.

2. Extract and assess the material properties of the optically sensitive materials under test

3. Determine the conductivity ranges required of future generations of optically controlled polymers.

4. Show the possible design of an optically-tunable microwave antenna.

\subsection{Thesis Organization}

The first section of Chapter 2 gives basic details on dielectric properties of materials and polarization in dielectric materials. Section 2.2 describes the properties and applications of polymers. The photorefractive and photoconductive properties of polymers are also reviewed in this section. Section 2.3 reviews the different types of tunable microwave components related to our research, methods of tuning and the limitations of these methods. The characterization of the hybrid polymer is discussed in Chapter 3. The basic technique is to apply a photo-sensitive polymer on to a microwave interdigital capacitor and measure the change in capacitance under optical illumination using a vector network analyzer (VNA). Many different geometries of a tunable interdigital capacitor were studied. The geometry, measured capacitance and the selfresonant frequency of these capacitors with or without optical illumination are presented in section 3.3. The modeling and the extraction of the properties of the material under test 
were also investigated using commercially available software ANSOFT HFSS and Agilent Advance Design System (ADS).

A tunable dipole antenna is designed in Chapter 4 based on the approximate parameters that were extracted from the results in Chapter 3 . The conductivity of the material was used to change the resonant frequency of the antenna from $1900 \mathrm{MHz}$ to $2100 \mathrm{MHz}$.

Chapter 5 gives a summary of the results and the work done in the thesis. Opportunities for more research are also presented. 


\section{Chapter 2}

\section{Material Properties of Polymers and}

\section{Application to Tuning Microwave Devices.}

\subsection{Introduction.}

Section 2.2 gives a background of dielectric properties of materials, the effect of applications of strong electric field, and optically sensitive polymer and its applications. Tunable microwave devices are discussed at the last Section, and different methods of microwave tuning are reviewed.

\subsection{Dielectric Properties of Materials.}

Dielectric materials are substances with very low conductivity usually in the range of $10^{-20}$ to $10^{-12}(\Omega \mathrm{m})^{-1}$. They are also known as insulators because the electrons are bound to the atomic nuclei by strong forces. They are very useful because of the electrical polarization properties they exhibit. On applying electric field $\vec{E}$ to most dielectric materials, the polarization of the atoms and molecules create a dipole moment $\vec{P}$ that increases the displacement flux density $\vec{D}$ [10]. The relationship between, $\vec{D}, \vec{E}$ and $\vec{P}$ is given as 


$$
\vec{D}=\varepsilon_{o} \vec{E}+\vec{P}
$$

where $\varepsilon_{o}$ is the permittivity of free space.

In linear isotropic materials, the polarization of the dielectric materials relates to the electric field by

$$
\vec{P}=\varepsilon_{o} \chi_{e} \vec{E}
$$

where $\chi_{e}$ the is the electric susceptibility. Using Eqn. (2.2) in (2.1) gives

$$
\vec{D}=\varepsilon_{o}\left(1+\chi_{e}\right) \vec{E}
$$

or

$$
\vec{D}=\varepsilon_{o} \varepsilon_{r} \vec{E}=\varepsilon \vec{E}
$$

where $\varepsilon_{r}=1+\chi_{e}$ is the relative permittivity, and $\varepsilon$ is the permittivity. The complex permittivity can be written as

$$
\varepsilon=\varepsilon^{l}-j \varepsilon^{\| \prime}
$$

The real part $\varepsilon^{\mid}$relates to the capability of the material to store electric energy. The imaginary part $\varepsilon^{\|}$relates to the losses in the dielectric material, due to damping of vibrating dipole moment or polarization loss [10][11]. Eqn. (2.6) expresses the loss tangent of a good insulator,

$$
\tan \delta=\frac{\varepsilon^{\|}}{\varepsilon}
$$


If it is not a good insulator, the material may also have some conductor loss characterized by conductivity $\sigma$. The loss tangent including both polarization loss and conductor loss is given by

$$
\tan \delta=\frac{\omega \varepsilon^{\|}+\sigma}{\omega \varepsilon^{1}}
$$

where $\omega=2 * \pi * f$

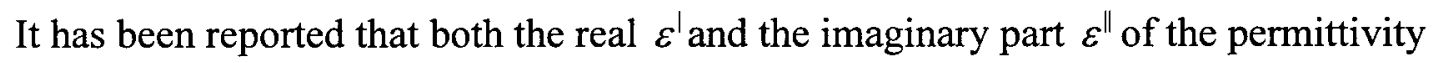
depend on temperature, light intensity and pressure (piezoelectric effect) [5][12]. There is also strong frequency dependence of both real and imaginary part of the dielectric as shown Figure 2.1. " $\varepsilon$ " generally decreases with increasing frequency, with perturbations of this trend attributable to atomic and polarization effects.

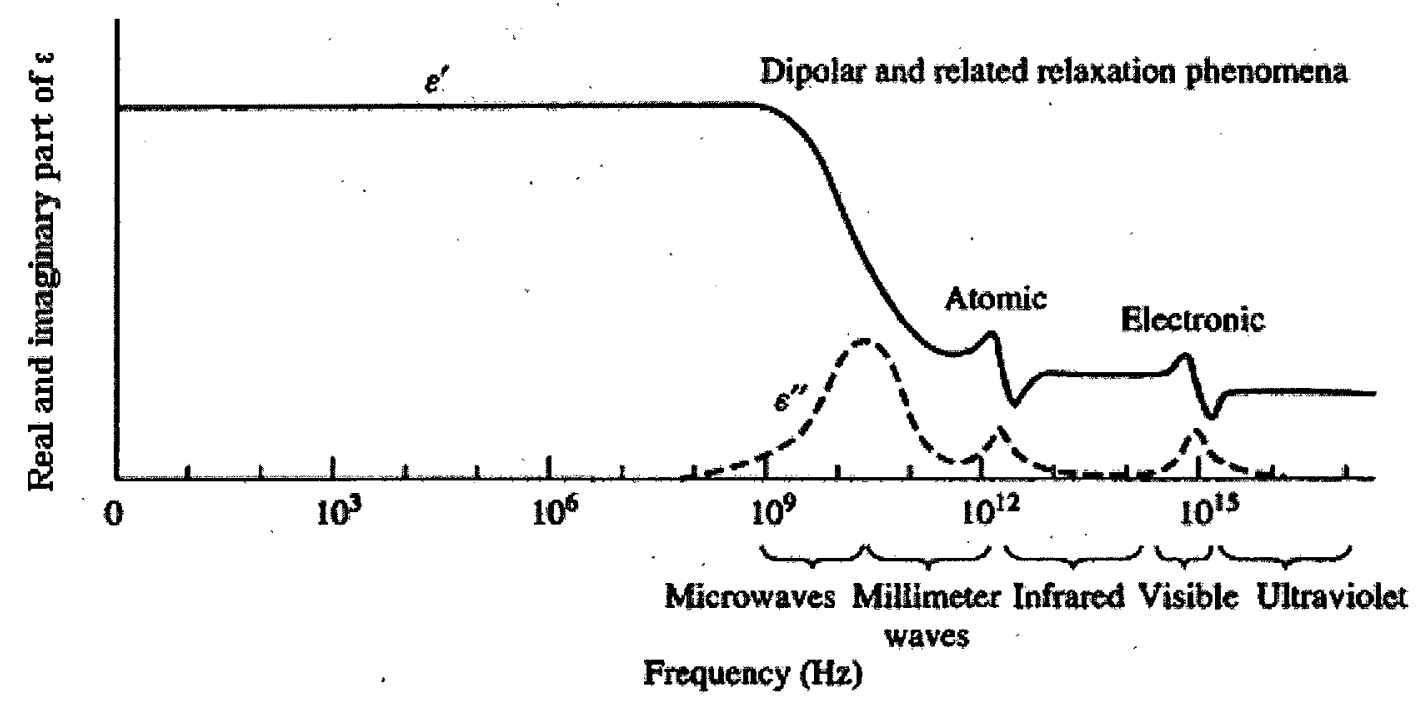

Figure 2.1 Frequency dependence of permittivity for a hypothetical dielectric [10]. 
It can be seen that electronic polarization dominates at the optical frequency $10^{15} \mathrm{~Hz}$, while atomic polarization peaks at $10^{12} \mathrm{~Hz}$ which is between the millimeter range and the infrared region. Both these effects alter the dielectric's properties (potentially useful for microwave circuit tunability) and will be described in the next section.

\subsubsection{Polarization in Dielectric.}

Polarization in a dielectric is the process by which electric dipoles are formed or aligned under the strong force of an electric field $\vec{E}$. The different types of polarizations are listed below [4][5][8][9][10]

- Electronic Polarization: This take place in neutral atoms. It occurs when an electric field displaces the electron cloud surrounding the parent nucleus as shown in Fig 2.2.

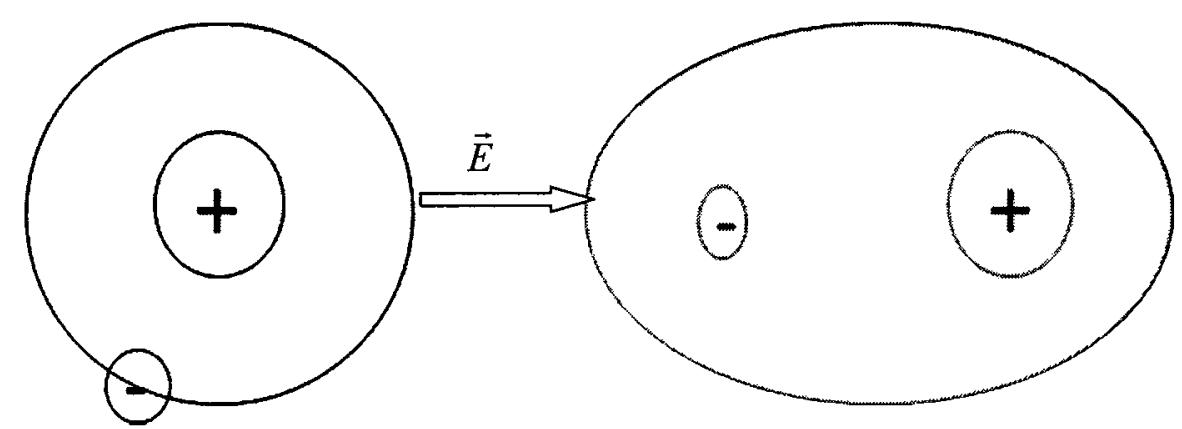

Figure 2.2 Electronic polarizations in

- Atomic Polarization: It occurs when adjacent positive and negative ions stretch under an applied electric field. Both electronic and atomic polarization are similar [12]. 
- Ionic Polarization: Similar to atomic polarization, this involves the separation of different ionic species under the influence of the applied electric fields as shown in Figure $2.3[10]$.

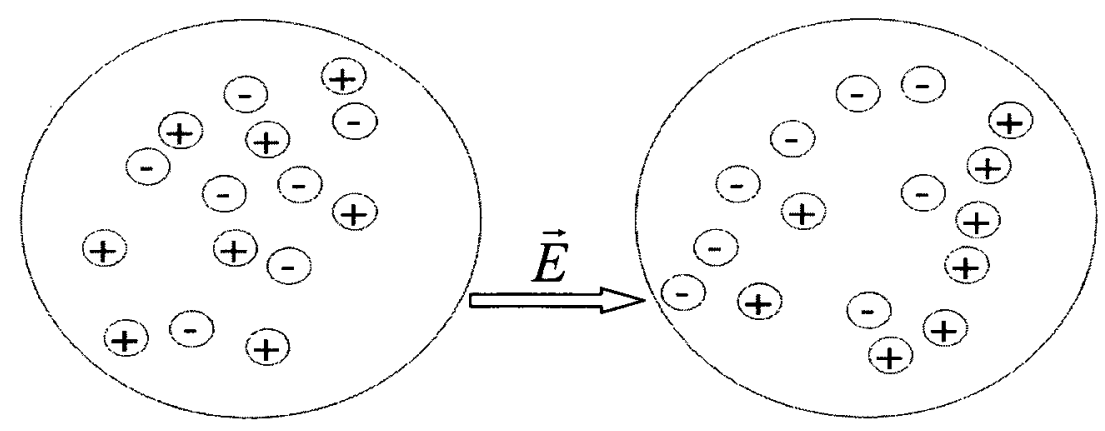

Figure 2.3 Ionic polarizations showing the application of E-Field.

It is only found in ionic substances whose molecules are formed of atoms having excess charges of opposite polarities [9]. The effect of ionic polarization usually leads to a very high dielectric constant.

- Dipolar Polarization: On a macroscopic scale the electric dipoles can follow an applied electric field [4][9]. This gives rise to reorientation of the dipole moment as shown in Fig. 2.4. It also called molecular or orientation polarization.

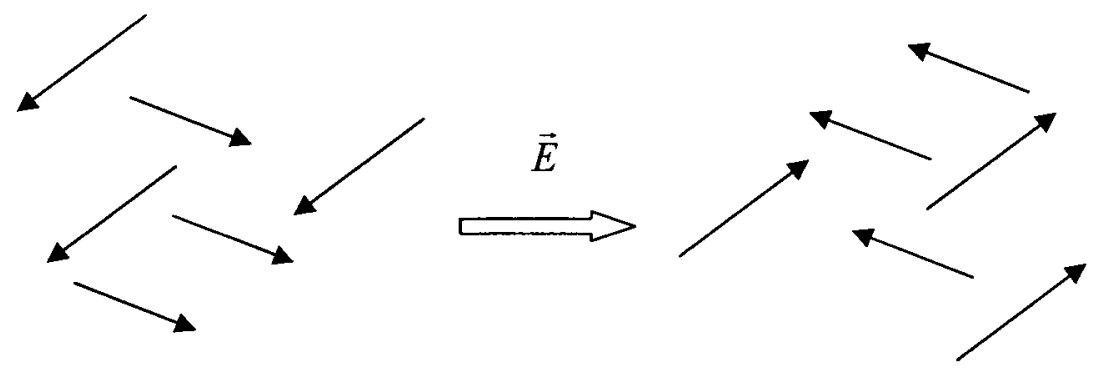

Figure 2.4 Dipolar polarization. 


\subsection{Optically Controllable Polymer.}

Polymers are organic materials that are made from many molecules bonding together to form a long molecular chain. Polymers are mostly used as insulating materials because they possess strong covalent bonds. Polymers are readily available, cheap and non-toxic. Polyethylene, Polypropylene, Polystyrene, Poly(vinyl chloride) (PVC), Polytetrafluoroethylene (Teflon) are examples of polymers that are used in making plastic bags, wire insulation, fibers, clear food wrap, video cassettes tape etc .

Polymers are now replacing inorganic materials in many applications because some can have electrical properties that are very similar to semiconductors and metals $[4][5][8]$. Figure 2.5 shows the conductivity of carbon based polymer over a broad conductivity range. Polyester, teflon, nylon and Cis- $(\mathrm{CH})_{\mathrm{x}}$ are listed as the insulators. They have long carbon-carbon bond length. The length of the carbon-carbon bond is shorter in semiconductor polymers. Poly (acetylene)s, poly(pyrrole)s, poly(thiophene)s, polyanilines, polythiophenes, poly(p-phenylene sulfide), and poly(p-phenylene vinylene)s (PPV) are examples of conductive polymer [34]. Conductive polymers are used in making circuit board, shielding, and sensors [16].

A lightweight, readily moldable, highly photosensitive polymer material would be desirable for many applications. The optical properties such as photorefractivity or photoconductivity of a polymer can be improved by adding suitable dopant to increase the hole/electron mobility. 


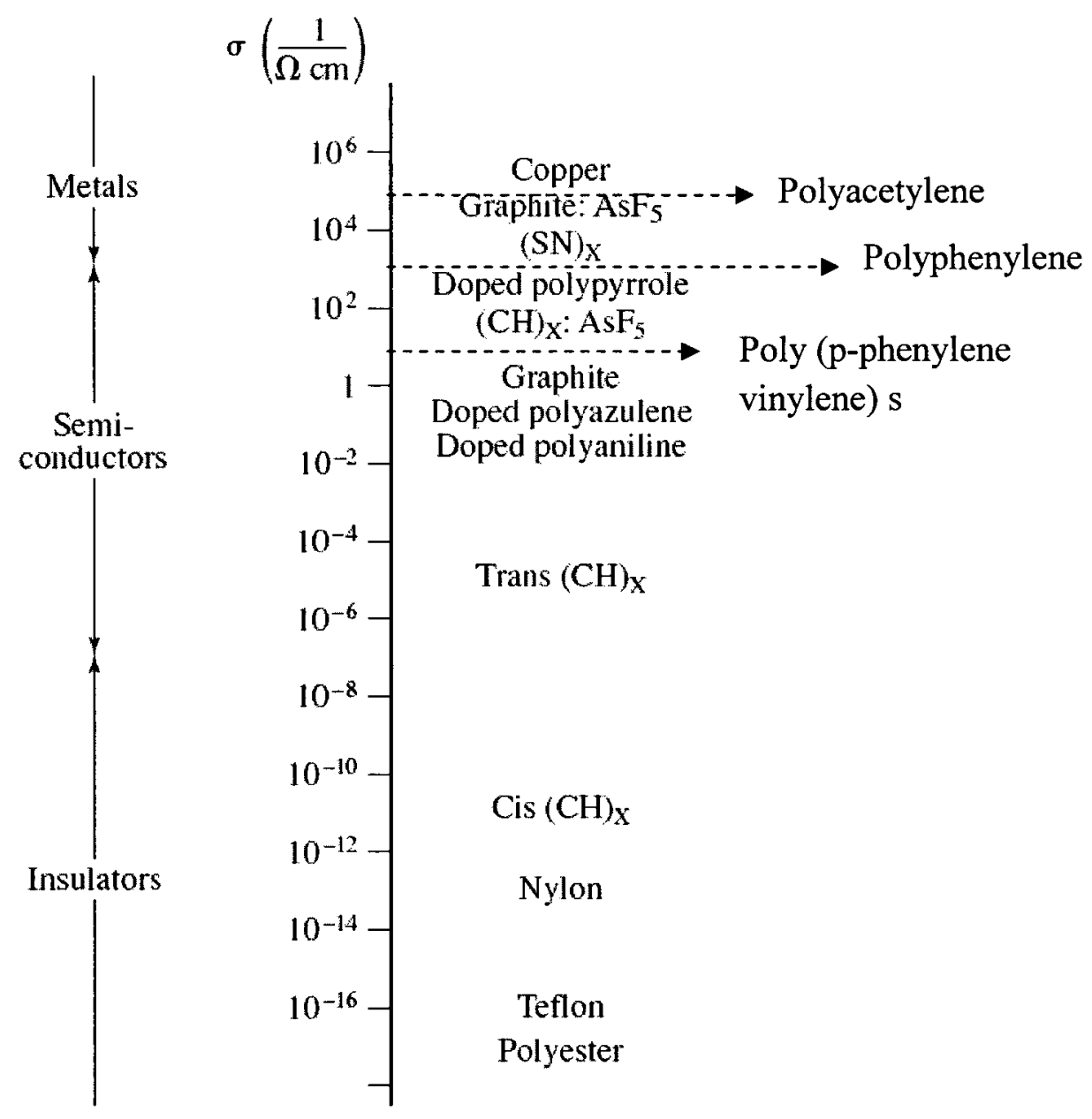

Figure 2.5 Conductivities of various polymeric materials covering the conductivity span [5], [34].

\subsubsection{Photoconductive Polymer.}

Photoconductive materials are materials in which the conductivity $\sigma$ increases when illuminated by light. Photoconductive polymers are typically very good insulators in the absence of light. Upon light excitation, the holes and electrons that were initially immobile move in response to an applied electric field and the material becomes 
conductive [16]. The increase in conduction arises from an increase in the concentration of charge carriers upon the absorption of photons. Eqn. (2.8) relates the conductivity of a material as function of the mobility, magnitude and concentration of charge carrier:

$$
\sigma=q\left(n \mu_{e}+p \mu_{p}\right)
$$

where $\sigma$ is conductivity, $q$ is the electron charge, $\mu_{\mathrm{e}}$ is electron mobility, $\mu_{p}$ is hole mobility, $n$ is the electron concentration and $p$ is the hole concentration.

Poly-N-vinylcarbozole (PVK) was the first photoconductive polymer that was synthesized [16]. Conduction can be increased by several orders of magnitude due to charge carriers produced upon absorption of photons [5]. The photoconductive properties can be improved when doped with sensitizer. Fullerene is a family of carbon allotropes (i.e. molecules composed entirely of carbon in the form of a hollow sphere, ellipsoid, or tube). They consist of at least 60 atoms of Carbon with the designation of C60. PhenylC61-Butyric-Acid-Methyl-Ester ([60] PCBM). 4-Fluoro Tetracyanoquinodimethane (TCNQ) , Tetracyanopyrazinide Dimer Dianion (TCNP) etc are examples of sensitizers [6][7][8]. Figure 2.6 shows the structures of PVK, and the sensitizers. Recently polymers are also being doped with inorganic material in order to enhance photoconductivity [5][8]. The mixtures of the two compounds are also known as composite polymers. Silicon nanoparticles (Si), Se-Te alloys (Selenium-Tellurium) and cadmium sulphide nanoparticles $(\mathrm{CdS})$ are examples of semiconductor materials that are being used to improve the conductivity of the polymer. 


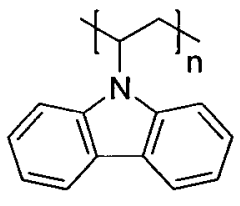

PVK

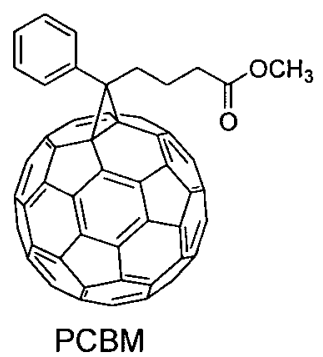

PCBM<smiles>N#CC(C#N)=c1c(F)c(F)c(=C(C#N)C#N)c(F)c1F</smiles>

4F-TCNQ<smiles>N#CC(C#N)=c1ccc2cc(=C(C#N)C#N)ccc2c1</smiles>

TCNP

Figure 2.6 PVK with the fullerene PCBM, 4F-TCNQ, TCNP.

Photogeneration of charge carriers and charge mobility in a polarization field are the two areas in which the study of photoconductivity of polymers has been extensively reviewed. They both contribute to the photoconductive properties independently [5]. Photogeneration of charge carriers depends on the wavelength of the incident photons. It results from the separation of an electron from some chemical group leaving positively charged holes. However, charge mobility results from the separation of holes and electrons and the transfer of an electron from a neighboring neutral group to leave a positive hole in the case of hole migration, or the transfer of an electron to a neighboring neutral group in the case of electron migration [5][16].

\subsubsection{Photorefractive Polymer.}

Photorefractive polymers are special polymers that produce large refractive index change upon exposure to light. The photorefractive effect refers to the field-induced change in refractive index of an optical material, resulting from a light-induced 
redistribution of electrons and holes [20]. Eqn. (2.9) shows the relationship between the refractive index $n$, relative permittivity $\varepsilon_{\mathrm{r}}$ and permeability $\mu_{\mathrm{r}}$ of a material.

$$
n=\sqrt{\varepsilon_{r} \mu_{r}}
$$

From Eqn. (2.9) a change in $\varepsilon_{r}$ will change the refractive index $n$. The different steps leading to the formation of a photorefractive grating are listed below [20] and are shown in Fig. 2.7.

1. Absorption of light and generation of charge carriers. The light intensity is high at this region as shown in Fig. 2.7(a). The material absorbs photons and this leads to the separation of charge carriers, as shown in Fig. 2.7(b).

2. The transport through diffusion and drift of electrons and holes over distances that are fraction of the grating spacing leading to separation of holes and electrons, as shown in Fig. 2.7(b).

3. Trapping of these carriers and build-up of space charge field, as seen in Fig. $2.7(\mathrm{c})$

4. The modulation of the refractive index by periodic charge field. Here the resulting index grating as shown in Fig. 2.7(e) has been phase shifted in response to the initial light distribution

Photorefractive organic composites have applications in medical imaging, optically induced focusing-to-defocusing switching, optical storage, and volume holograms [19]. 


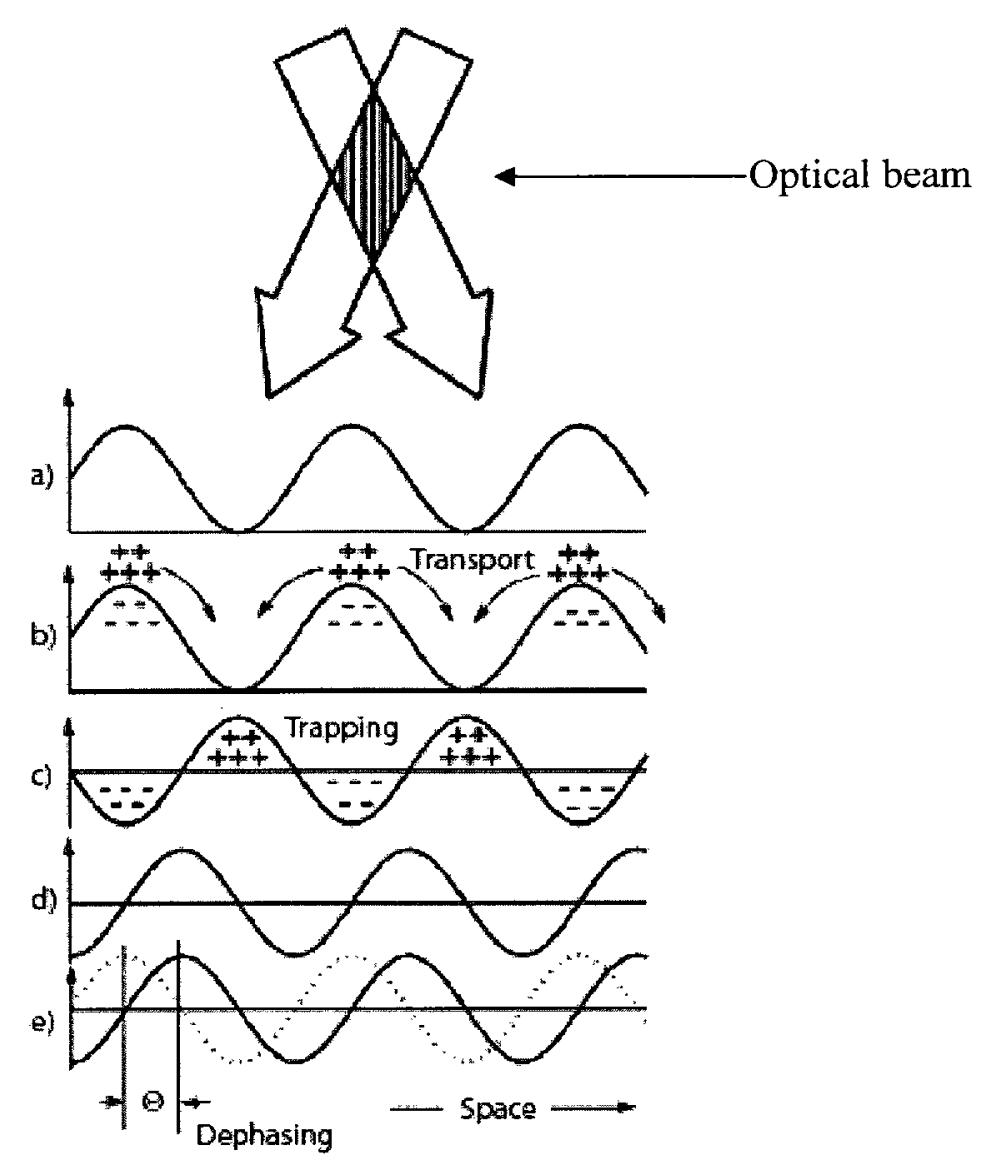

Figure 2.7 (a)-(e) Eplanation of photorefractive effect (a) The absorption of the light. (b) Transport of the charge carriers. (c) Trapping of the carriers. (d) and (e) Dephasing [20].

\subsection{Tunable Microwave Device.}

The growth and the application of wireless technology have led to a need for a single electronic device to be able to effectively switch between different networks and wireless technologies. The possibility to use the same device for different applications is the motivation for the development of tunable microwave devices. With the growth of future wireless networks, there will be a crisis of spectrum availability under the current 
spectrum allocation scheme. The IEEE body is working towards the effective spectrum allocation sharing to avert the crisis [32]. The introduction of software-define radio (SDR) and cognitive radio (CR) has help the regulating body to effectively manage and share the spectrum effectively. SDR provides a flexible radio platform capable of operating over a continuously set of commutations standard and modes without any change in the hardware components [33], while it is been enable by the CR. Figure 2.8 shows different applications of wireless devices relying on the same source for wireless signals.

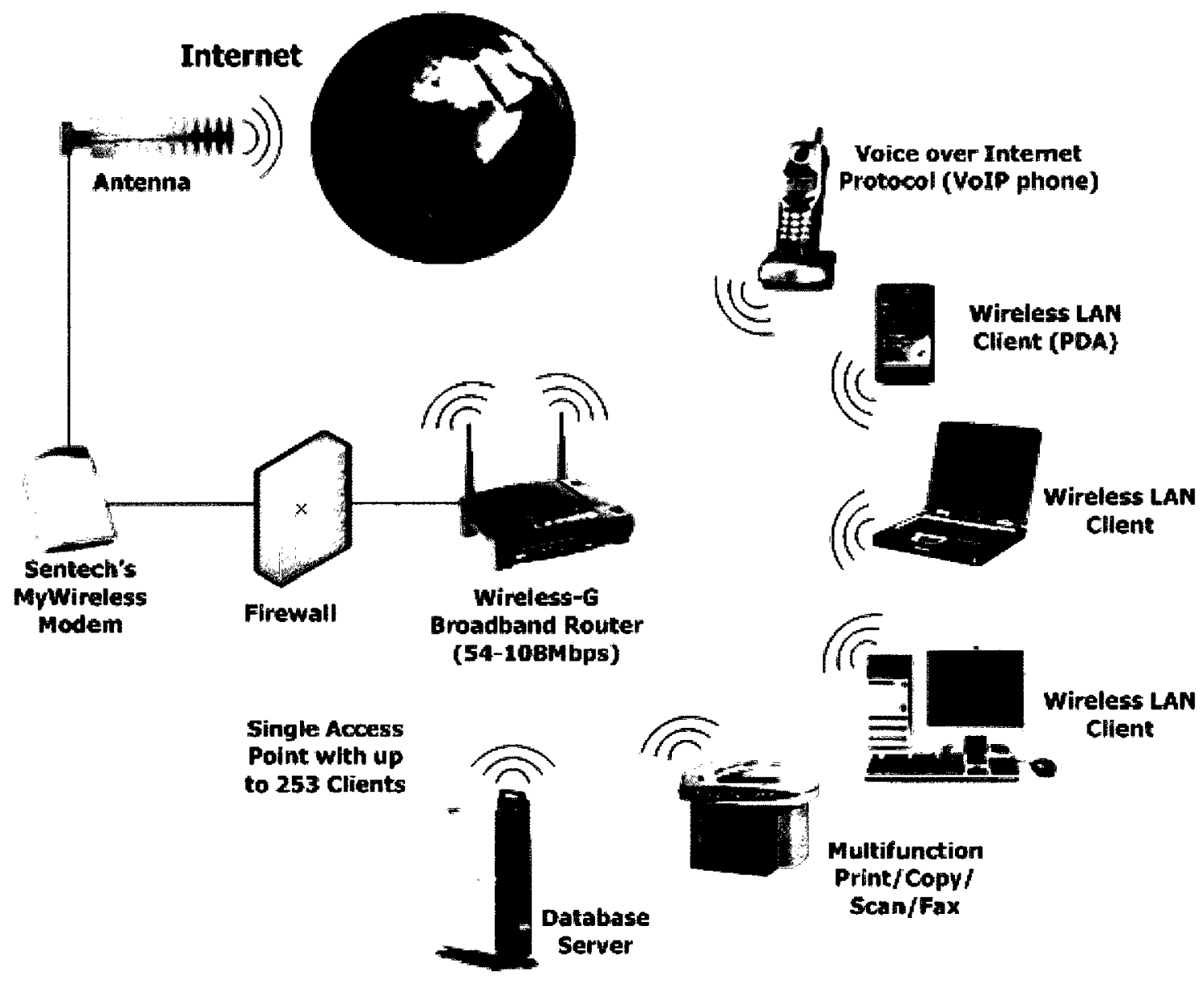

Figure 2.8 Common wireless usages for different applications. 
Some other well known methods of tuning microwave devices are mechanical tuning, magnetic tuning, variation of dc bias voltage, temperature, and Micro Electro Mechanical Systems (MEMS).

Ref. [21] studied the effect of tuning a microstrip travelling wave antenna by applying a dc bias voltage. The principle behind the tunability is the property of ferroelectric materials having a dielectric constant which can be modulated at high frequencies under the effect of an electric field bias operating perpendicular to the direction of propagation. Figure 2.9 shows the configuration of the electrically controllable scan antenna. The antenna was made from a microstrip line with $200 \mu \mathrm{m}$ thick ceramic-polymer substrate. The antenna with width (w) $10 \mathrm{~mm}$ and length (L) of $96 \mathrm{~mm}$ is fed by a metal strip of width (W). The voltage is applied to the structure perpendicular to the direction of propagation (ZOX) at the end of a $\lambda / 2$ high impedance transmission line. The antenna pattern of scan measured at $7.8 \mathrm{GHz}$ with $0 \mathrm{~V}, 100 \mathrm{~V}$ and $200 \mathrm{~V}$, is shown in Fig.2.10. 


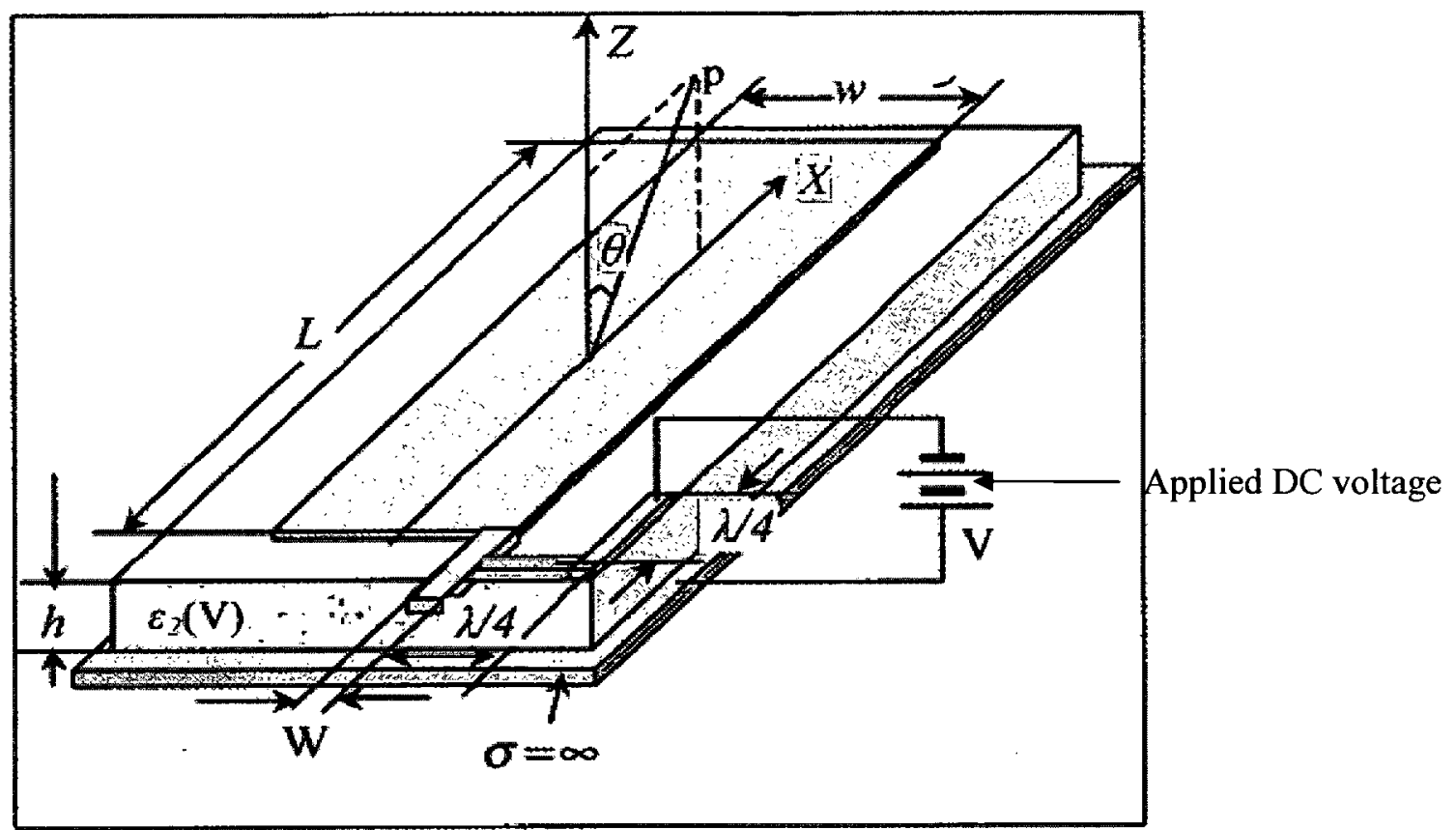

Figure 2.9 Configuration for the electrically controllable antenna with the voltage applied perpendicularly to the direction of the propagation [21]. 


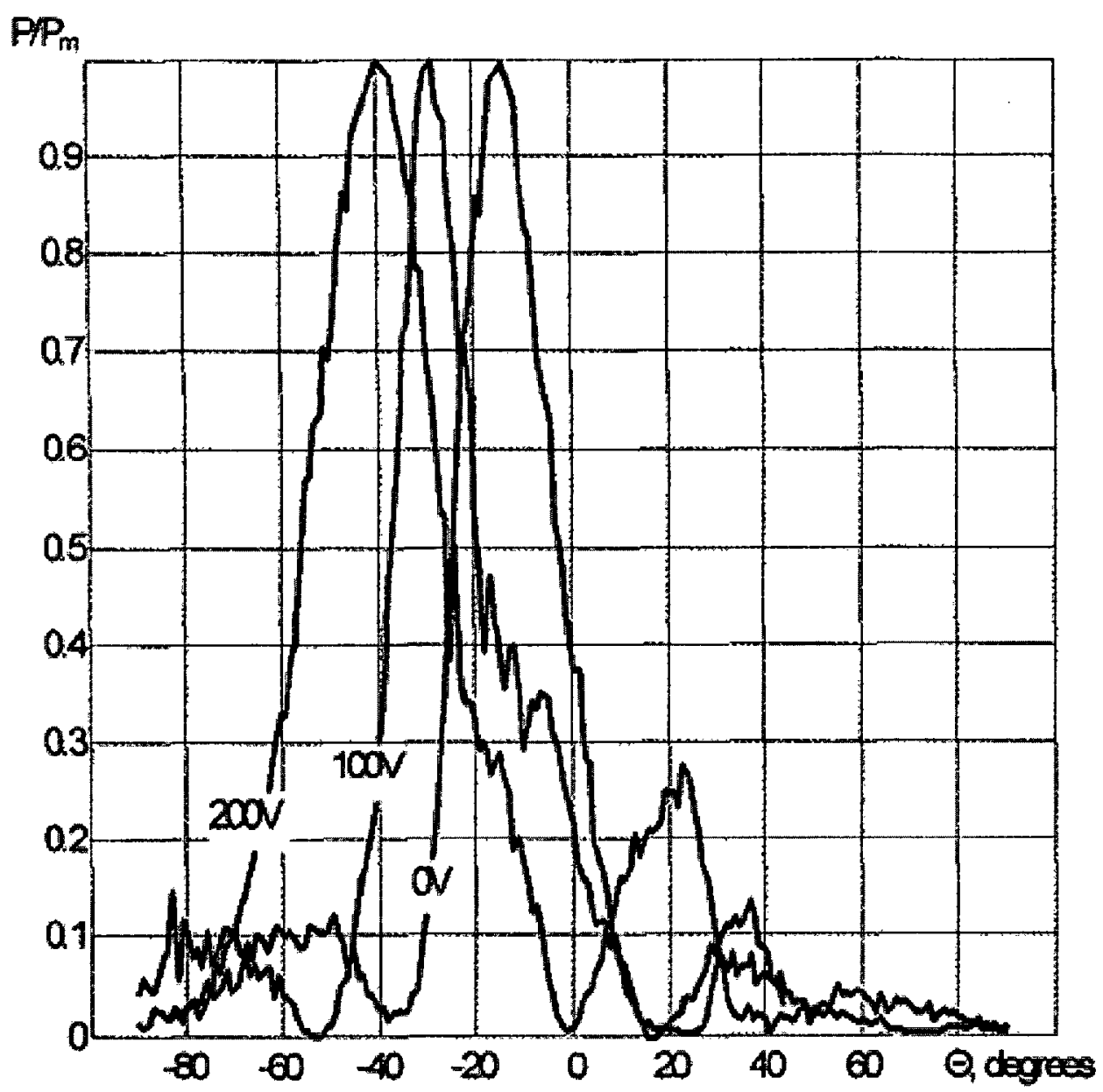

Figure 2.10 Measured antenna pattern at $7.8 \mathrm{GHz}$ as a result of bias voltage [21].

From Figure 2.10, on applying 0 to $200 \mathrm{~V}$ an approximate 50 degree of phase change was obtained which demonstrates beam steering. The high voltage required to achieve more tunability in this device is a major drawback of this method.

Mechanical tuning of a resonant cavity (i.e. changing its dimension) which is realized by using screws, motors, may pose some difficulties as mechanical devices are prone to noise, wear and tear and sometimes rust. This method ensures precision, but leads to a very slow operation. 
Conventional electronic tuning element i.e. varactors, pin diodes, are seriously limited by nonlinear effects, leading intermodulation products and low power handling capabilities [11]. MEMS technology can also be used to tune a microwave component. High power handling, low intermodulation distortion and very small size are the attractive features offered by MEMS [24]. MEMS devices require careful fabrication and packaging processes [23]. Figure 2.11 shows a single pole single throw MEMS switch with the dc actuator and the RF signal line when the switch is open and closed [22].

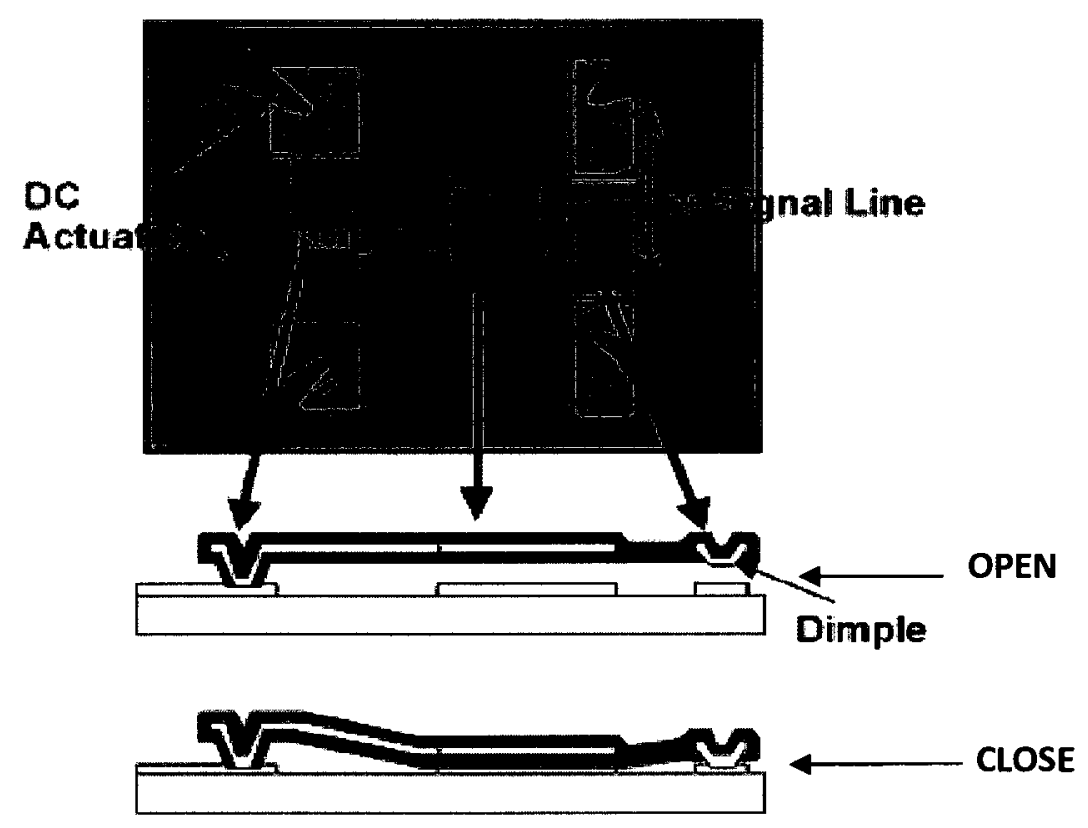

Figure 2.11 A single pole single throw RF MEMS switch [22].

In this device, MEMS switches are integrated to reconfigure a dipole by placing the switches at the quarter wavelength from end of each arm, as shown in Fig. 2.12. When 
the switches are closed the dipoles has a length $\lambda_{1} / 2$ and when the switches are open, the dipole has shortened length $\lambda_{2} / 2$.

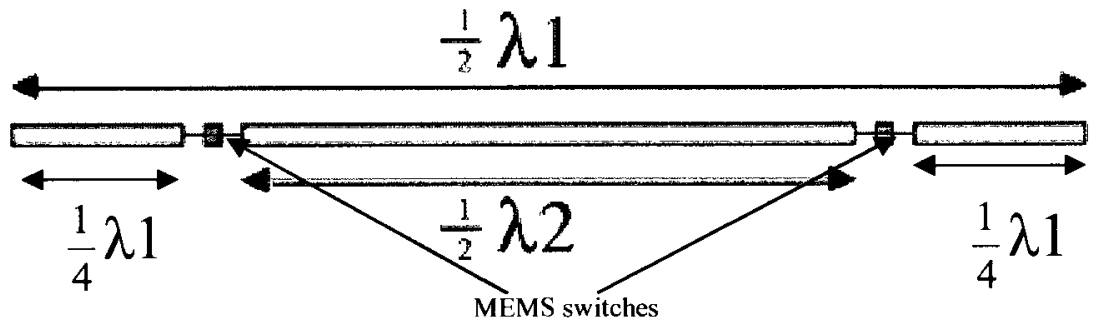

Figure 2.12 Dipole antenna with RF MEMS along the length of the arm [22].

The measured change in radiation pattern at $11 \mathrm{GHz}$, corresponding to $\lambda_{1}$ and at $18 \mathrm{GHz}$, corresponding to $\lambda_{2}$ is shown in Figure 2.13.
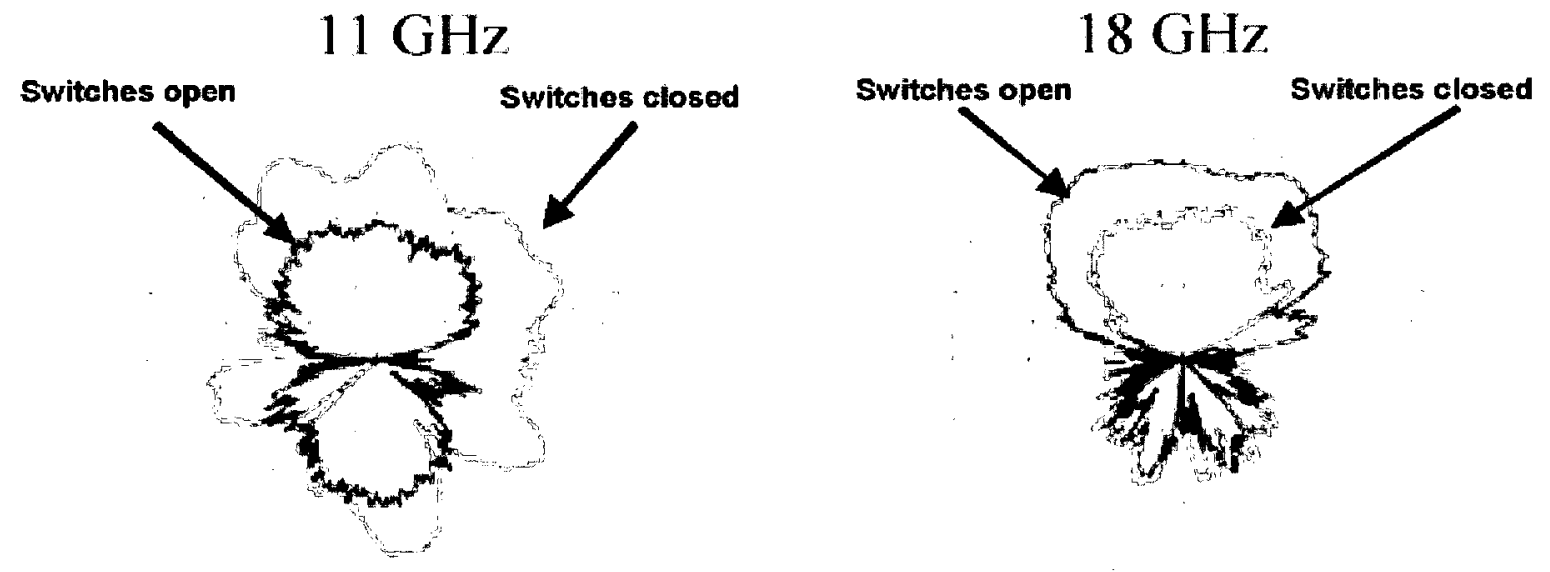

Figure 2.13 Antenna pattern of the RF MEMS tunable dipole antenna.

Reliability is an issue due to the mechanical moving parts (switches on and off) [25]. 


\subsection{Proposed Optical Tuning of Microwave Components.}

The tunable microwave concept pursued in this thesis is the replacement of the RF MEMS devices in Figure 2.12 by an optically sensitive polymer capable of producing the same ON/OFF function, but in a simpler way. Although beyond the scope of this research, the same technique could be applied to the other microwave components such as the tunable bandpass filter as shown in Figure 2.14.

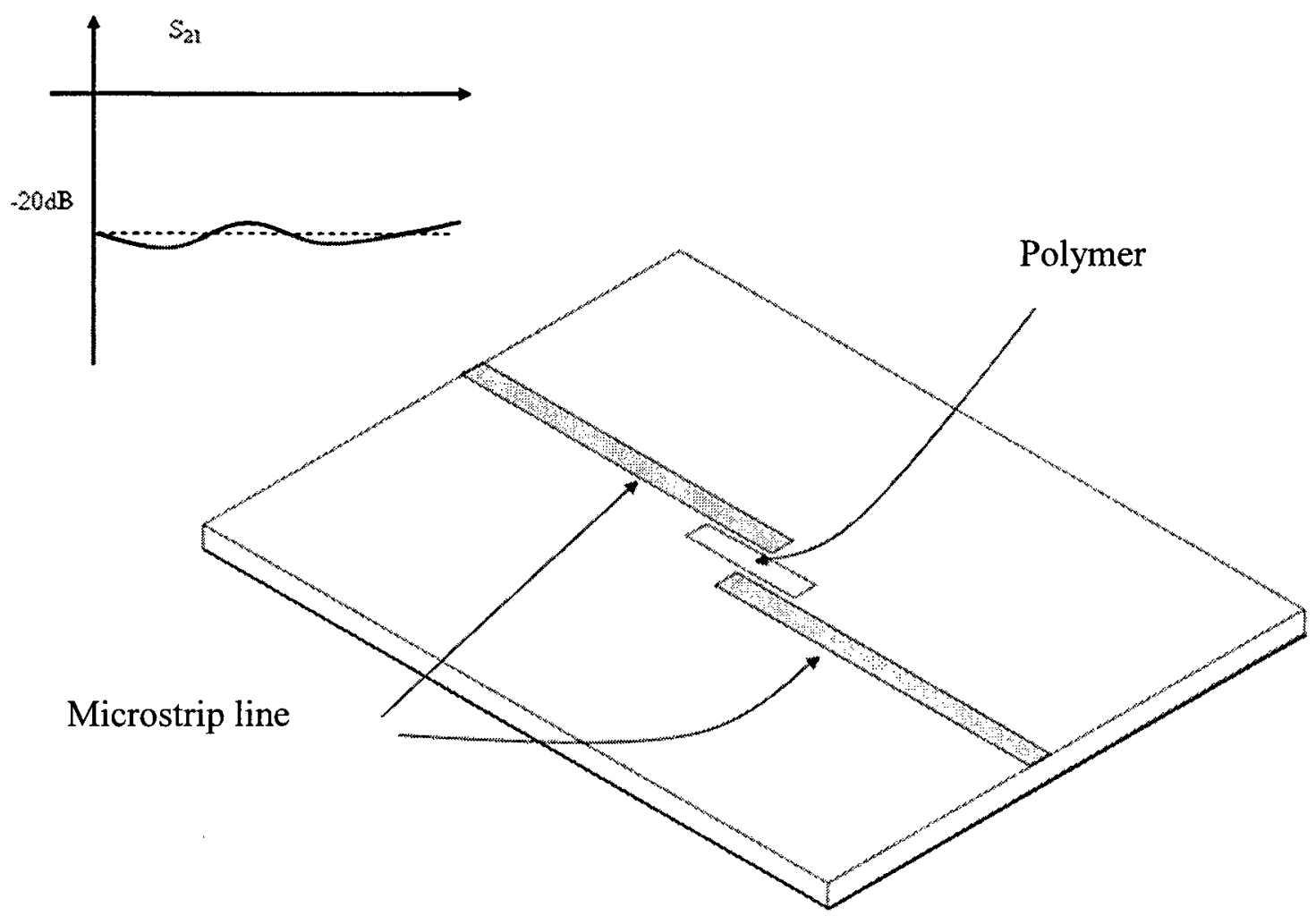

Figure 2.14 Tunable bandpass filter with its response overlaid with optically sensitive polymer. 
In essence, what is being ultimately being pursued is the development of polymer materials that can be deposited on planar microwave components so as to change their operating characteristics (frequency, bandwidth, etc.) through optical illumination. Both photoconductor and the photorefractive properties of polymers could potentially be exploited to achieve tunability.

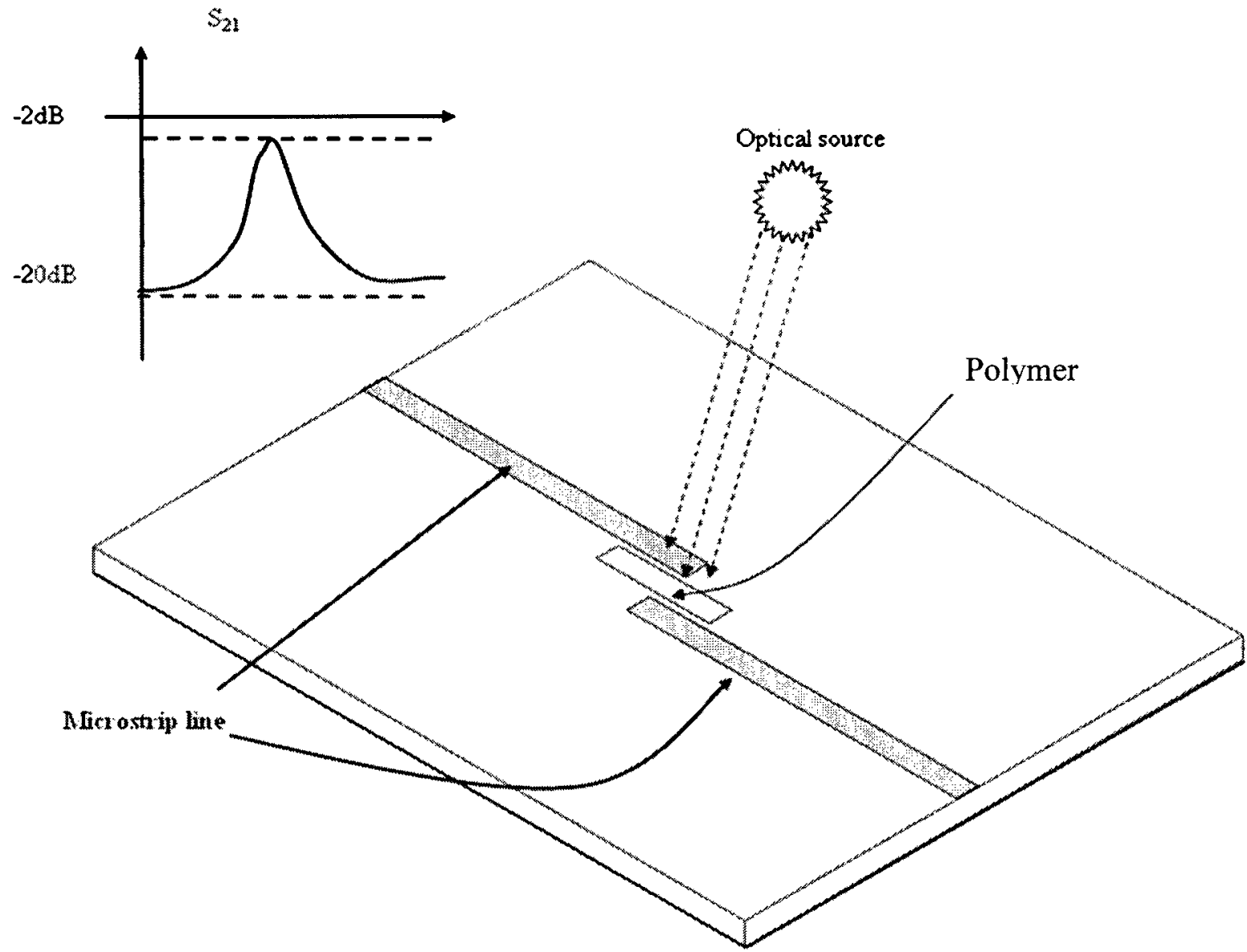

Figure 2.15 Tunable bandpass filter with its response overlaid with optically sensitive polymer upon illumination. 


\subsection{Chapter Summary and Conclusions}

The dielectric properties of material were reviewed; the photoconductive and photorefractive properties of polymer were described with applications. Tunable microwave devices and different methods of tuning such as mechanical tuning, magnetic tuning, variation of dc bias voltage, temperature, and Micro Electro Mechanical Systems (MEMS) were also described. The proposed method of optical tuning in this work was also introduced. 


\section{Chapter 3}

\section{Characterization of a Novel Polymer.}

\subsection{Introduction: Techniques and Proposed Method of}

\section{Characterization.}

The properties of a material must be known before it can be applied to a passive microwave device to achieve tunability. The process by which the properties of a material are determined is called characterization. The reflection method, the transmission method, the resonator method, the resonant-perturbation method are different methods to characterize a material at microwave frequencies [10].

In this chapter, the reflection method will be used for the material characterization of planar microwave capacitors. A capacitor made with the polymer material under test is a useful structure for performing the characterization work in the thesis. First the material properties can be extracted fairly easily from the measured impedance of the capacitor and, second the capacitor itself could be used directly as a tuning element in a microwave circuit or antenna with precise knowledge of its behavior having been determined. Such an approach is called "in-situ" material characterization. In the reflection method, an electromagnetic wave is directed to the material under test, and the parameters of interest are extracted from the reflection coefficient defined at the reference plane [10]. A Vector network analyzer (VNA) can be used to measure the reflection coefficient S11. Initially a metal-insulator-metal (MIM) capacitor was 
proposed as the test device, but due to the fabrication constraints an interdigitated capacitor (IDC) was finally used. The substrate used for the planar microwave capacitor must be optically transparent so the material under test (MUT) can be illuminated by light. For this reason Corning 7059 glass (Barium Borosilicate) was used for the substrate. Table 3.1 shows its physical properties obtained from [31]. The IDC will be fed with a co-planar wave-guide (CPW), so as to allow the IDC and the MUT to be on the same plane. This allows the light to get to the MUT without being blocked by the ground plane.

\subsection{Monolithic Metal Insulator Metal (MIM) Capacitor.}

By measuring the impedance of a MIM, the dielectric constant and the loss tangent of a material can be extracted [27]. The MIM is constructed by sandwiching a thin dielectric material, the MUT, between two metal plates as shown in Figure 3.1.

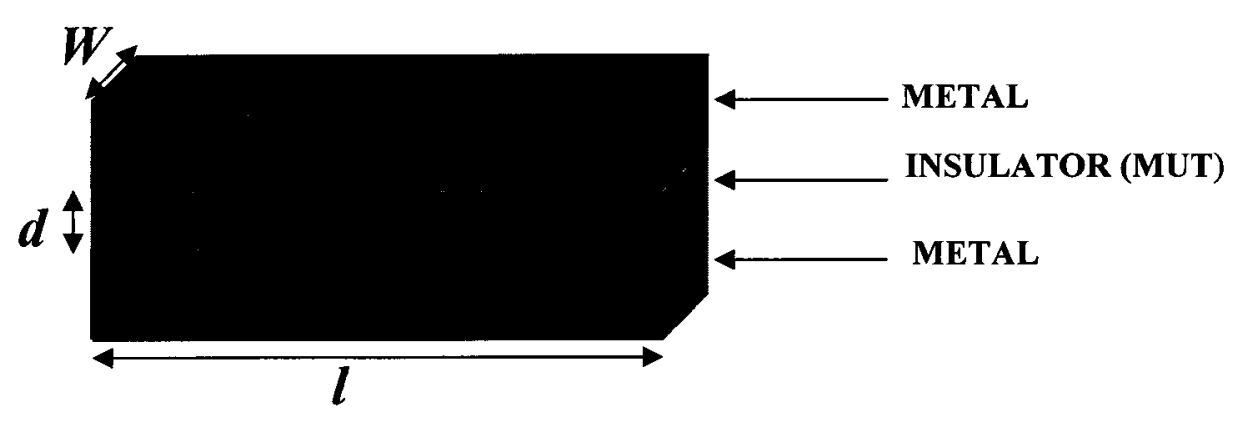

Figure 3.1 Metal Insulator Metal (MIM) Capacitor 
Table 3.1 Properties of Corning 7059 Substrate [31].

\begin{tabular}{|c|c|}
\hline Properties & Value \\
\hline Density & $2.76 \mathrm{~g} / \mathrm{cm}^{3}$ \\
\hline & $1.5440 @ 435.8 \mathrm{~nm}$ \\
Refractive Index & $1.5354 @ 546.1 \mathrm{~nm}$ \\
& $1.5311 @ 643.8 \mathrm{~nm}$ \\
\hline Dielectric constant & $5.84 @ 1 \mathrm{MHz} / 20^{\circ} \mathrm{C}$ \\
\hline Loss Tangent & $0.10 \% @ 1 \mathrm{MHz} / 20^{\circ} \mathrm{C}$ \\
\hline & $\sim 70 \%(320 \mathrm{~nm})$ \\
& $\sim 90 \%(360 \mathrm{~nm})$ \\
Transmittance & $>90 \%(380-2200 \mathrm{~nm})$ \\
\hline
\end{tabular}

The electrical lumped element equivalent circuits of a MIM is shown in Figure 3.2.

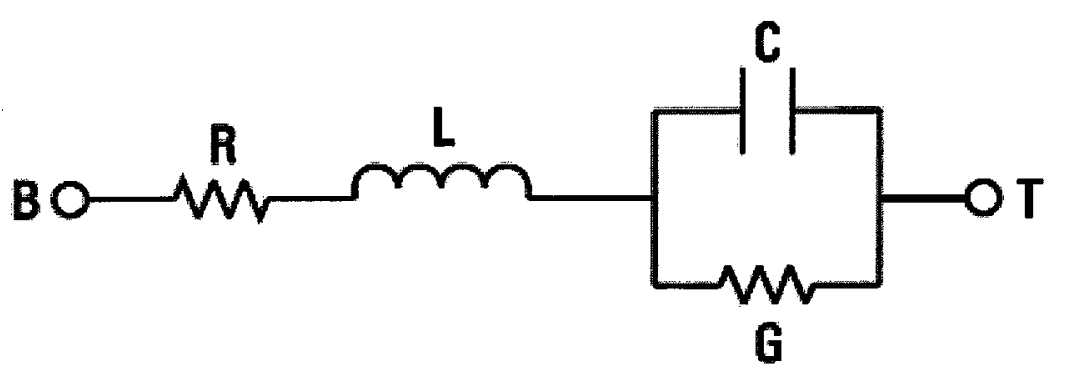

Figure 3.2 Equivalent lumped element model MIM. 
The notation $\mathrm{B}$ and $\mathrm{T}$ represent the bottom and the top plate of the capacitor, respectively. The parameters Resistance (R), Inductance (L), Capacitance (C), and Conductance (G) can be approximated with Eqns. (3.1), (3.2) and (3.3) [26].

$$
\begin{aligned}
& R=\frac{2}{3} \frac{R_{s}}{W} l \\
& C=\varepsilon_{o} \varepsilon_{r d} \frac{W l}{d}=\frac{\varepsilon_{r d} 10^{-15}}{36 \pi} \frac{W l}{d} \quad(F) \\
& G=\omega C \tan \delta=\frac{1}{18} \varepsilon_{r d} f \frac{W l}{d} \times 10^{-6} \tan \delta \quad \text { (mho) }
\end{aligned}
$$

where $R_{s}$ is the sheet resistance of the bottom plate, $\varepsilon_{r d}$, and $\tan \delta$ are the dielectric constant and the lost tangent of the material under test, respectively. The length $l$, width $W$ and depth $d$ as shown in Figure 3.1 are in micrometers, and the frequency $\mathrm{f}$ is in GHz.

For optical characterization, one of the conducting layers must be transparent. Indium tin oxide (ITO) which is a transparent metal was considered as the lower layer. The idea was to coat the surface of the glass with ITO, deposit the polymer, and then coat the top surface with aluminum. Figure 3.3(a) shows the top view of the structure with the material under test modeled in Ansoft HFSS with ITO coated on the glass substrate. The $\mathrm{CPW}$ is a $50 \Omega$ line having a center conductor (signal) $\mathrm{S}$ with a width of $2 \mathrm{~mm}$ and spacing (gap) $\mathrm{G}$ to the adjacent ground of $0.32 \mathrm{~mm}$. 


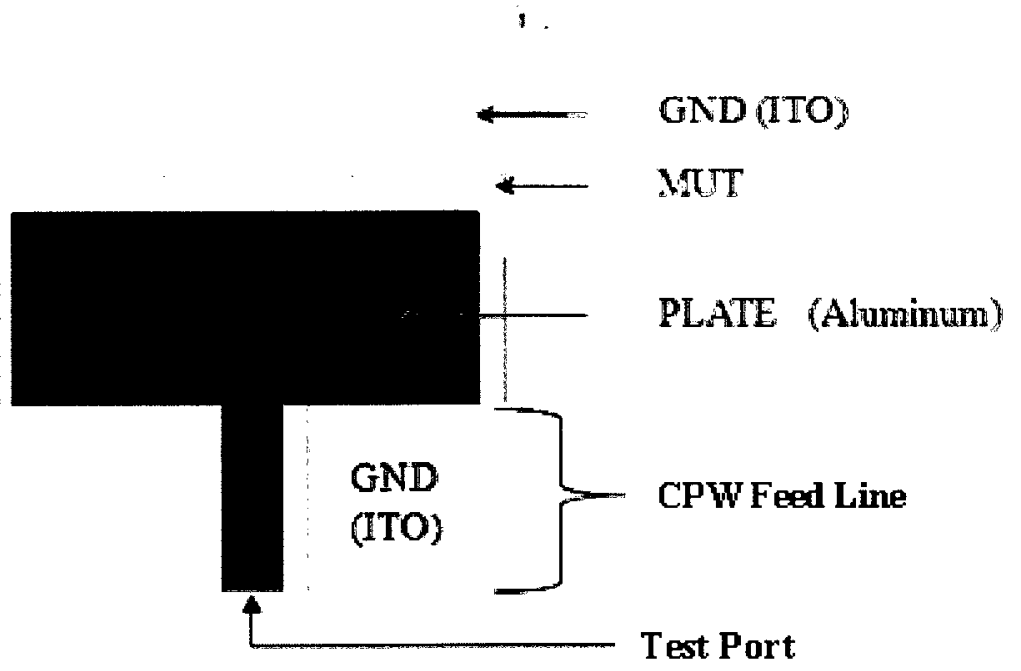

Figure 3.3(a) The top view of HFSS model of CPW fed MIM capacitor.

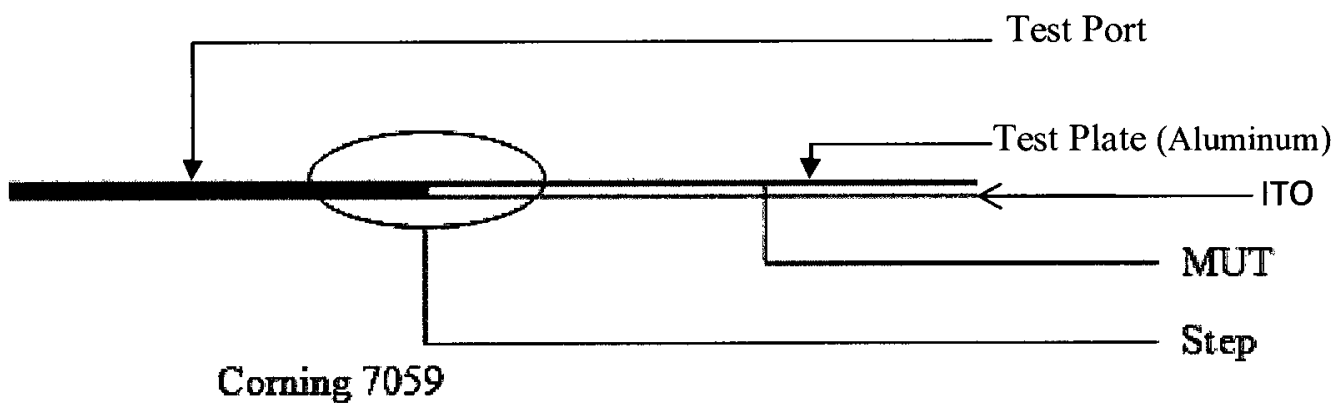

Figure 3.3(b) The cross-sectional view of the model showing the "step".

An extra step of coating the top surface of the glass with ITO must be done. ITO is also known to be very lossy at microwave frequencies due to its low conductivity. In addition, there is a vertical step from the aluminum CPW feed line to the aluminum top plate of the capacitor over the MUT, as shown in Fig.3.3 (b). At microwave frequencies, accounting 
for this discontinuity poses a major challenge while extracting the material properties. Hence, the MIM capacitor was not used as the test structure.

\subsection{Interdigitated Capacitor (IDC).}

An interdigitated capacitor comprises a number of thin parallel conducting strips of metal fingers interconnected alternatively to form a structure [26] as shown in Figure 3.4. This structure does not suffer from the two-layer fabrication difficulties associated with a MIM capacitor. The capacitance is determined by the number of fingers, the length and the spacing between the fingers, as well as the dielectric material under and between the fingers. The equivalent lumped element model is shown in Figure 3.5.

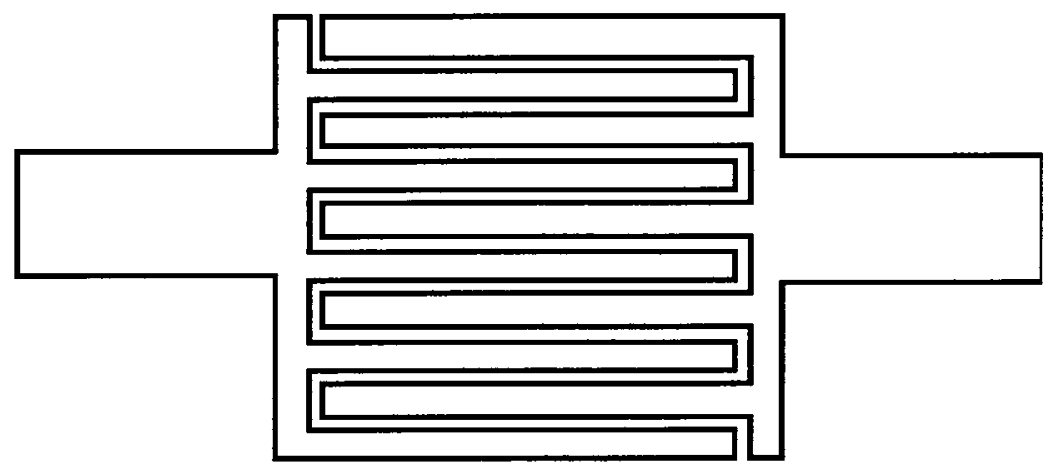

Figure 3.4 A two port interdigitated capacitor.

It operates based on the coupling between each thin parallel finger. To enhance coupling, the gap between each finger and at the end of each finger should be made as small as possible $(\sim 10 \mu \mathrm{m})$. For uniform capacitance density, the parallel strips and the spacing between each of the fingers should be made equal [28]. The expression for the equivalent 
model elements of Fig. 3.5 are more complicated than for a MIM capacitor, An electromagnetic simulation is preferred to determine the values of each element.

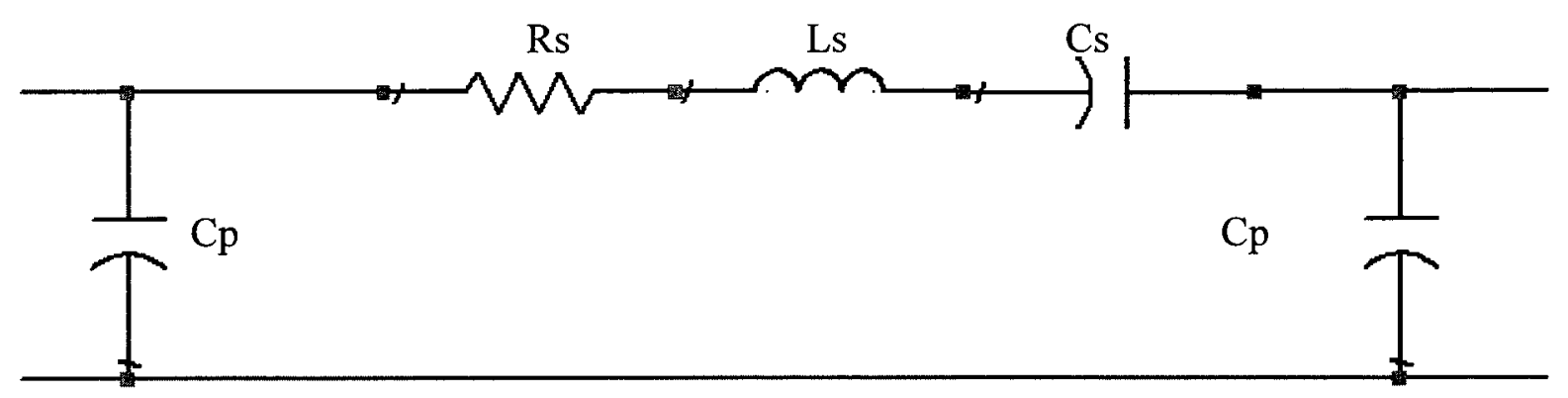

Figure 3.5 A lumped equivalent model of IDC. Rs, Ls and Cs are the series resistor, inductor and capacitor respectively. The $\mathrm{Cp}$ is the parallel capacitor to the ground.

An interdigitated capacitor is one of the best ways to characterize dielectric material as reported by [29]. Capacitance of the material under test can easily be extracted by subtracting the capacitance obtained before and after the material is applied on the fingers. Other parameters of interest such as permittivity $\varepsilon_{r}$, loss tangent $\tan \delta$ and conductivity $\sigma$ can also be extracted by modeling the structure and matching measured results to the modeled results. 


\subsection{Development of Interdigitated Structure for Polymer}

\section{Characterization.}

For this design, different geometries of a single ended (i.e. with one terminal grounded) interdigitated capacitor were simulated using Ansoft HFSS. A number of performance and fabrication objectives were simultaneously pursued:

1. The capacitance value of the IDC had to be sufficiently large in order to distinguish it (and its optically induced variations) from feedline/connector parasitics.

2. The self-resonance frequency (SRF) had to be sufficiently high in order to treat the IDC as a simple capacitor over a broad bandwidth (at least $2 \mathrm{GHz}$ ).

3. The minimum feature size of the IDC had to be greater than $10 \mu \mathrm{m}$ to allow fabrication at Carleton University's Microfabrication Laboratory.

A $50 \Omega$ coplanar waveguide was first designed on Corning 7059 (Barium Borosilicate) glass with thickness of $1.22 \mathrm{~mm}$. Aluminum was the metal type that was used with a $3 \mu \mathrm{m}$ thickness. The width $(\mathrm{S}=2 \mathrm{~mm})$ and the gap $(\mathrm{G}=0.32 \mathrm{~mm})$ of the CPW feed line were determined by the width of the SMA connector that will be edge mounted to test the structure. Figure 3.6 shows the parameters that define the geometry of the CPW-fed IDC under test. Table 3.2 shows the different values of these parameters that were used along with the resulting modeled capacitance and the self-resonance frequency. The width of the Fingers (WF) was kept at $0.1 \mathrm{~mm}$ and not varied in the parametric study because any larger value of WF will restrict the maximum possible 
numbers of fingers $(N F)$ and a smaller value of WF would lead to inefficiency of the IDC.

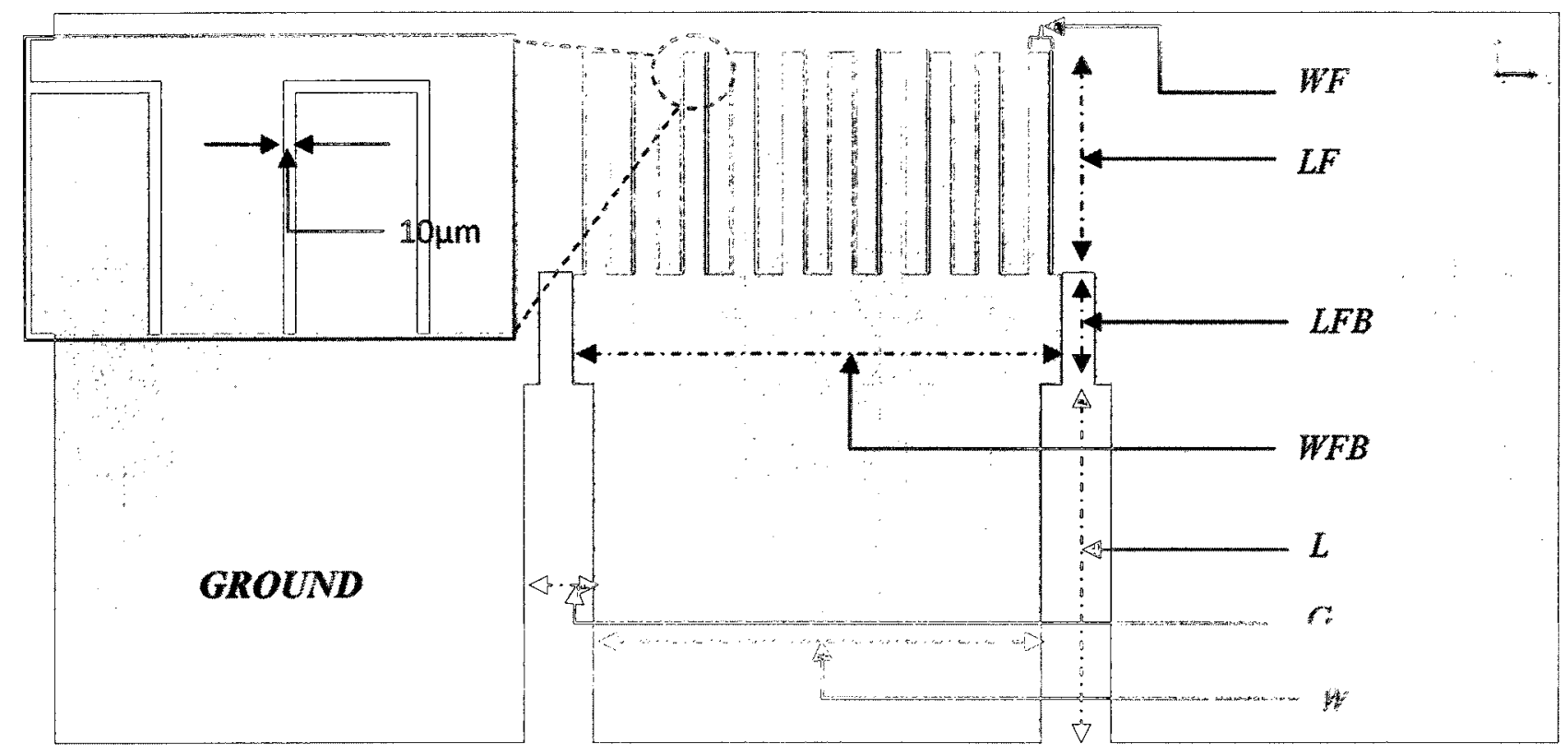

Figure 3.6 HFSS model of interdigitated capacitor with the zoomed section showing the 10 um spacing between each fingers, where $\mathbb{L F}$ is the length of the Finger, $\mathbb{W} F$ is the width of the finger, WFB (2.2mm) is the width of the feedbar CPW, WW (2mm) is the width of the $\mathbb{C P W}, \mathbb{L}$ is the length of CPW ( $2 \mathrm{~mm}), \mathbb{L F B}(0.5 \mathrm{~mm})$ is the length of the feed bar, and $G$ gap between ground and signal line $(0.32 \mathrm{~mm})$.

It was observed that as length (LF) of the fingers increases, while keeping the number of fingers $(\mathbb{N F})$ constant, the self-resonance frequency decreases and the capacitance increases. From all the cases studied in Table 3.2, it was decided to proceed with the fabrication of two IDC structures: 20 fingers with finger length of $1 \mathrm{~mm}$ or $0.5 \mathrm{~mm}$ were chosen based on values of a reasonable capacitance and $\mathbb{S R F}$ above $2 \mathrm{GHZ}$.

To verify the concept of material characterization, a thim layer of polymer material was then placed on the $\mathbb{I D C}$ and simulated in $\mathbb{H}$ FSS. Figure 3.7 shows the material under 
test placed on the IDC with a thickness of $50 \mu \mathrm{m}$ covering the fingers. The effects of change in the dielectric constant and the dielectric loss tangent of the material were observed.

Table 3.2 Different geometries of IDC for $(\mathrm{L}=2 \mathrm{~mm}, \mathrm{~W}=2 \mathrm{~mm}$ and $\mathrm{G}=0.32 \mathrm{~mm})$ with the corresponding Capacitance and SRF.

\begin{tabular}{|c|c|c|c|}
\hline \multirow[t]{2}{*}{$\begin{array}{c}\mathbf{L F}(\mathbf{m m}) \\
\text { Finger length }\end{array}$} & \multirow{2}{*}{$\begin{array}{l}\mathbf{N F} \\
\text { Numbers of } \\
\text { Fingers }\end{array}$} & \multicolumn{2}{|l|}{$\begin{array}{l}\mathbf{W F}=0.1 \mathrm{~mm} \\
\text { Finger width }\end{array}$} \\
\hline & & $\begin{array}{l}\text { Capacitance (pF) } \\
\text { @ } 100 \mathrm{MHz}\end{array}$ & $\mathrm{SRF}(\mathrm{GHz})$ \\
\hline$\overline{0.5}$ & 40 & 4.62 & 2.27 \\
\hline 1.0 & 40 & 8.27 & 1.59 \\
\hline 1.5 & 40 & 10.7 & 1.21 \\
\hline 0.5 & 20 & 2.57 & 3.23 \\
\hline 1.0 & 20 & 3.7 & 2.6 \\
\hline 1.5 & 20 & 5.2 & 2.06 \\
\hline 0.5 & 10 & 1.4 & 4.32 \\
\hline 1.0 & 10 & 2.0 & 4.24 \\
\hline 1.5 & 10 & 3.7 & 2.5 \\
\hline
\end{tabular}




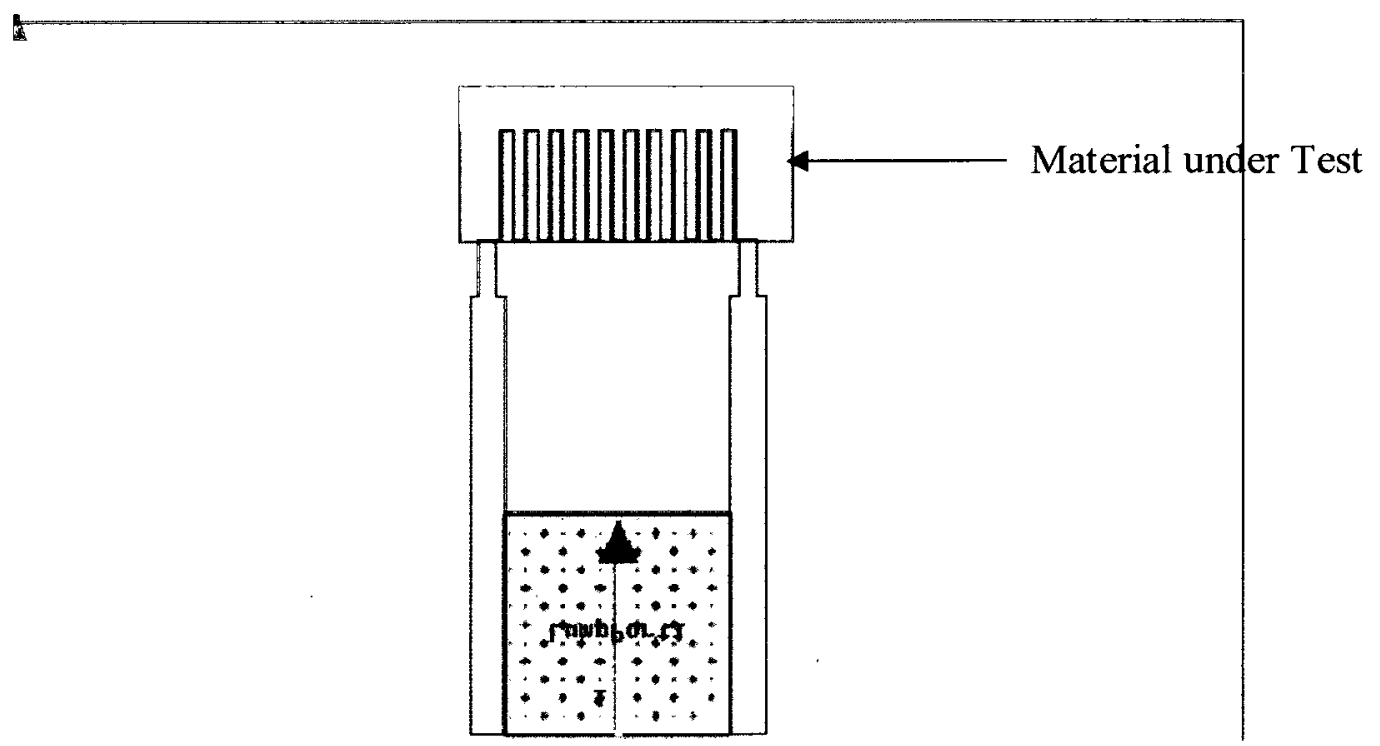

Figure 3.7 HFSS model of the material under test placed on interdigitated capacitor with 1 min finger length.

Initially the $\varepsilon_{r}$ was kept at 5.0 while the loss tangent was varied from 0.05 to 0.2 . Figure 3.8 shows the simulated S11 on the Smith chart. From the zoomed section of the Smith chart, it was observed that as the loss tangent of the material increases, S11 moves towards the centre of the Smith chart, which denotes that the material is becoming lossy. The return loss increases with frequency for loss tangent 0.05 , but as loss tangent increases, the loss peaks near 1.0GHz, as shown in Fig.3.9. 


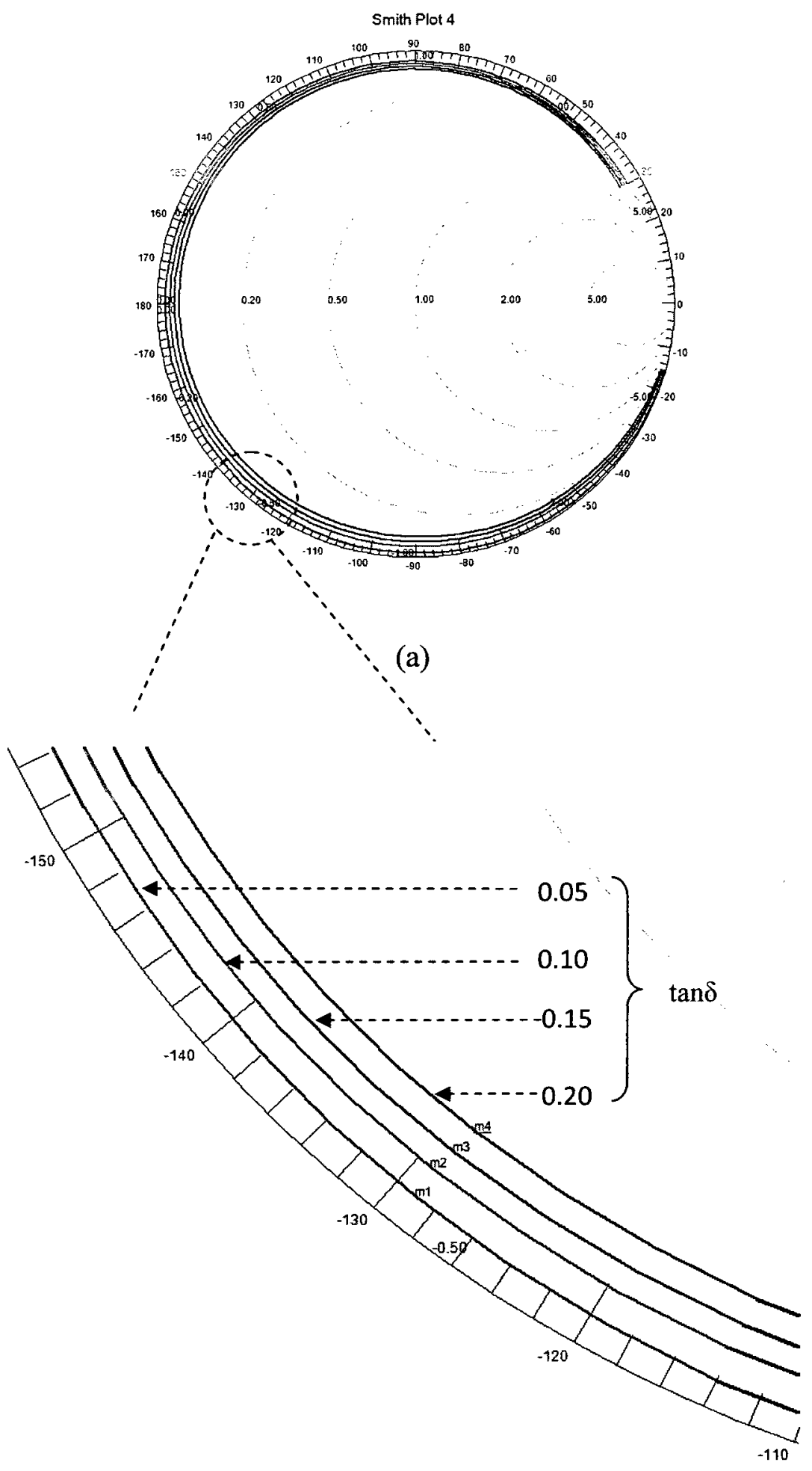

(b)

Figure 3.8 (a) and (b). The Simulated S11 on Smith chart for $1 \mathrm{~mm}$ finger length interdigitated capacitor with lossy dielectric overlay having $\varepsilon_{\mathrm{r}}=5$ over frequency range of $100 \mathrm{MHz}$ to $5 \mathrm{GHz}$ with $\tan \delta$ as a parameter. 


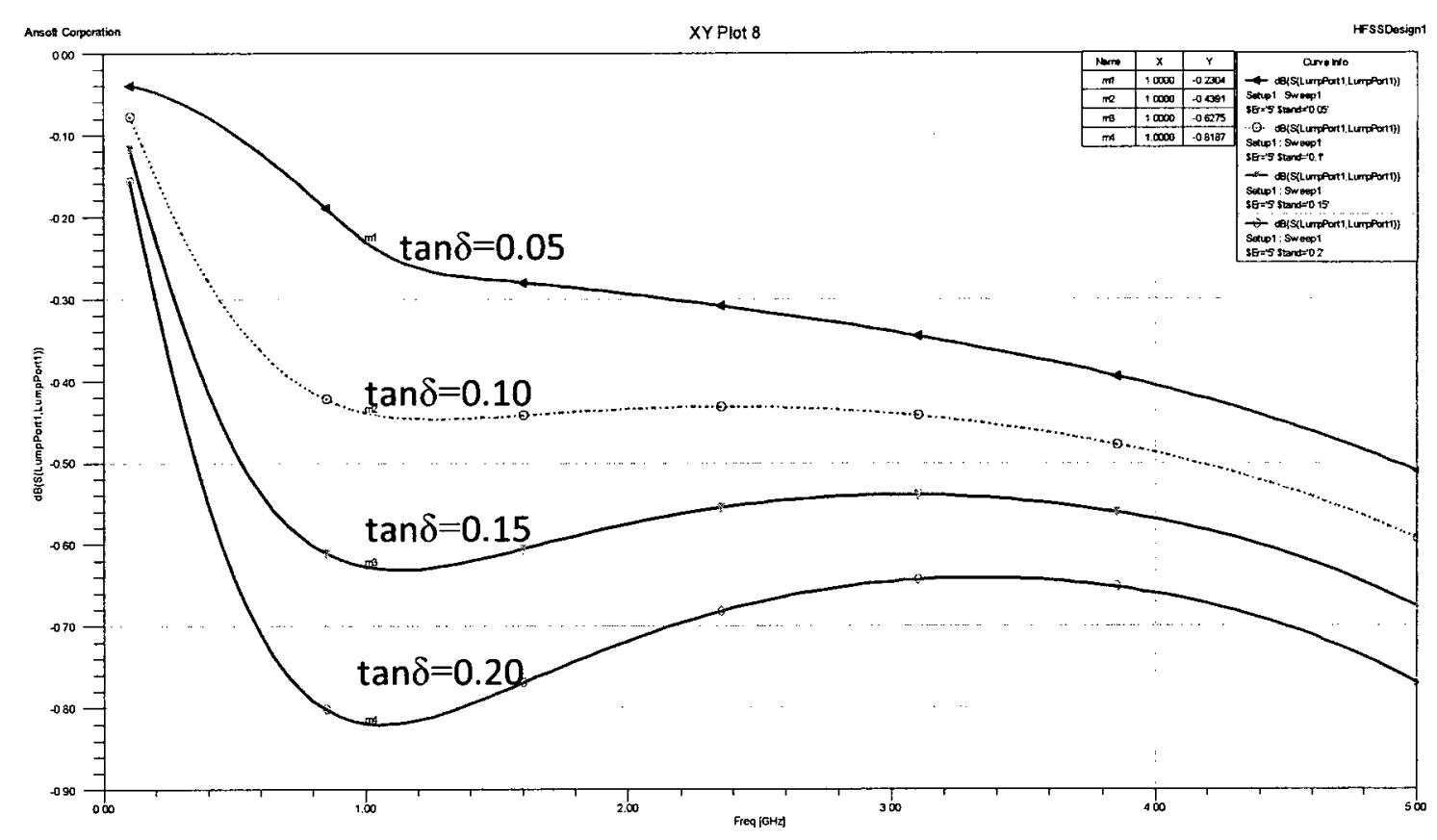

Figure 3.9 Simulated S1 1 for the $1 \mathrm{~mm}$ finger length interdigitated capacitor with lossy dielectric overlay having $\varepsilon_{\mathrm{r}}=5$ over frequency range of $100 \mathrm{MHz}$ to $5 \mathrm{GHz}$ with $\tan \delta$ as a parameter.

To observe the effect of the change in dielectric constant, the loss tangent was fixed to 0.05 and the relative permittivity was varied from 5.0 to 5.1 . The $180^{\circ}$ phase at $1.68 \mathrm{GHz}$ moved to $1.63 \mathrm{GHz}$ as the $\varepsilon_{r}$ increased as shown in Figure 3.10 (a) and the zoomed section in Figure 3.10 (b). 


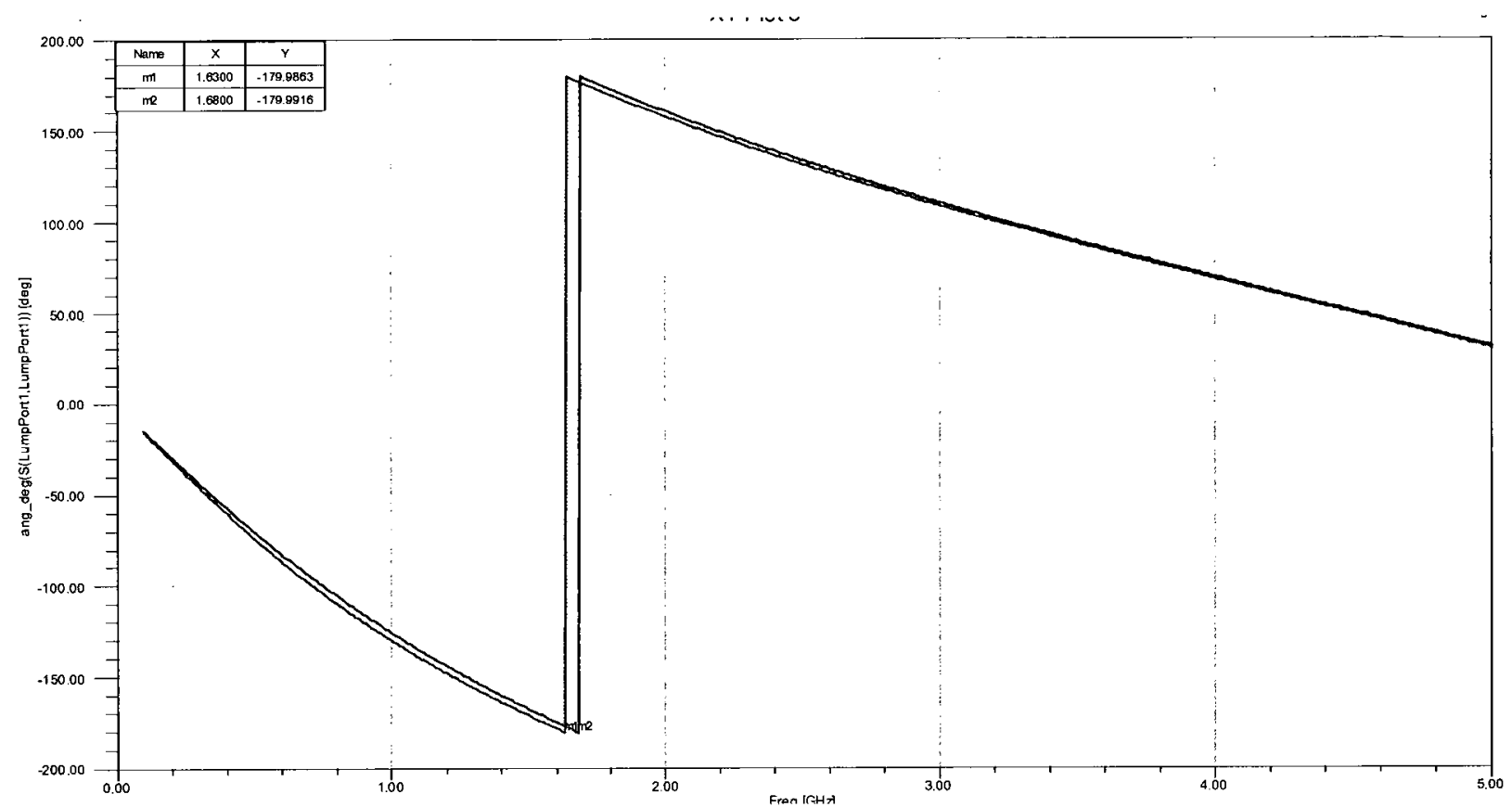

(a)

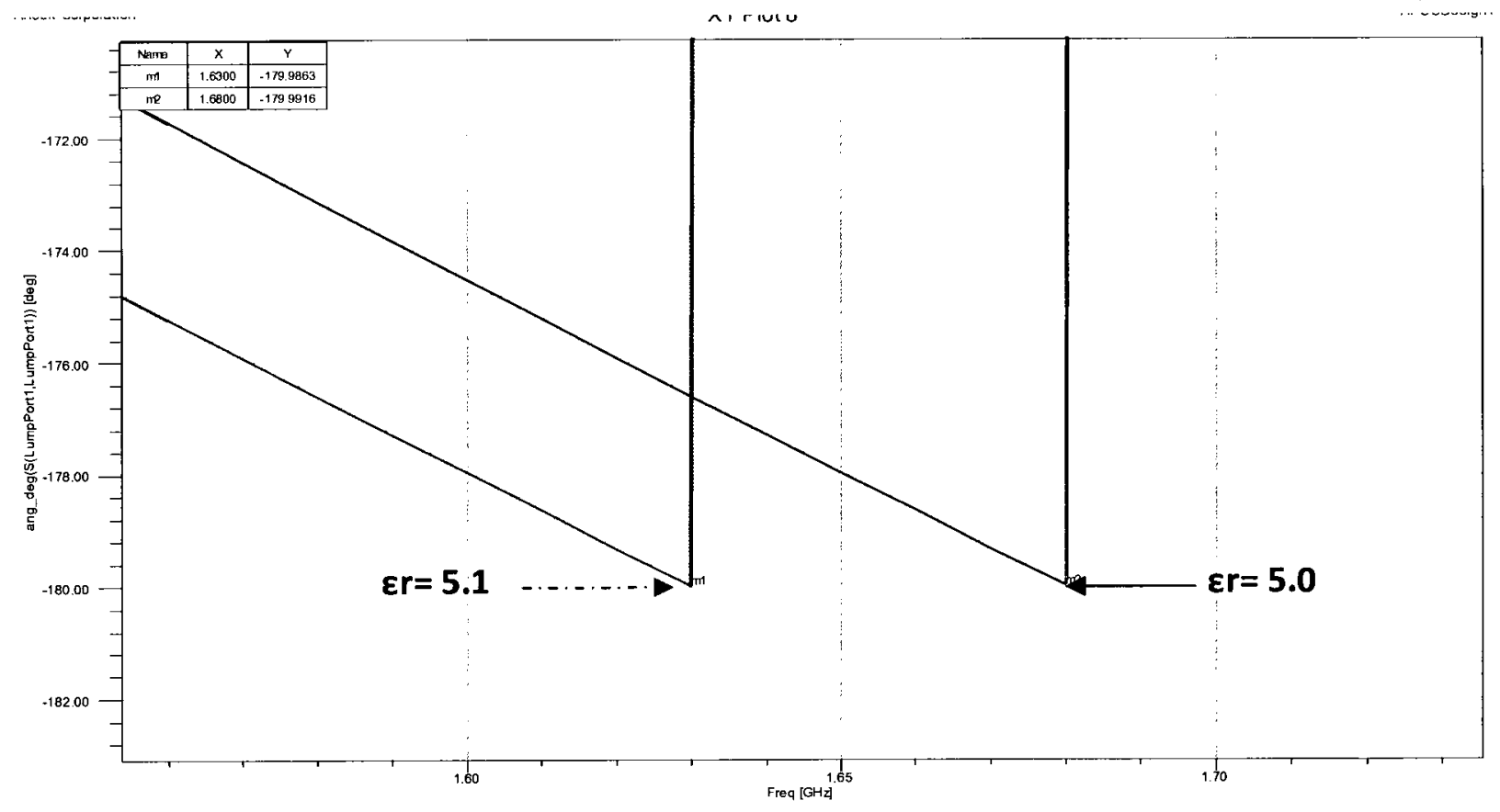

(b)

Figure 3.10 (a) and (b) The simulated phase of S11 for the $1 \mathrm{~mm}$ finger length interdigitated capacitor with lossy dielectric overlay having $\tan \delta=0.05$ over frequency range of $100 \mathrm{MHz}$ to $5 \mathrm{GHz}$ with $\varepsilon_{r}$ as a parameter. 


\subsection{Experimental Characterization of Novel Polymer.}

In this section, a mixture of thermoplastic (polymer) and nano-particles of Cadmium Sulphide (CdS) was characterized (composite polymer) with the use of the two fabricated IDC test structures developed. The thermoplastic used was DuPont 3571 proprietary polymer and its properties were not known. CdS is known to be an inorganic semiconductor with photoconductive properties. CdS typically has a relative permittivity of about 8 and a very high loss tangent. The fabricated wafer, measurement setup, measurement procedure and the extraction of the material properties will be discussed.

\subsubsection{Fabricated IDC Test Wafer.}

The interdigitated capacitors were laid out with L-Edit, a commercial layout editor to generate the photomask. Figure 3.11 shows the fabricated IDC on a circular glass substrate. Although previous simulations in Section 3.4 used a finger spacing of $10 \mu \mathrm{m}$, this was not possible to fabricate due to the minimum feature size of $12.5 \mu \mathrm{m}$ of the David Mann pattern generator. In addition, the nominal finger length of $1 \mathrm{~mm}$ $(1000 \mu \mathrm{m})$ becomes $982.5 \mu \mathrm{m}$ and the $0.5 \mathrm{~mm}$ length became $482.5 \mu \mathrm{m}$. Due to undercut from wet etching of IDC, the final dimensions as measured under a microscope are shown in Fig. 3.12. Also the length the CPW feed line was increased from $2 \mathrm{~mm}$ to $13.2 \mathrm{~mm}$ to move the structure further away from the edge of the glass slide. 


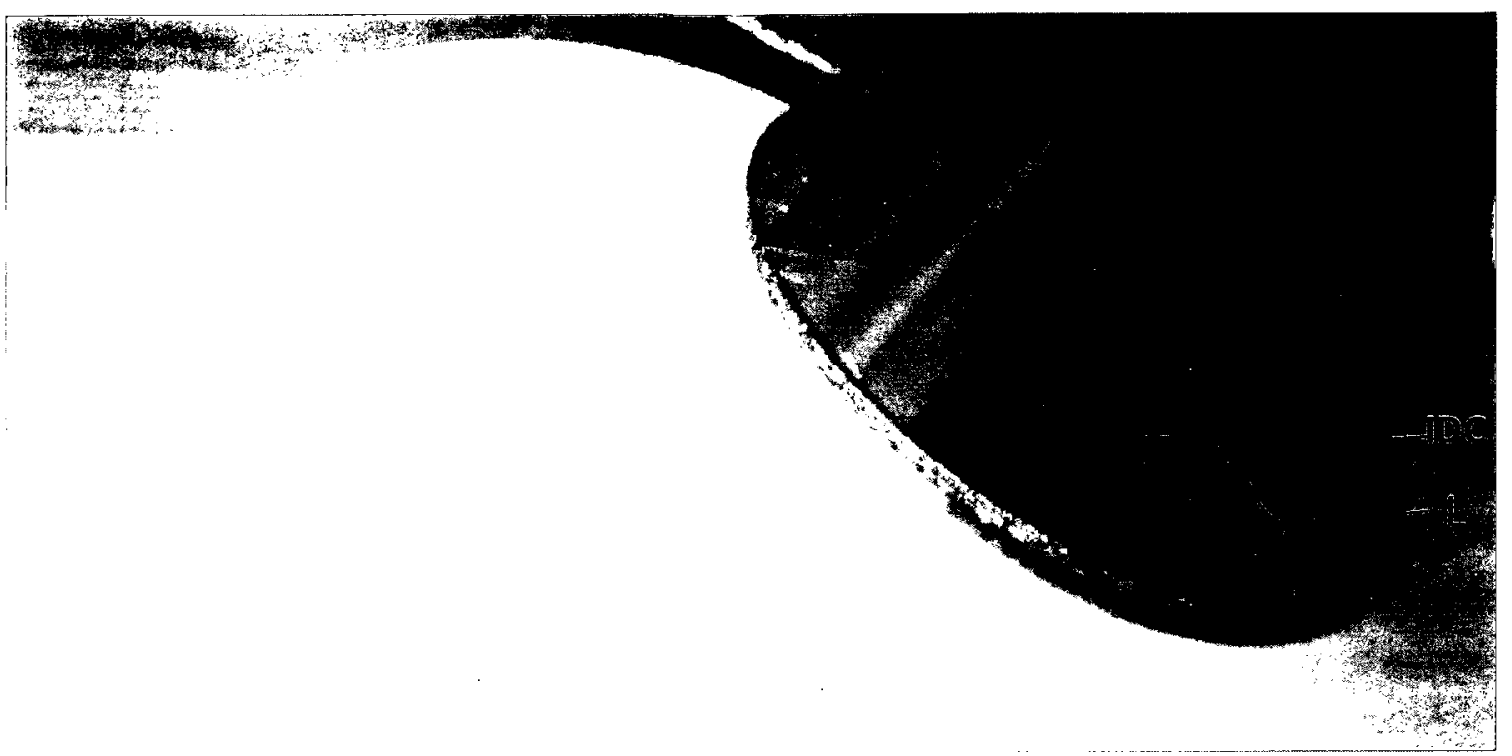

Figure 3.11 Fabricated IDC on a circular glass substrate.

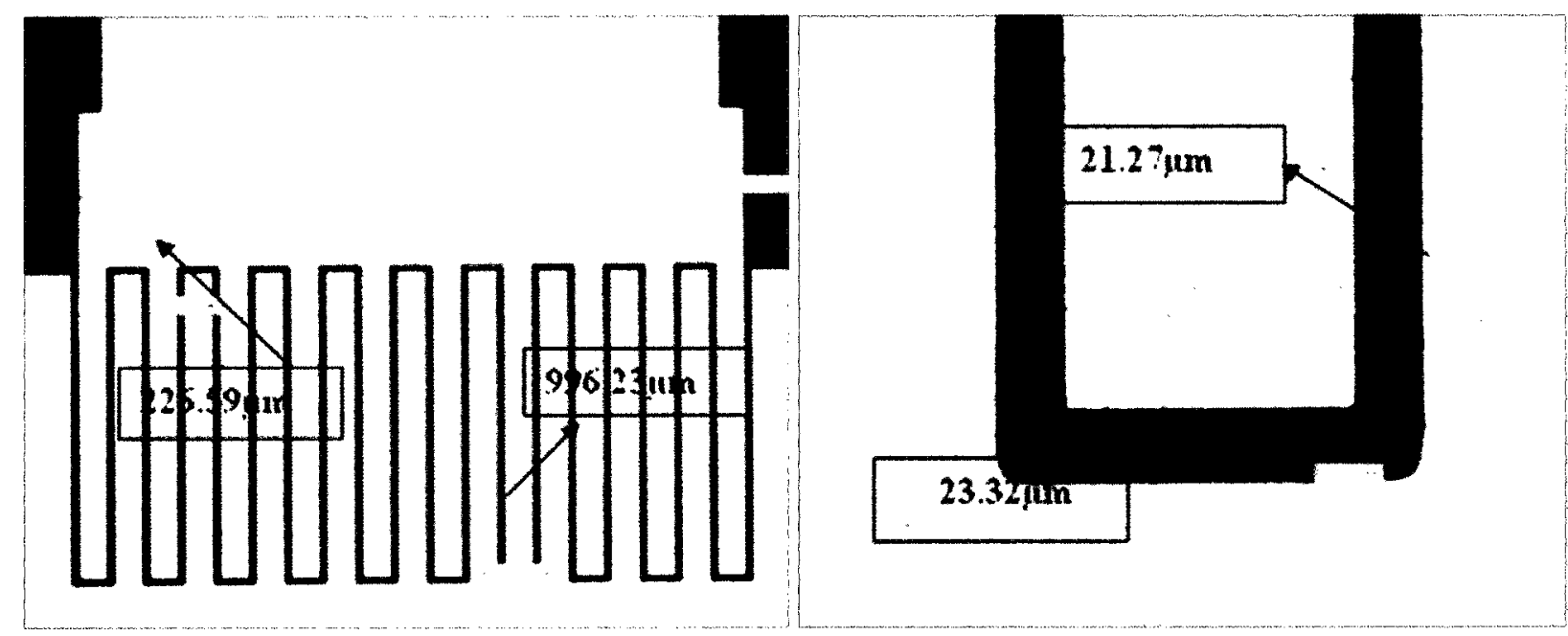

Figure 3.12 IDC with the new dimensions after fabrication.

The minimum feature size of the circuit has increased to about $21 \mu \mathrm{m}$. This will cause the IDC's capacitance to decrease and its self-resonance frequency to increase, as will be seen in Section 3.6. A 50- $\Omega$ end launch SMA connector as shown in Figure 3.15 was mounted at the edge of the disk using silver epoxy. 


\subsubsection{Measurement Setup}

\section{An Agillent Vector Network Amalyze. (VNA) and a broadband halogen lamp}

(wavelength of about $600 \mathrm{~nm}$ to $1500 \mathrm{~nm}$ ) were used for the reflection measurement.

Figure 3.13 shows the set-up for the measurement. Before making S11 measurements, the VNA was properly calibrated for one-port measurement using the precision open, short and load from the HP 850525 economy calibration kit.

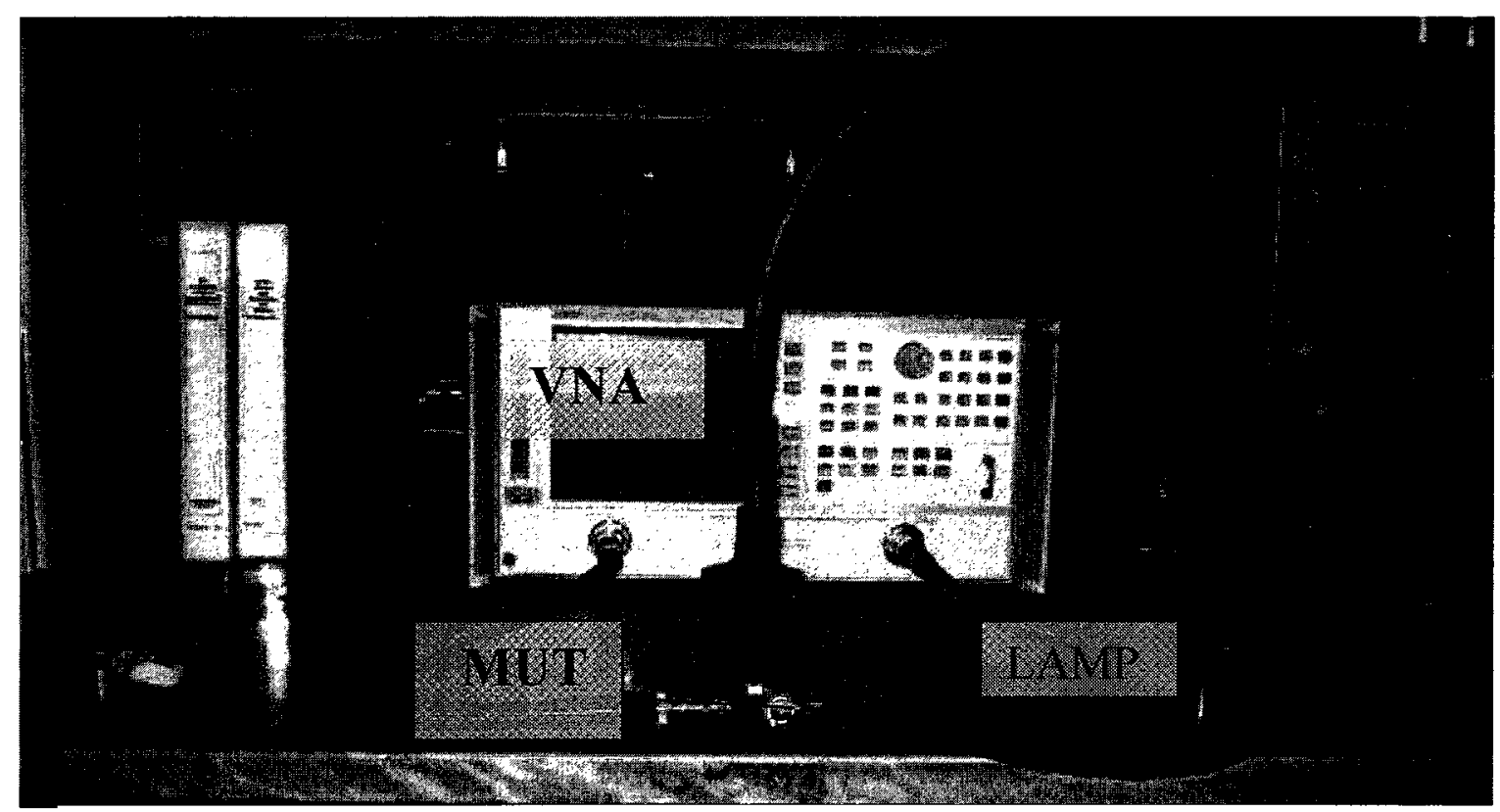

Figure 3.13 Characterization Setup showing the VNA, LAMP and the MUT.

\subsubsection{Measurement Results.}

The interdigitated capacitor with nominal length $1 \mathrm{~mm}$ without any overlay material was first measured from $100 \mathrm{MHz}$ to $5 \mathrm{GHz}$. The reference plane of the 
measurement was taken at the tip of the connector, i.e. measurement includes the long length of CPW to the IDC. Figures 3.14 (a), (b) and (d) shows the S22 parameters obtained from the measurement (the DUT was connected to port 2 of the VNA), while Figure 3.14 (c) shows the extracted capacitance. The return loss increases as the frequency increases as seen in Figure 3.14(a). The resonant frequency of the combined CPW and IDC structure occurs at $1.7 \mathrm{GHz}$ as shown in Figure 3.14(b) and Figure 3.14(c), respectively.

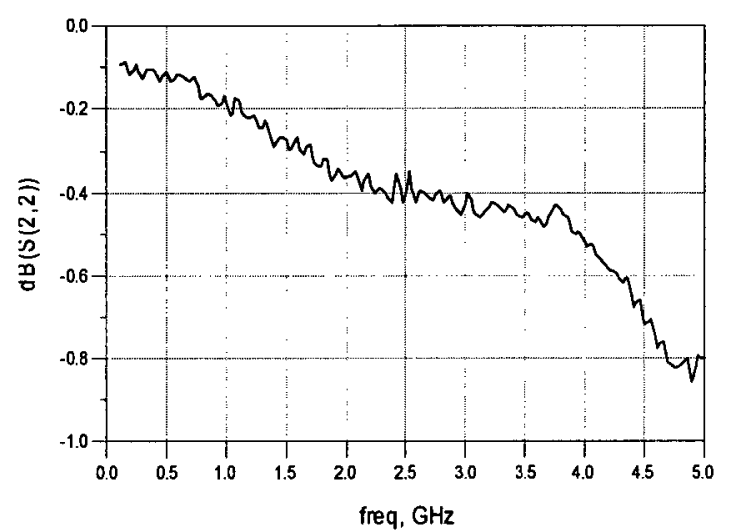

a) Return Loss.

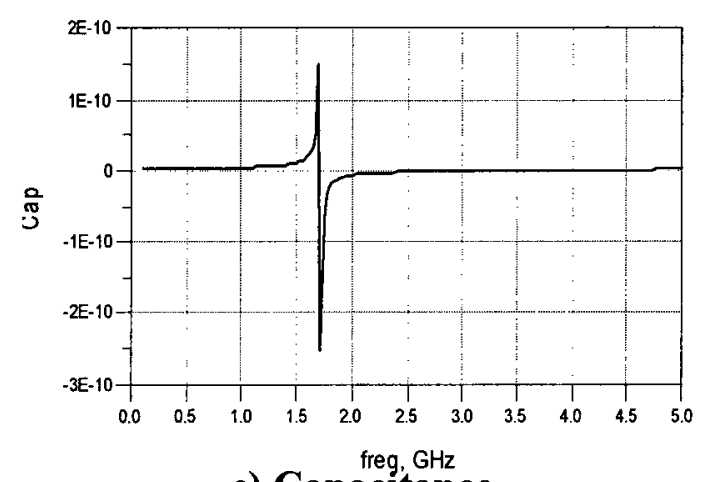

c) Capacitance.

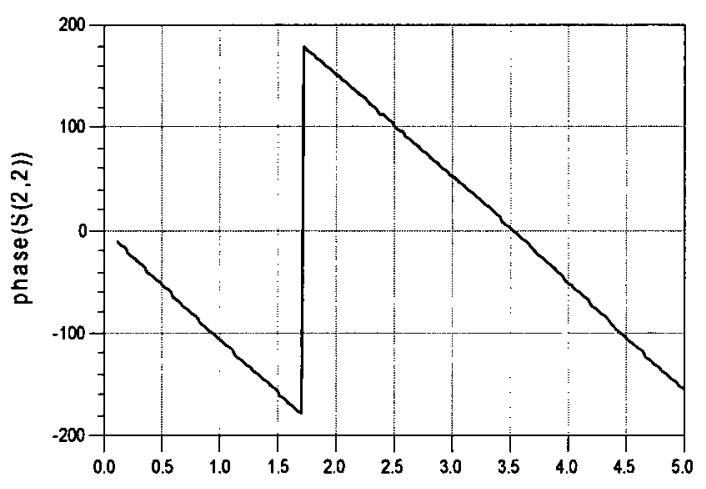

b) Phase of of $S 22$.

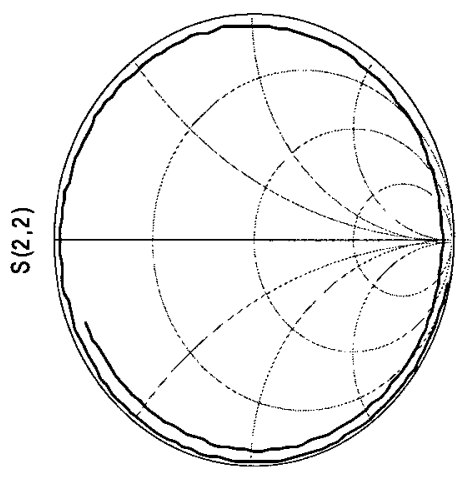

freq $(100.0 \mathrm{MHz}$ to $5.000 \mathrm{GHz})$

d) Smith chart.

Figure 3.14 S22 measurements of the interdigitated capacitor with nominal length $1 \mathrm{~mm}$ and no overlay material from $100 \mathrm{MHz}$ to $5 \mathrm{GHz}$. a) Return loss. b) Phase of S22, d) The capacitance with resonance at $1.6 \mathrm{GHz}$. d) S22 on Smith Chart. 
The IDC was then coated with polymer containing CdS nanoparticles (CdS-polymer $0.25: 0.75$ by weight). The approximated thickness of the material under test was $170 \mu \mathrm{m}$ as determined by micrometer measurement, and it covered the entire IDC as shown in Figure 3.15.

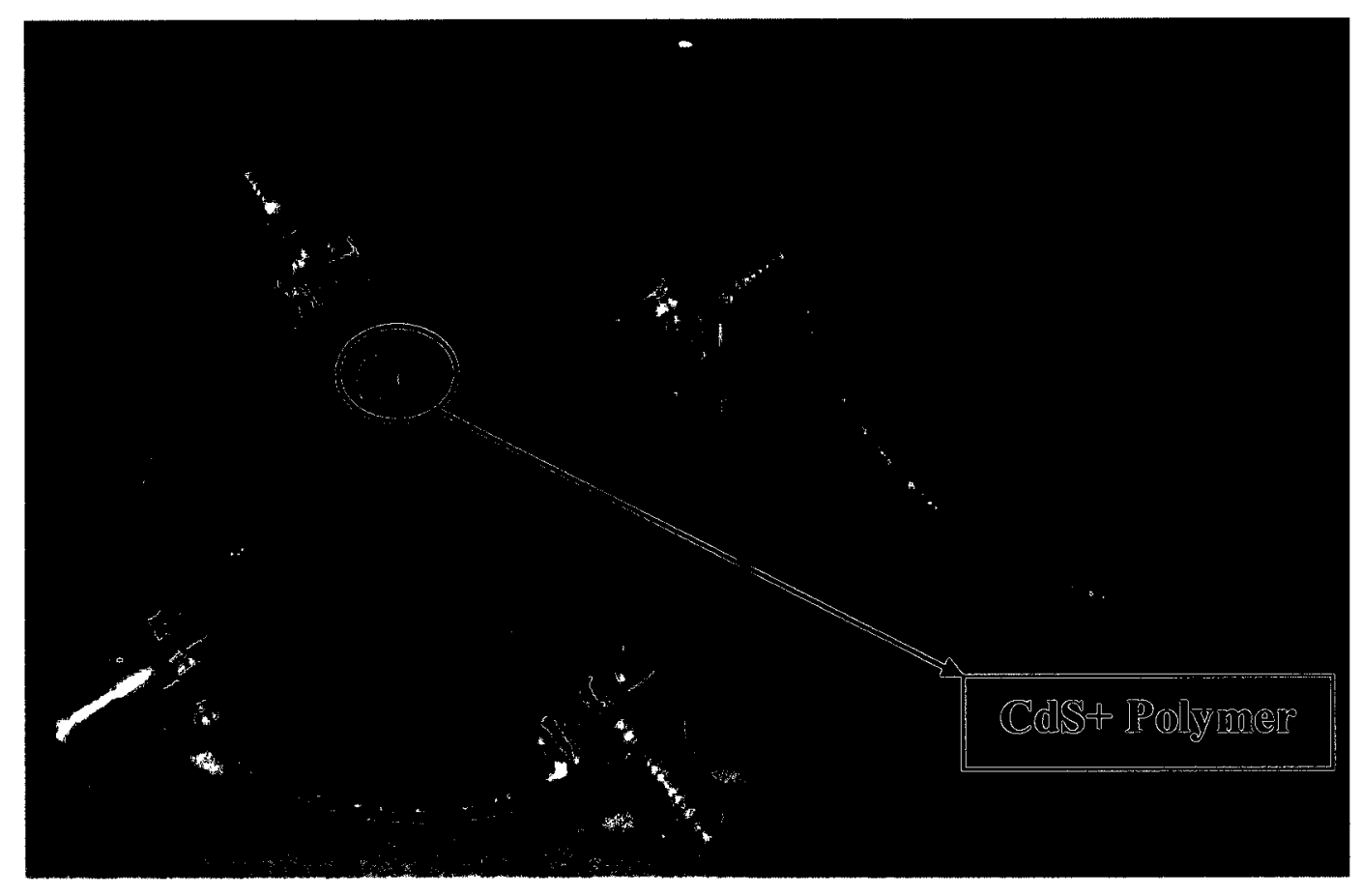

Figure 3.15 Mixture of CdS and polymer overlaid on the interdigitated capacitor with SMA connector mounted with silver epoxy.

The coated IDC was then measured under the same conditions as the uncoated IDC was measured, however, in this case, with and without illumination from the halogen lamp. Figures 3.16(a), 3.16(b) and 3.16(c) show the measured S22 in dB, phase of S22 in degree and S22 on the Smith Chart, respectively. (S44 denotes light ON.)

Figure 3.16(a) shows an increase in return loss when the light was on for all frequencies. This result correlates with Figure 3.8, which also shows an increase in return 
loss as the loss tangent increases. The curve moves towards the center of the Smith chart upon illumination as shown in Figure 3.16(b). This result is similar to Figure 3.8, which shows that the material is becoming lossy (increase in $\tan \delta$ ). Little or no change was observed with the resonant frequency upon illumination as shown in Figure 3.16(c). However, the shift of the $180^{\circ}$ phase point from $1.7 \mathrm{GHz}$ (Fig. 3.14 (b)) to $1.5 \mathrm{GHz}$ (Fig. 3.16 (b)) indicates that the polymer has a certain dielectric constant greater than 1 , whose value remains stable under illumination.

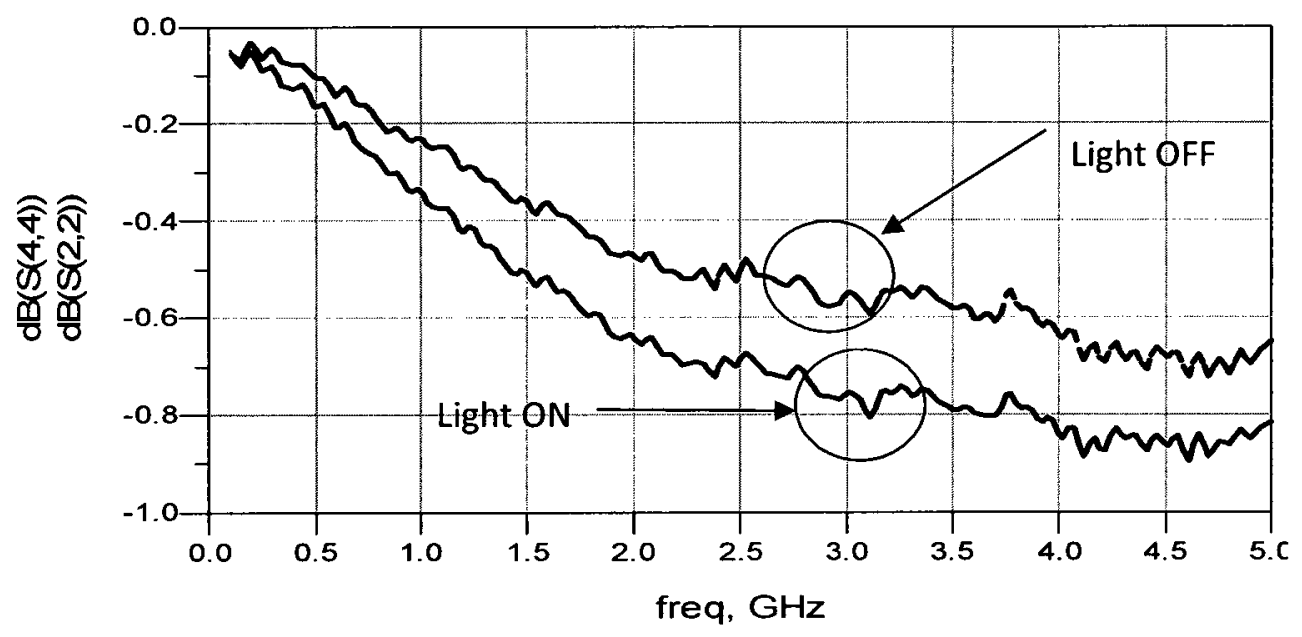

Figure 3.16(a) Return loss. 


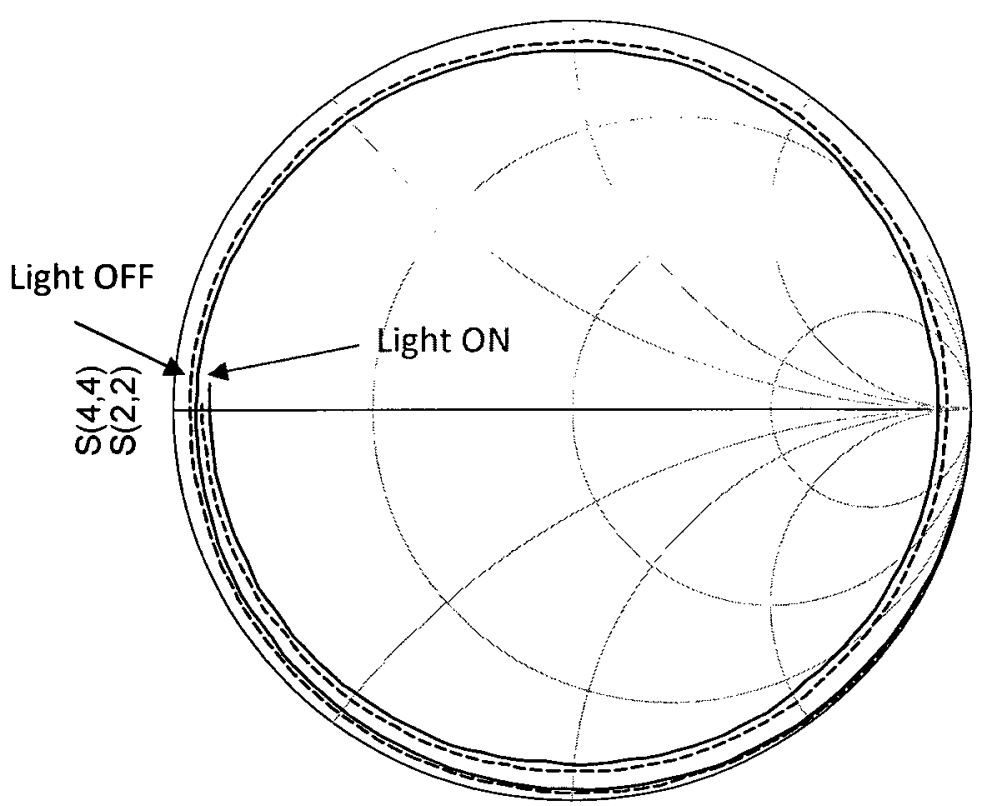

freq $(100.0 \mathrm{MHz}$ to $5.000 \mathrm{GHz})$

Figure 3.16(b) S22 on Smith Chart.

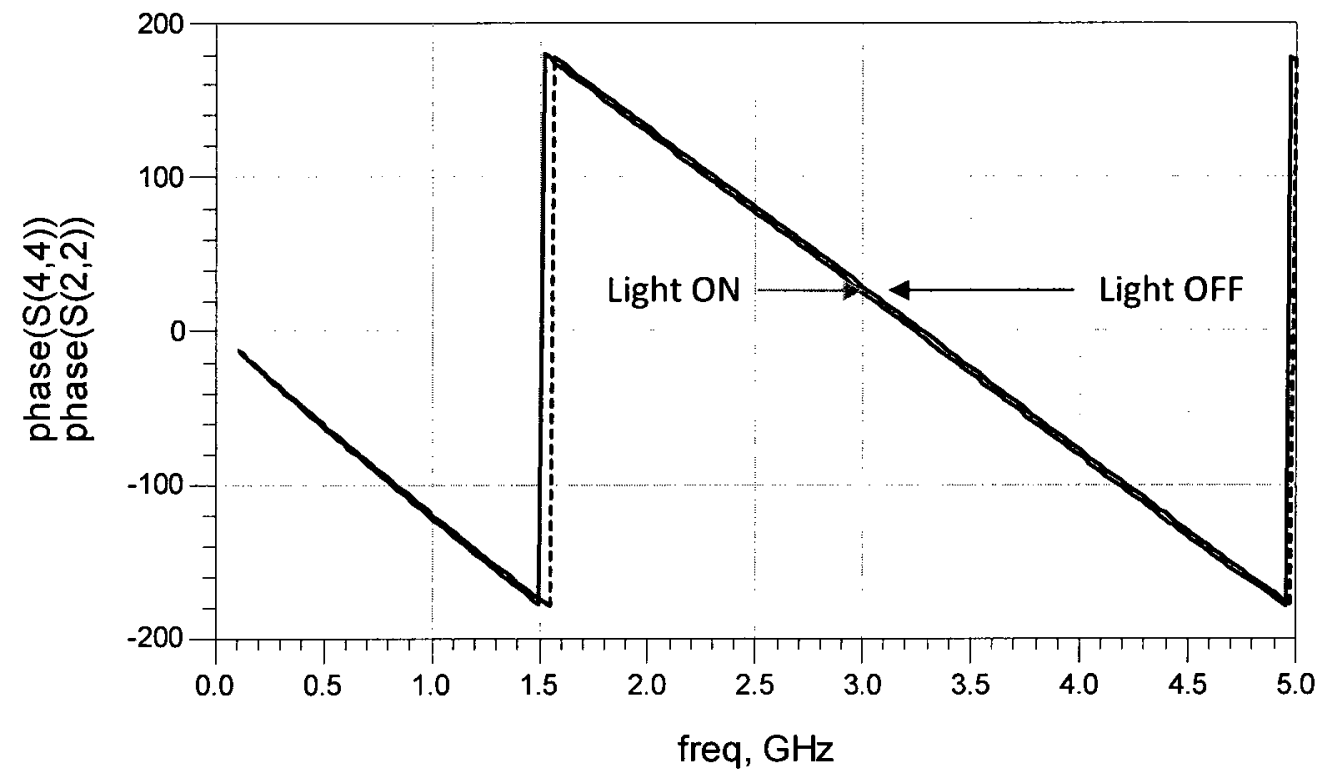

Figure 3.16(c) Phase of S22

Figure 3.16 Measured results for IDC having a nominal finger length of $\approx 1 \mathrm{~mm}$ and $\mathrm{CdS} /$ polymer overlay with and without broadband optical illumination. a) Return loss, b) Impedance on Smith chart, c) Phase of S22 
From the results shown in Figures 3.16(a), 3.16(b) and 3.16(c), it can be concluded that the $\mathrm{CdS} /$ polymer mixture exhibited photoconductive properties. Relating Figures (3.8), (3.9) (where the loss tangent was made a parameter) and Figures 3.14(a), 3.14(b) suggests there was increase in the loss tangent. An increase in loss tangent of a material is due to polarization loss or conduction loss, and these effects can be attributed to photo excitation as explained in Section 2.2.1. The DC resistivity of the CdS/polymer composite under illumination was $25 \mathrm{M} \Omega$ [34]. At this high level, it is unlikely that a change in conductivity attributed much to a change in loss tangent.

\subsection{Extraction and Modeling of Material Properties.}

The extraction of the material properties and the modeling of the fabricated structure, were done by matching the measured S11 parameters of the $1 \mathrm{~mm}$ finger length IDC, with and without overlay material, to a lumped element equivalent model based on (a) approximate IDC element values and (b) HFSS-simulated IDC S-parameters. Advanced Design System (ADS), a commercially available microwave CAD software, was used in the process. Figure 3.17 shows the resulting equivalent model for the alllumped approach (a). It comprises the SMA connector model, CPW line model, and IDC lumped element model. The SMA is modeled as a parallel capacitor (C2) in series with an inductor (L2) and resistor (R2), representing the transition from coaxial to CPW propagation. The capacitor represents the shunt capacitance between the centre connector and the outer conductor of SMA connector. The resistor and the inductor represent the 
distributed resistance and the inductance of the center conductor of the connector, respectively.

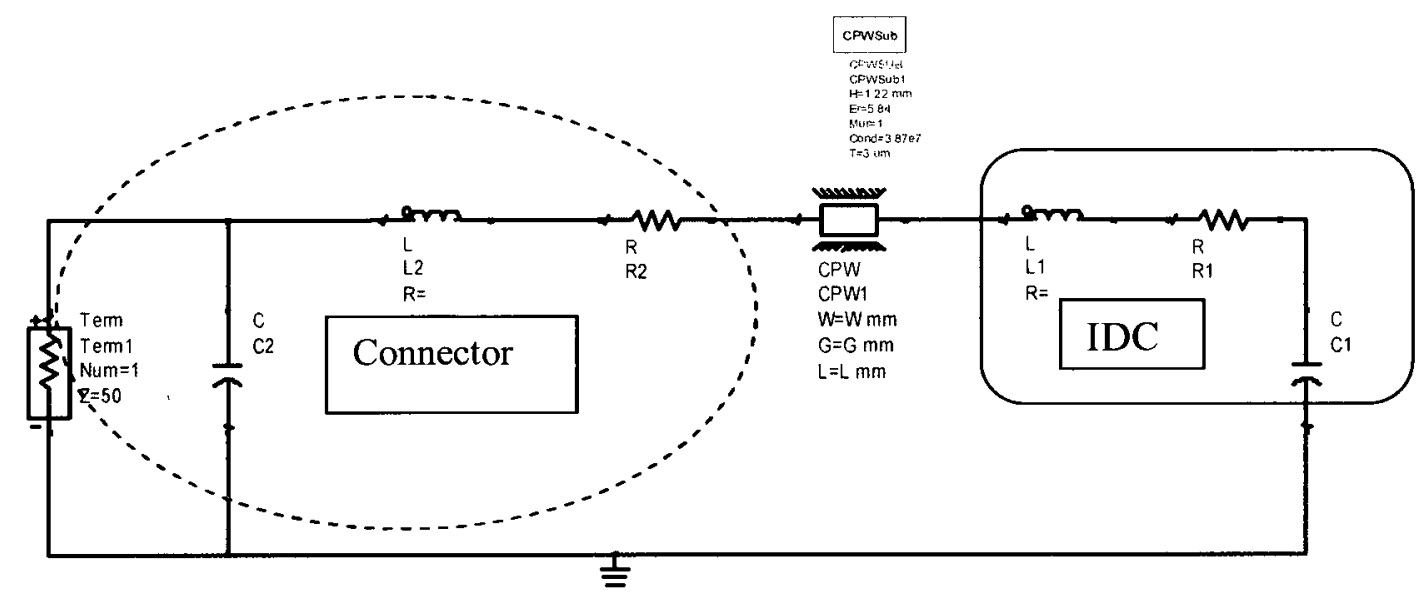

Figure 3.17 Lumped element equivalent circuit for the connector, CPW and IDC.

To determine the values of the elements and the parameters in the lumped equivalent model in Figure 3.17, the CPW line model and the IDC were first modeled and optimized to match the measured result over the range of $100 \mathrm{MHz}$ to $500 \mathrm{MHz}$. It is assumed that the connector model has little or no effect at these lower frequencies. The geometry of the CPW line was measured with a micrometer associated with the microscope. The measured values were gap $(\mathrm{G})=0.38 \mathrm{~mm}$, signal conductor width $(\mathrm{S})=$ $1.9 \mathrm{~mm}$ and length $\mathrm{L}=13.2 \mathrm{~mm}$, and these values were used in the CPW model provided by ADS. The estimated values for $\mathrm{C} 1, \mathrm{R} 1$, and $\mathrm{L} 1$ were determined from an approximate model in [26] and [28] using the true (fabricated) dimensions of the IDC. ADS was then used to tune $\mathrm{R} 1, \mathrm{C} 1$, and $\mathrm{L} 1$ to match the measured result over the range of $100 \mathrm{MHz}$ to $500 \mathrm{MHz}$. The optimized values for the IDC model are, $\mathrm{C} 1=1.05 \mathrm{pF}, \mathrm{L} 1=1.2 \mathrm{nH}, \mathrm{R} 1=$ $1.7 \Omega$, self-resonating approximately at $4.48 \mathrm{GHz}$. The connector model was then 
included and its parameters $\mathrm{C} 2, \mathrm{~L} 2$ and R2 was varied and optimized to match the measured result over the wider frequency range of $100 \mathrm{MHz}$ to $5 \mathrm{GHz}$.

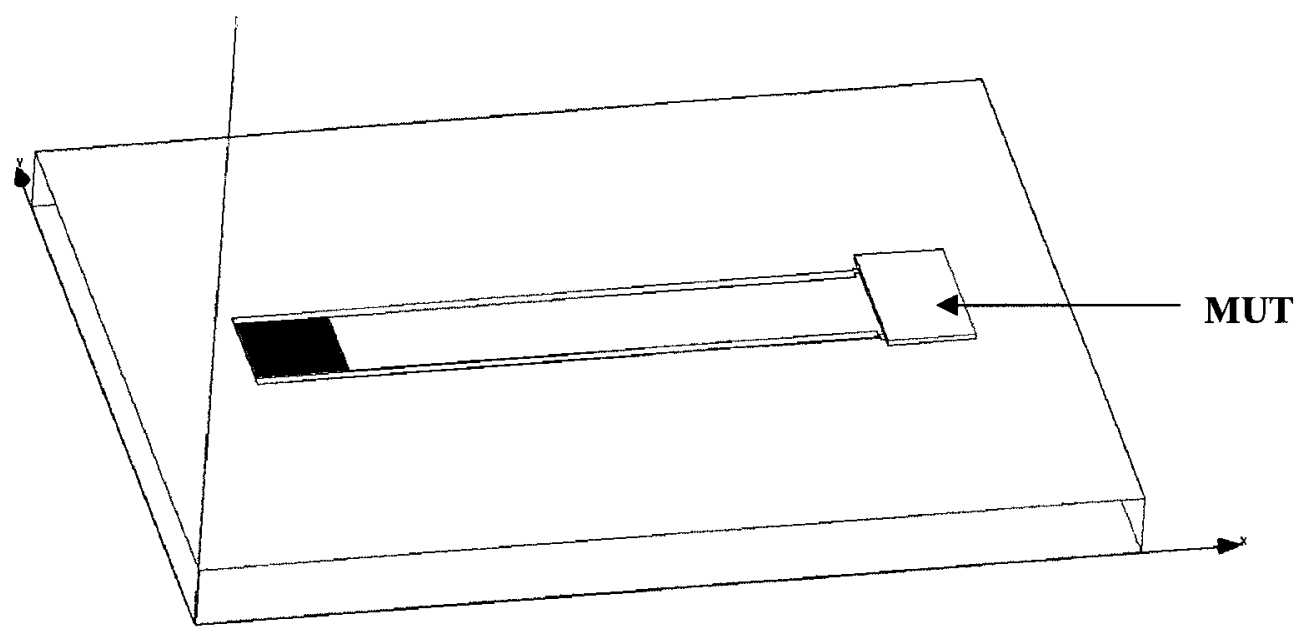

Figure 3.18 HFSS simulation structure for the fabricated IDC with MUT overlaid on the IDC

The optimized values for the connector model are $\mathrm{L} 2=0.8 \mathrm{nH}, \mathrm{C} 2=0.3 \mathrm{pF}, \mathrm{R} 2=0.12 \Omega$ resonating at approximately at $10 \mathrm{GHz}$.

Next, an HFSS simulation was performed as illustrated in Figure 3.18 to model the CPW line and IDC. The resulting equivalent model for the hybrid lumped/HFSS approach (b) is shown in Figure 3.19. The IDC dimensions of the fabricated structure, as shown in Figure 3.12 and the dimensions of the CPW line were used in the HFSS model. To account for the connector model, the S-parameters obtained from the simulation were exported to ADS and connected to the complete model as shown in Figure 3.19. 


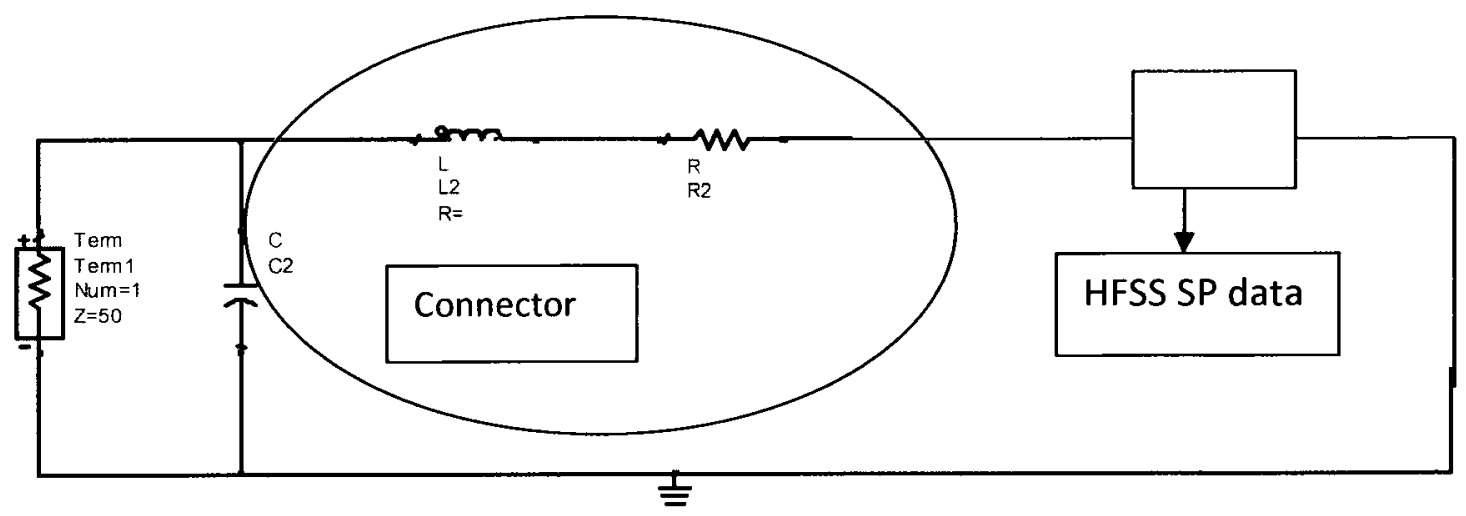

Figure 3.19 Equivalent lumped/HFSS model with s-parameter (SP) data from HFSS.

The two models were simulated in Agilent ADS. Figures 3.20 and 3.21 show the correlation between the measured results, the equivalent lumped element model of the structure and the lumped/HFSS model for the IDC with no overlay of MUT. There was a very close agreement between the equivalent lumped element model and the lumped/HFSS model, within $0.1 \mathrm{~dB}$ in magnitude of $\mathrm{S} 11$ over $100 \mathrm{MHz}$ to $5 \mathrm{GHz}$ and within 20 degrees in phase of S1 1 up to $2.5 \mathrm{GHz}$. The HFSS model shows a better agreement with the measured phase up to $5 \mathrm{GHz}$ than the lumped model. 


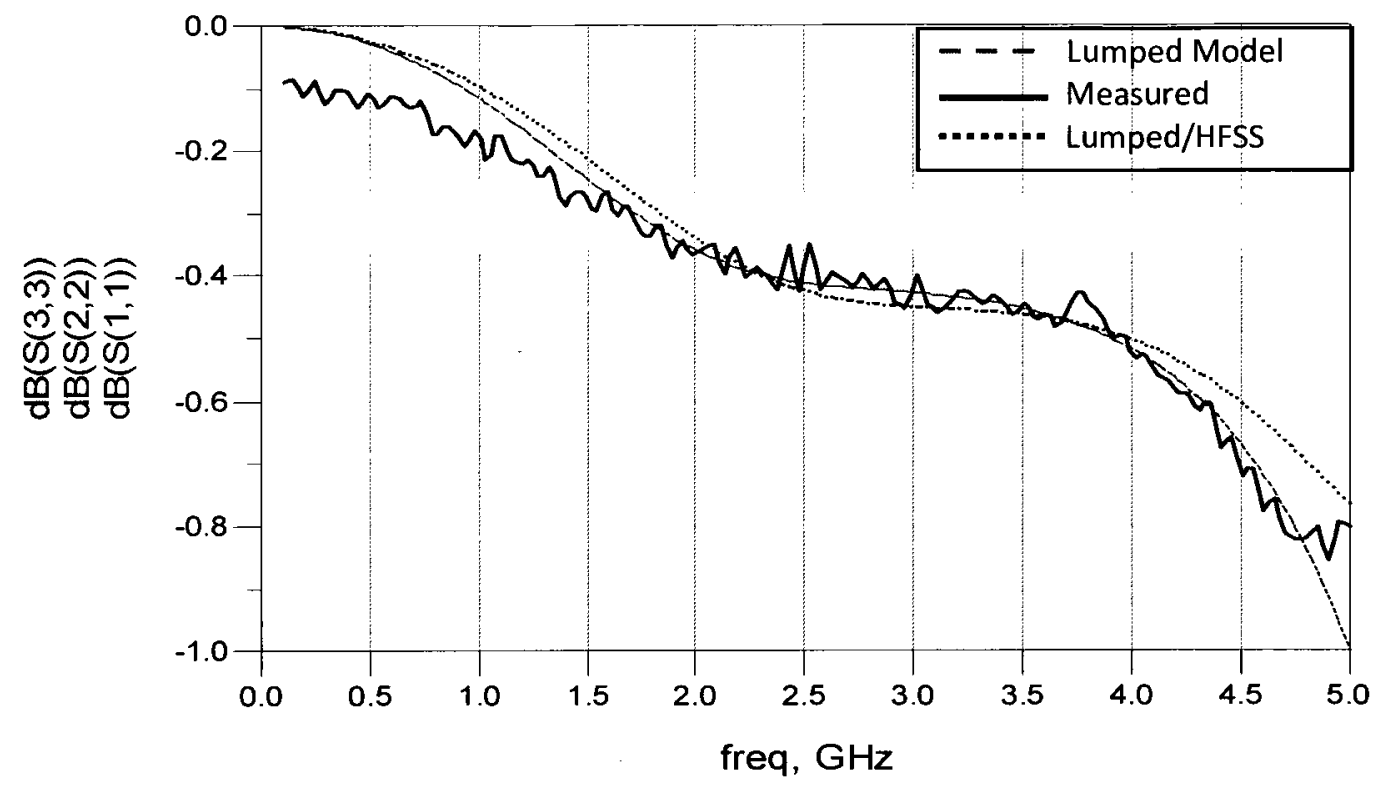

Figure 3.20 Return loss comparison of the measured result, lumped element equivalent model and lumped/HFSS model without polymer overlay.

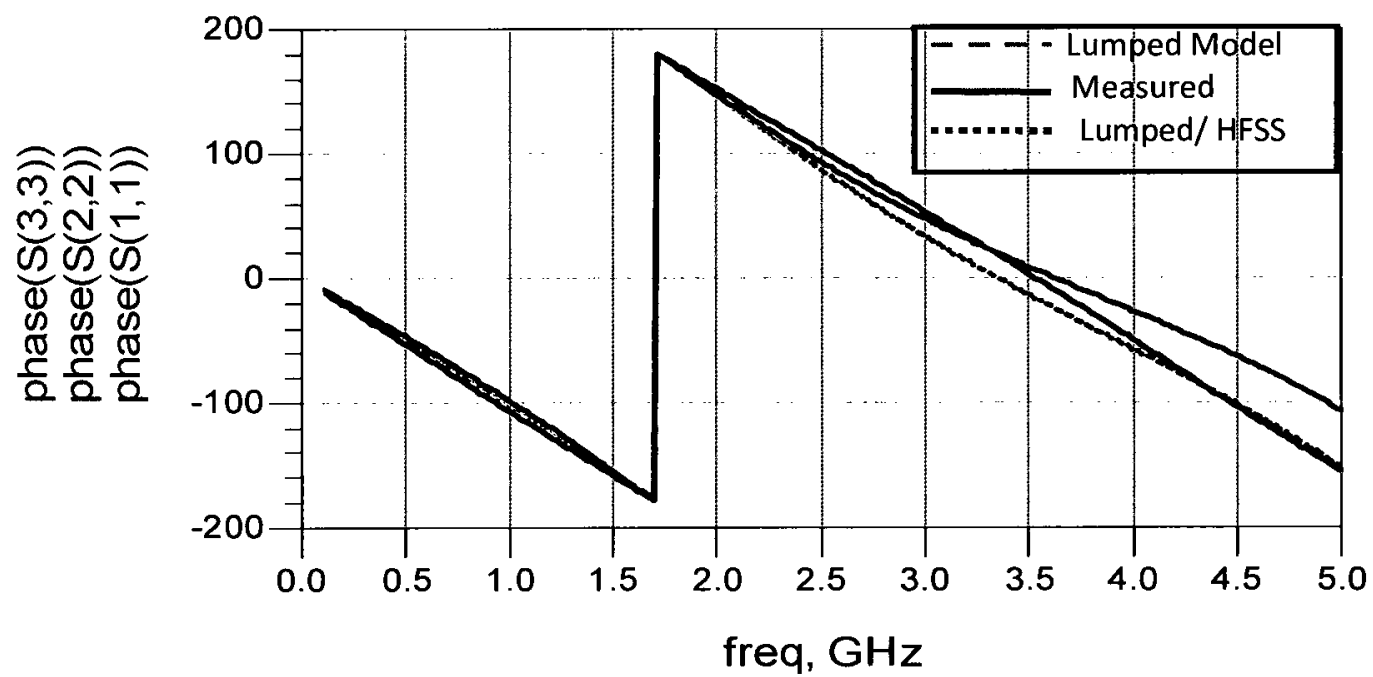

Figure 3.21 Reflection phase comparison of the measured result, lumped element equivalent model and lumped/HFSS model without polymer overlay. 
To model the IDC with the polymer material overlaid on it, the initial step of optimizing $\mathrm{L} 1, \mathrm{Cl}$, and $\mathrm{R} 1$ of the equivalent lumped element model of the IDC to match the measured S parameters of the fabricated IDC was repeated. The optimized values were $\mathrm{L} 1=1.1 \mathrm{nH}, \mathrm{Cl}=1.3 \mathrm{pF}$, and $\mathrm{R} 1=1.8 \Omega$. As expected, there was an increase in the capacitance $\mathrm{C} 1$ and resistance $\mathrm{R} 1$, compared to the initial values obtained with no polymer overlay. The increase is due to the MUT that was placed on the IDC, while the inductance L1 value decreases slightly. Different values of $\varepsilon_{r}$ and $\tan \delta$ of the overlaid material were then simulated in the HFSS model and then transferred to ADS for the final comparison. From the range of values simulated, $\varepsilon_{r}$ of 4 and $\tan \delta$ of 0.004 were the closest values realized. These values were expected due to the ratio $25 \%$ to $75 \%$ by weight of the polymer to CdS mixture. Figure 3.22 and Figure 3.23 show the return loss and reflected phase comparisons of the lumped element equivalent model, the lumped/HFSS model and the measured results, without illumination. The return loss curves for the lumped/HFSS model and the measured results were very close over the entire $0.1 \mathrm{GHz}$ to $5 \mathrm{GHz}$ frequency range, while the lumped element equivalent model differed by about $0.2 \mathrm{~dB}$ between $1.5 \mathrm{GHz}$ and $3.5 \mathrm{GHz}$. As seen in Figure 3.23 there was very good agreement for the reflection phase between the two models and the measured results up to $3.5 \mathrm{GHz}$. 


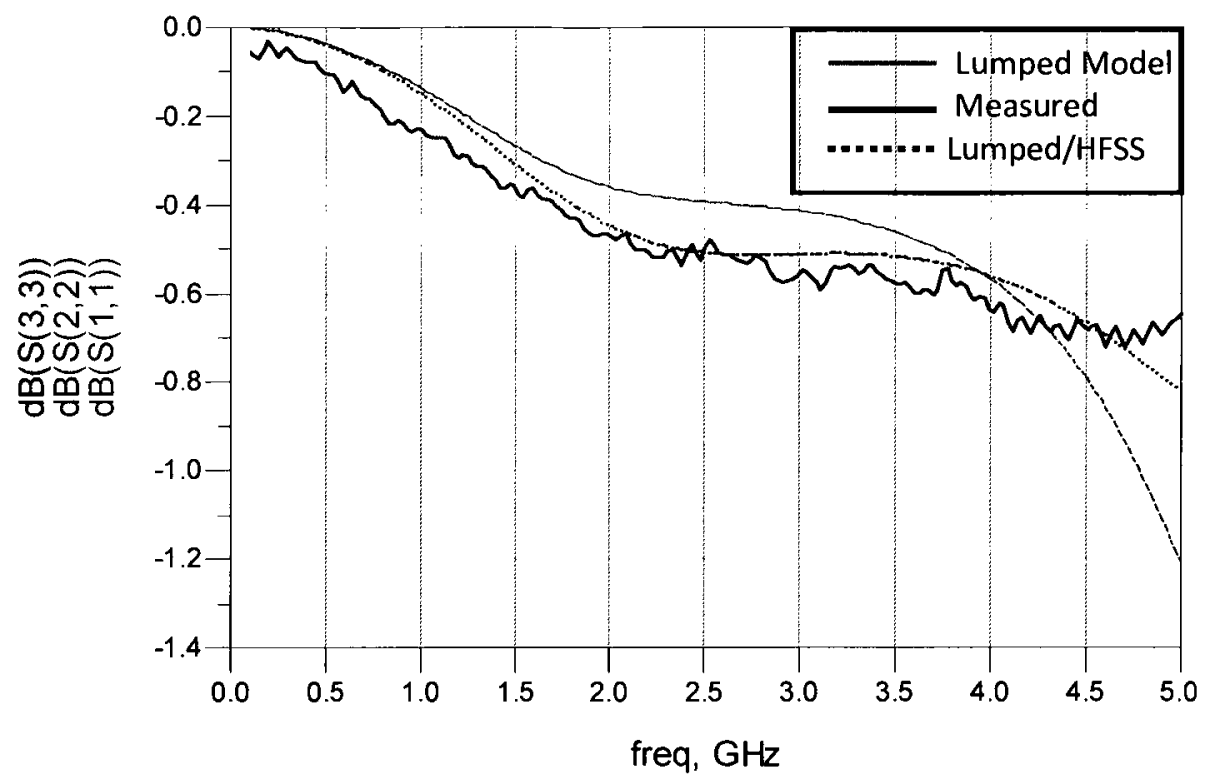

Figure 3.22 Return loss comparison of the measured result, lumped element equivalent model and lumped/HFSS model with polymer overlay having $\varepsilon_{r}=4$ and $\tan \delta=0.004$ No illumination.

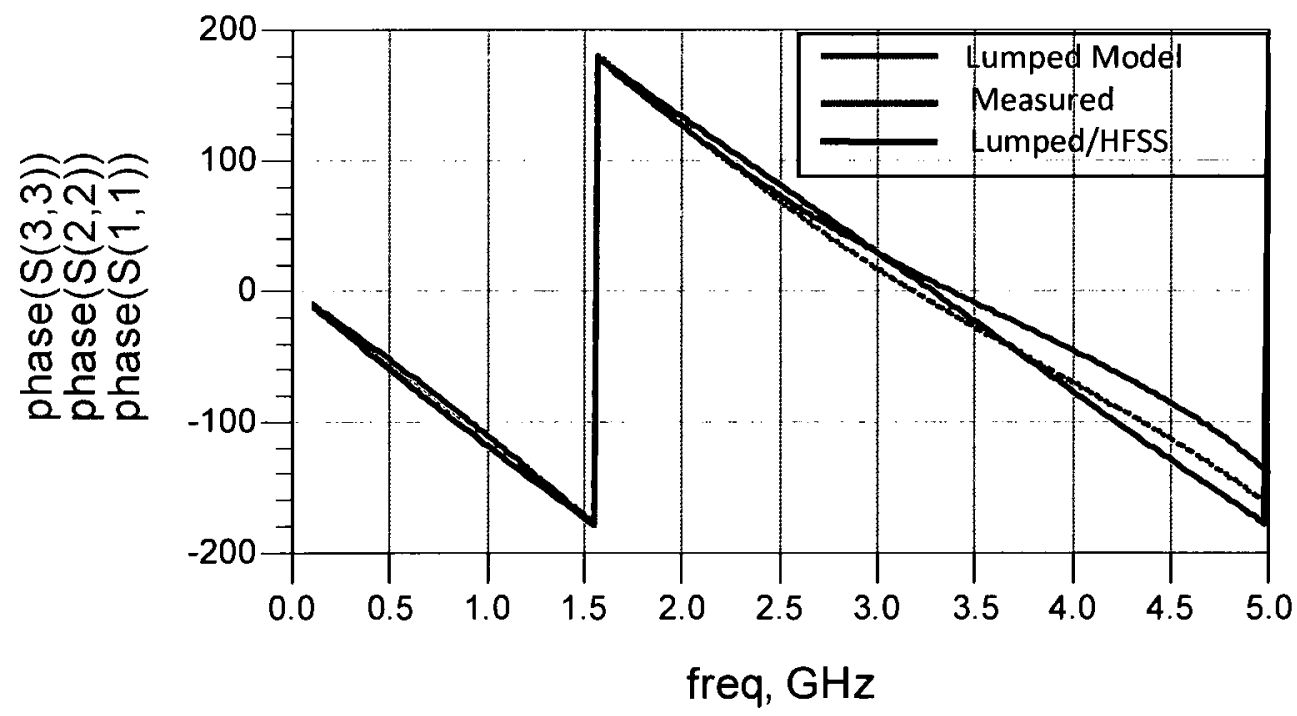

Figure 3.23 Reflection phase comparison of the measured result, lumped element equivalent model and lumped/HFSS model with polymer overlay having $\varepsilon_{r}=4$ and $\tan \delta$ $=0.004$ - No illumination. 
Modeling the IDC with polymer overlay and light applied, the C1, L1, and R1 values of the lumped element model were re-tuned to match the S-parameters measured with light on. The optimized values were $\mathrm{C} 1=1.35 \mathrm{pF}, \mathrm{L} 1=1.08 \mathrm{nH}$, and $\mathrm{R} 1=2.6 \Omega$. There was a slight increase in capacitance $\mathrm{C} 1$ for the lumped element equivalent model with light on as compared to when it was off. The resistance R1 increased by $0.8 \Omega$ for the model with light on, showing that in fact the MUT is becoming more lossy. In the HFSS model, the loss tangent of the overlaid material was increased periodically with a random interval while keeping $\varepsilon_{r}$ constant. The S parameters for each sweep were exported to ADS for comparison with the measured result. A loss tangent of 0.11 , which is 30 times greater than the non-illuminated case, was the best fit as shown in Figure 3.24 and Figure 3.25. As seen in Figure 3.24, the lumped element model was off by about 0.2 $\mathrm{dB}$ in return loss for most of the frequency range, while there was better agreement between the measured result and the lumped/HFSS model. Referring to Figure 3.25 there was again very good agreement for the reflection phase between the two models and the measured results up to $3.5 \mathrm{GHz}$. 


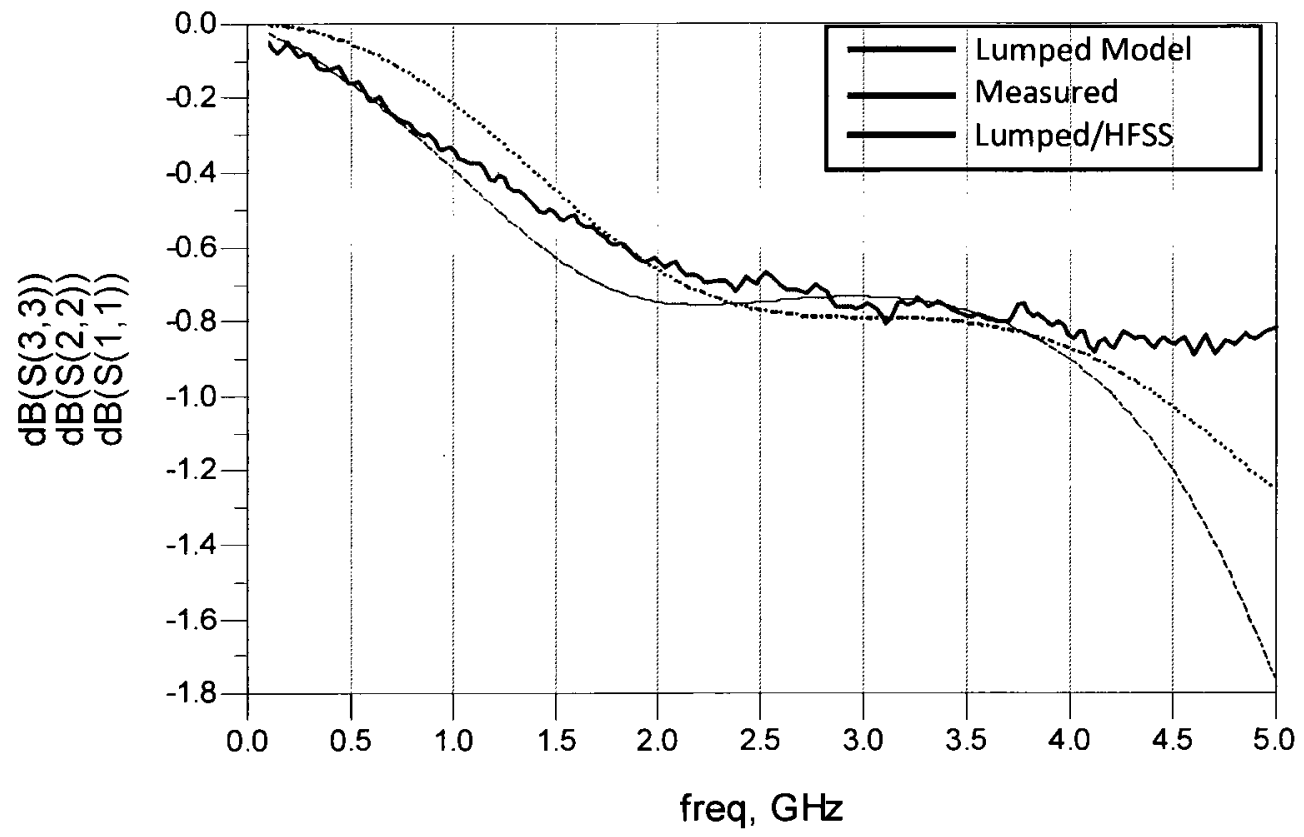

Figure 3.24 Return loss comparison of the measured result, lumped element equivalent model and lumped/HFSS model with polymer overlay having $\varepsilon_{r}=4$ and $\tan \delta=0.004$ With illumination.

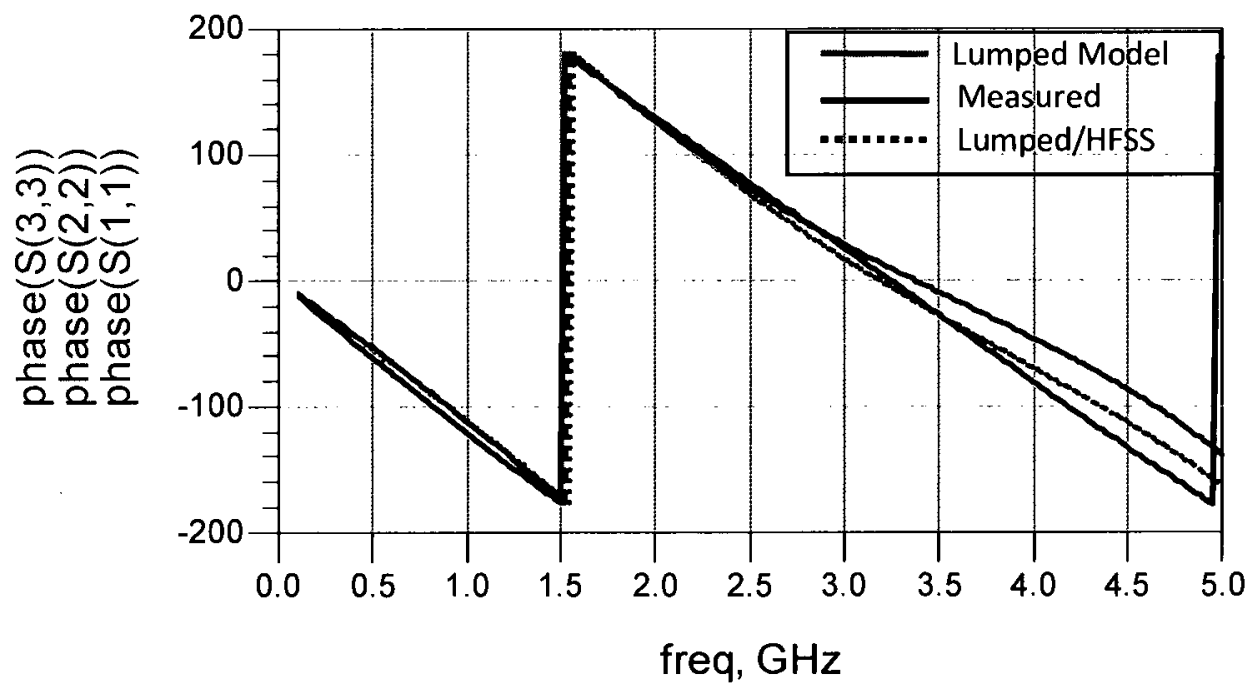

Figure 3.25 Reflection phase comparison of the measured result, lumped element equivalent model and lumped/HFSS model with polymer overlay having $\varepsilon_{r}=4$ and $\tan \delta$ $=0.004-$ With illumination. 


\subsection{Chapter Summary and Conclusions}

In this chapter, an original CPW-fed IDC structure was developed for in-situ material characterization of optically-sensitive polymers at microwave frequencies.

Through a combination of lumped-element and EM-based modeling, and experimental measurements, the initial characterization of novel CdS nanoparticle-loaded polymer material has been successfully carried out. The extracted material properties and equivalent circuit element values, valid for the $0.1 \mathrm{GHz}$ to $5 \mathrm{GHz}$ range, are summarized in Table 3.3.

Table 3.3 Results of optically-sensitive polymer material characterization using the IDC test structure developed in this thesis

\begin{tabular}{|c|c|c|c|}
\hline & IDC & $\begin{array}{l}\text { Polymer-Coated IDC } \\
\text { - No Illumination }\end{array}$ & $\begin{array}{l}\text { Polymer-Coated IDC } \\
\text { - With Illumination }\end{array}$ \\
\hline C1 (pF) & 1.05 & 1.3 & 1.35 \\
\hline R1 ( $(\mathbf{\Omega})$ & 1.7 & 1.8 & 2.6 \\
\hline L1 (nH) & 1.2 & 1.1 & 1.1 \\
\hline Polymer $\varepsilon_{r}$ & - & 4 & 4 \\
\hline Polymer $\tan \delta$ & - & 0.004 & 0.11 \\
\hline
\end{tabular}


The new CdS-polymer 0.25:0.75 mixture was found to exhibit a moderate photoconductive effect, as evidenced by a 30 -fold increase in its loss tangent under broadband optical illumination.

These initial results are promising for tunable microwave circuits, but further work is needed to completely characterize the materials (for example at higher microwave frequencies and at different optical wavelengths and power levels). Also, more material development work is needed to fully explore the various nanoparticlepolymer mixtures. 


\section{Chapter 4}

\section{Study of Optically Tunable Dipole Antenna}

Given the availability of CdS composite polymer materials and their photoconductive properties as described in Chapter 3, it is interesting to investigate how they may now be applied to the realization of a practical optically-tuned antenna. This chapter presents the preliminary design of an optically tunable dipole antenna for the 1.9 $\mathrm{GHz}$ and 2.1 GHz GSM communication bands. The theoretical results obtained will be useful for guiding future polymer material development which, ultimately, could lead to a final working design.

\subsection{Tunable Dipole Antenna}

For the antenna design pursued here, the composite polymer is placed along the segmented length of the arm of the dipole. Upon illumination, there will be an increase in the conductivity of the material. Gaps between segments will become conductive creating continuity in the length of the dipole and thereby increasing the physical length.

References [13] and [29] used such an increase in the physical length to tune the bandwidth and the resonance frequency of a dipole antenna. In [13], PIN diodes are used to tune frequency. Each arm of the antenna was segmented and PIN diodes were placed between the segments as shown in Figure 4.1. The diodes were then turned ON and OFF by an external bias voltage. In the ON state, both the electrical and the physical length of 
the arm was increased thereby reducing the resonance frequency of the antenna, while in the OFF state, the electrical length of the arm became shorter and the resonance frequency was increased. Figure 4.2 shows the return loss of the dipole antenna. There was a shift in the resonance of the return loss from $5.94 \mathrm{GHz}$ to $5.8 \mathrm{GHz}$ when the inner diodes were turned on, and when all the diodes were turned on the resonance frequency shifted down to $5.69 \mathrm{GHz}$. An obvious drawback of this approach to realizing antenna tunability is the parasitics of the PIN diodes, which severely limit the achievable tuning range.

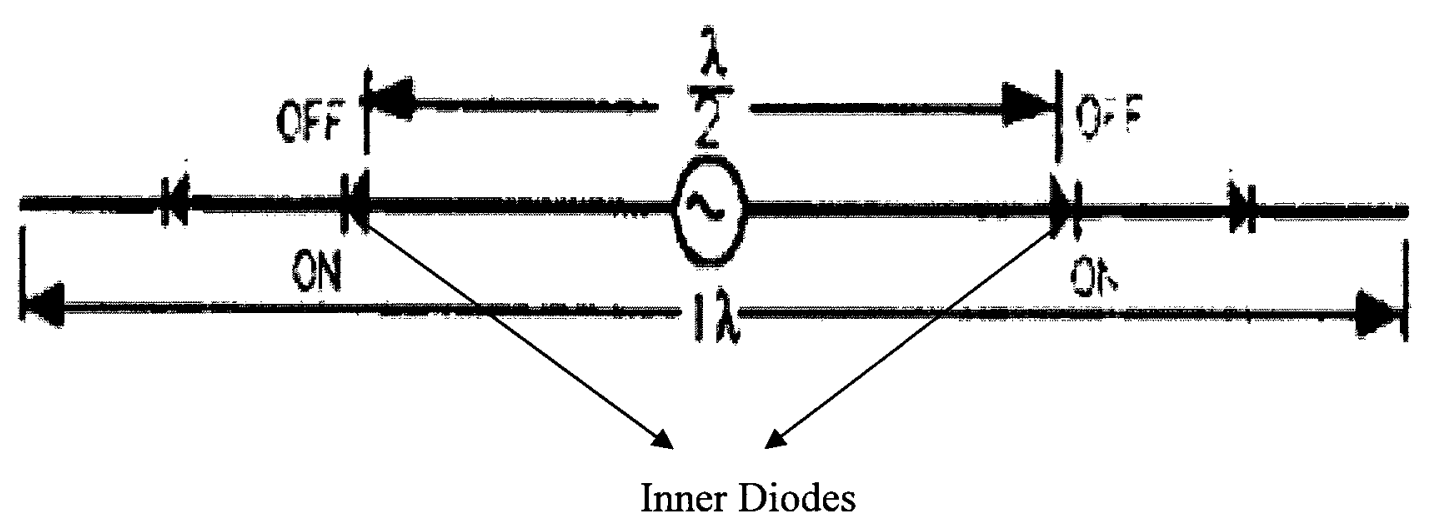

Figure 4.1 Dipole arm with two diodes on each arm [13]. 


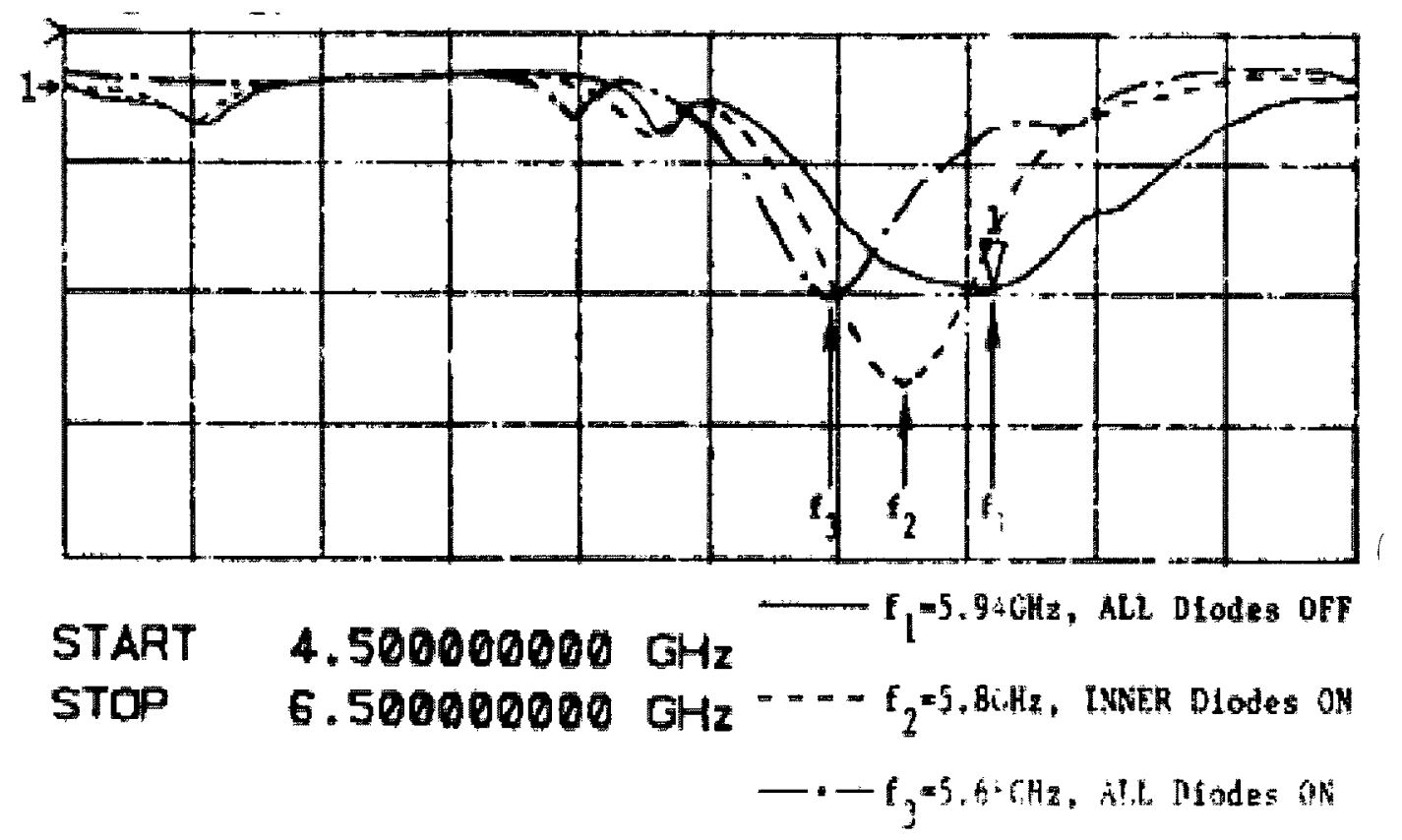

Figure 4.2 Measured return loss of multi-frequency dipole for: all diodes OFF, inner diodes $\mathrm{ON}$, all diodes $\mathrm{ON}[13]$.

Reference [29] also designed and implemented a multiband dipole antenna, but using optically activated silicon switches instead of PIN diodes. Here silicon switches were placed along the length of the dipole arm as shown in Figure 4.3. The switches were illuminated through an optical fibre at varying light intensity. 


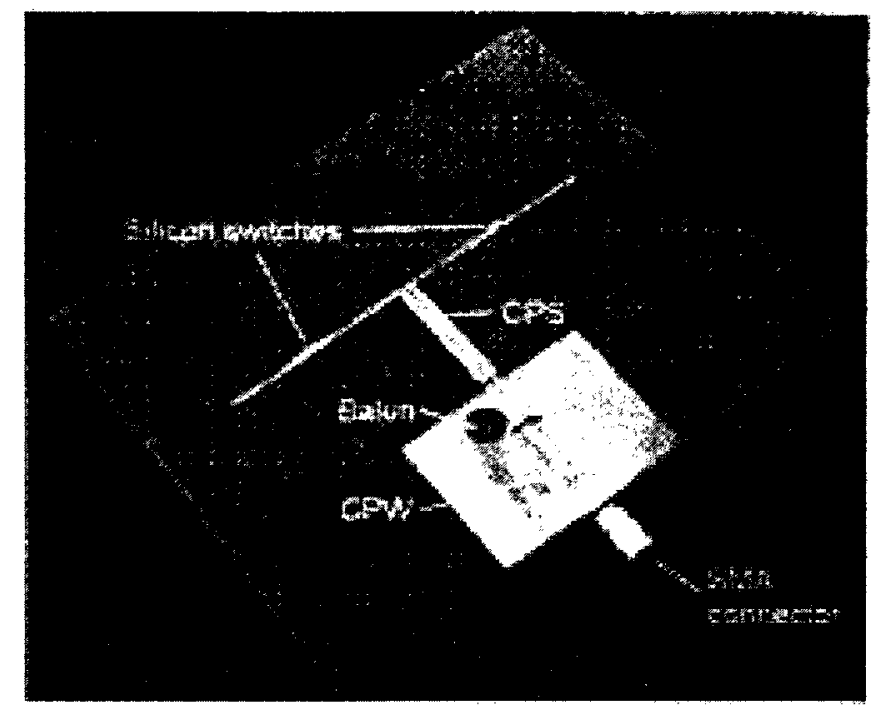

Figure 4.3 Silicon switch controlled dipole antenna [29].

Figure 4.4 shows the return loss of the antenna with different light intensities. It can be seen that at lower light intensity $(0 \mathrm{~mW}$ and $0.2 \mathrm{~mW})$, the silicon switch was not conducting (insulator). Hence the length of the dipole was still short, thereby resonating at about $3.2 \mathrm{GHz}$. As the light intensity increased, the switch conductivity also increased. This in turn increased the length of the dipole arm. A resonance at $2.3 \mathrm{GHz}$ was obtained at $10 \mathrm{~mW}$ illumination and the depth of the resonance grew as the illumination was increased to $20 \mathrm{~mW}$. 


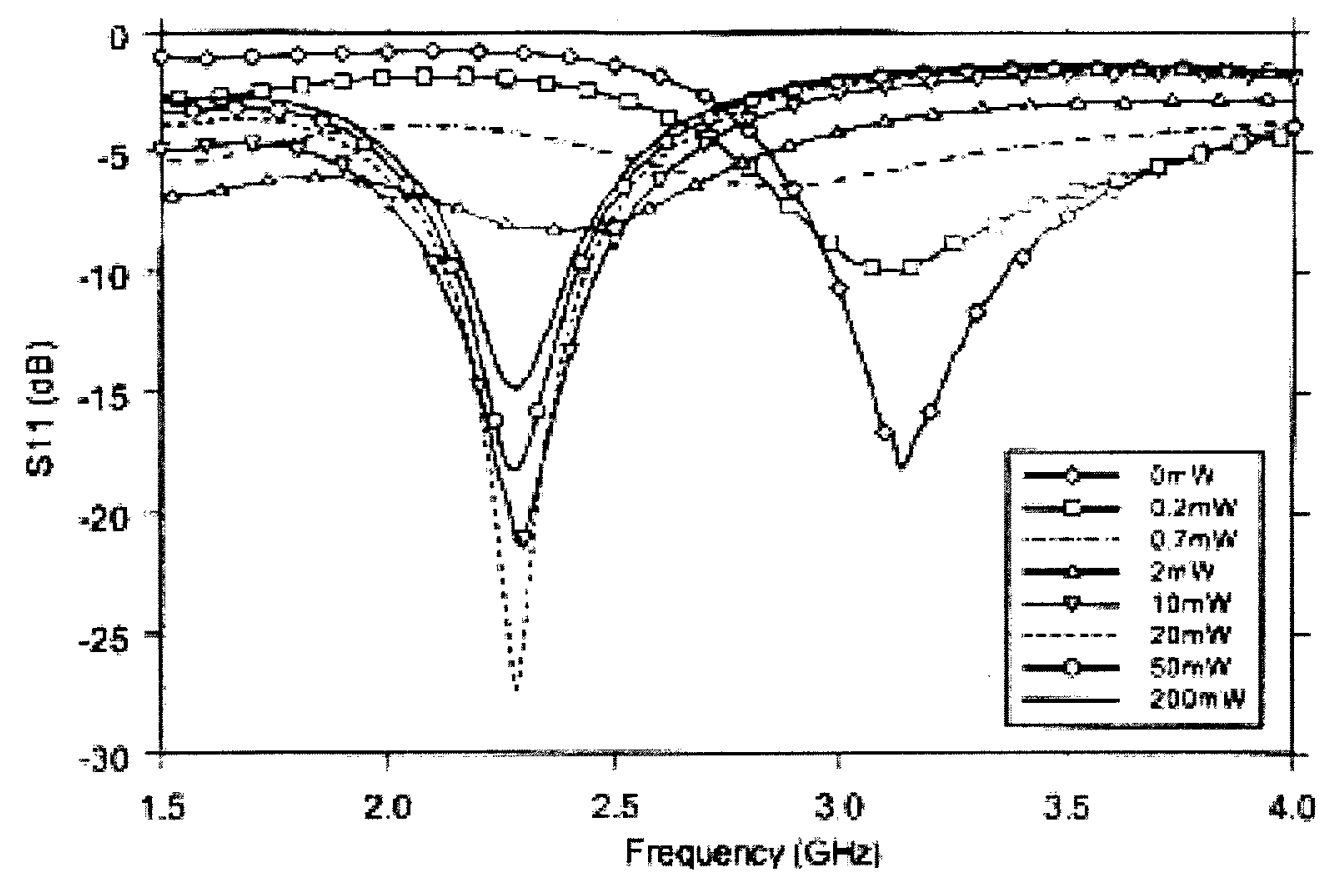

Figure 4.4 Return loss of the dipole antenna as a function of light intensity [29].

While this design successfully demonstrated optical control of an antenna, it suffers from the complexity and expense of inserting discrete electronic devices into the structure.

The novel antenna design presented in the next section attempts to facilitate the implementation of optical tunability through simple deposition of optically-sensitive polymer material in appropriate areas of the structure. 


\subsection{Tunable Dipole Antenna Design for GSM Band (1900 MHz}

\section{to $2100 \mathrm{MHz}$ ).}

The goal of this section is to achieve a tunable antenna whose centre frequency shifts from $1.9 \mathrm{GHz}$ to $2.1 \mathrm{GHz}$ upon optical illumination. Such a design is intended to provide partial coverage of the complete $1.9 \mathrm{GHz}$ to $2.2 \mathrm{GHz}$ frequency band with a reasonable impedance match (better than $10 \mathrm{~dB}$ return loss).

A half-wave dipole antenna can be designed using the transmission line model [30]. The antenna will be designed on Corning 7059 glass to allow the transmittance of light through the substrate. The length of each arm $\mathrm{L}$ is given as $L=\lambda_{\text {eff }} / 4$

$$
\text { with } \lambda_{e f f}=\frac{c}{f \sqrt{\varepsilon_{e f f}}}
$$

where $f$ is the resonance frequency $(1.9 \mathrm{GHz}$ and $2.1 \mathrm{GHz})$ while $c$ is the speed of light $3.0 \times 10^{8} \mathrm{~ms}^{-1}$. The effective dielectric constant $\varepsilon_{\text {eff }}$ can be calculated from Eqn. (4.2) [11]

$$
\varepsilon_{\text {eff }}=\frac{\varepsilon_{r}+1}{2}+\frac{\varepsilon_{r}-1}{2} \frac{1}{\sqrt{1+12 d / W}}
$$

This is valid for a microstrip line, but will serve to provide an initial estimate of the required strip length for the printed dipole without an underlying ground plane.

The parameters of the glass substrate are $\varepsilon_{r}=5.84$, and thickness $\mathrm{d}=1.22 \mathrm{~mm}$. For a trace width arbitrarily chosen as $\mathrm{W}=0.85 \mathrm{~mm}$, the $\varepsilon_{\text {eff }}=3.94$ and therefore the length $L$ at $1.9 \mathrm{GHz}$ is $19.89 \mathrm{~mm}$ while at $2.1 \mathrm{GHz}$ the length is $18.23 \mathrm{~mm}$. 
The antenna was designed with these starting values of $L$ in Ansoft HFSS as shown in

Figure 4.5. The antenna was fed by an internal 50 $\Omega$ "Lumped Port" as shown in Figure 1.6.

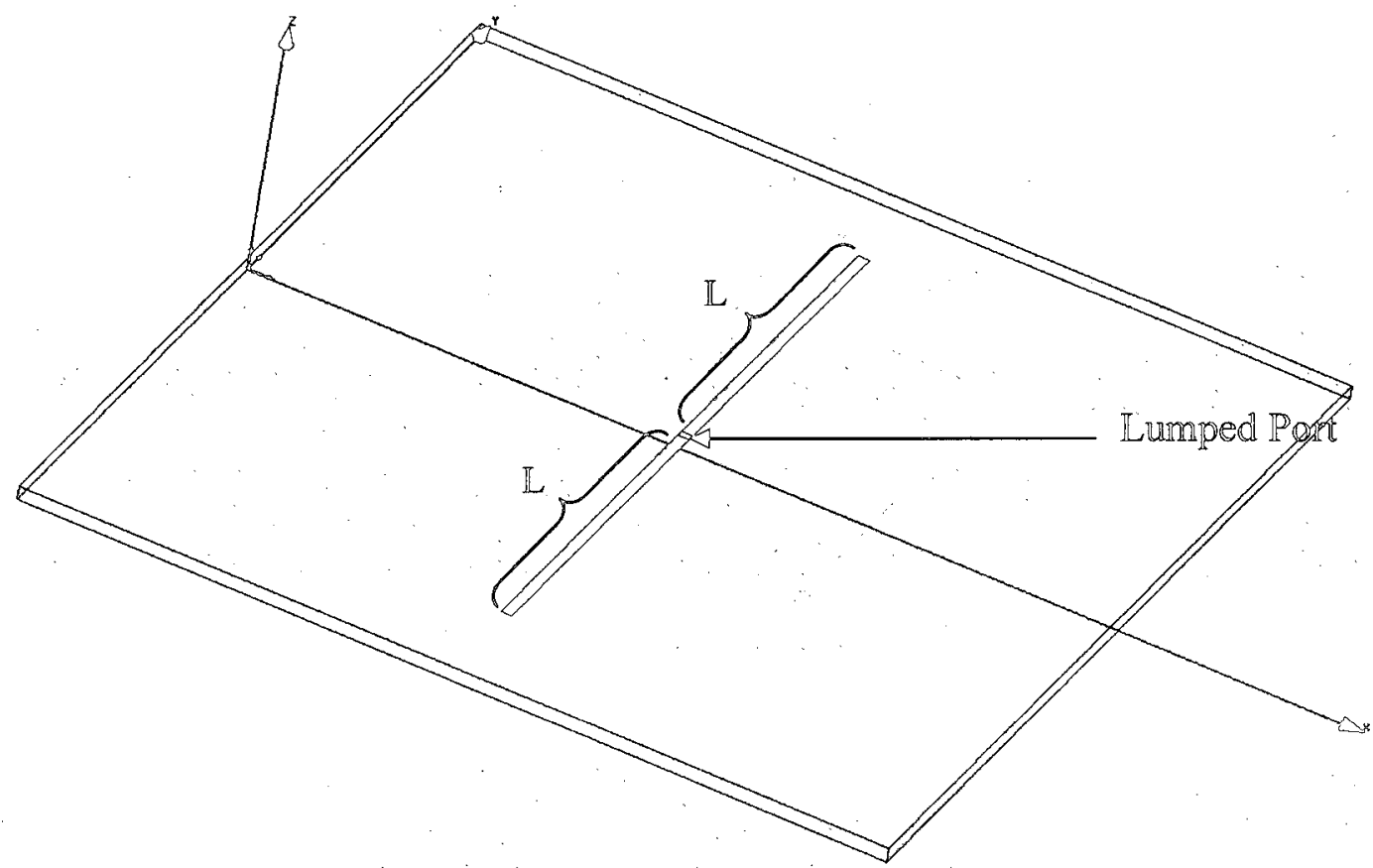

Figure 4.5 Dipole antenna structure in $\mathbb{H} \mathbb{F S S}$ (feed not included).

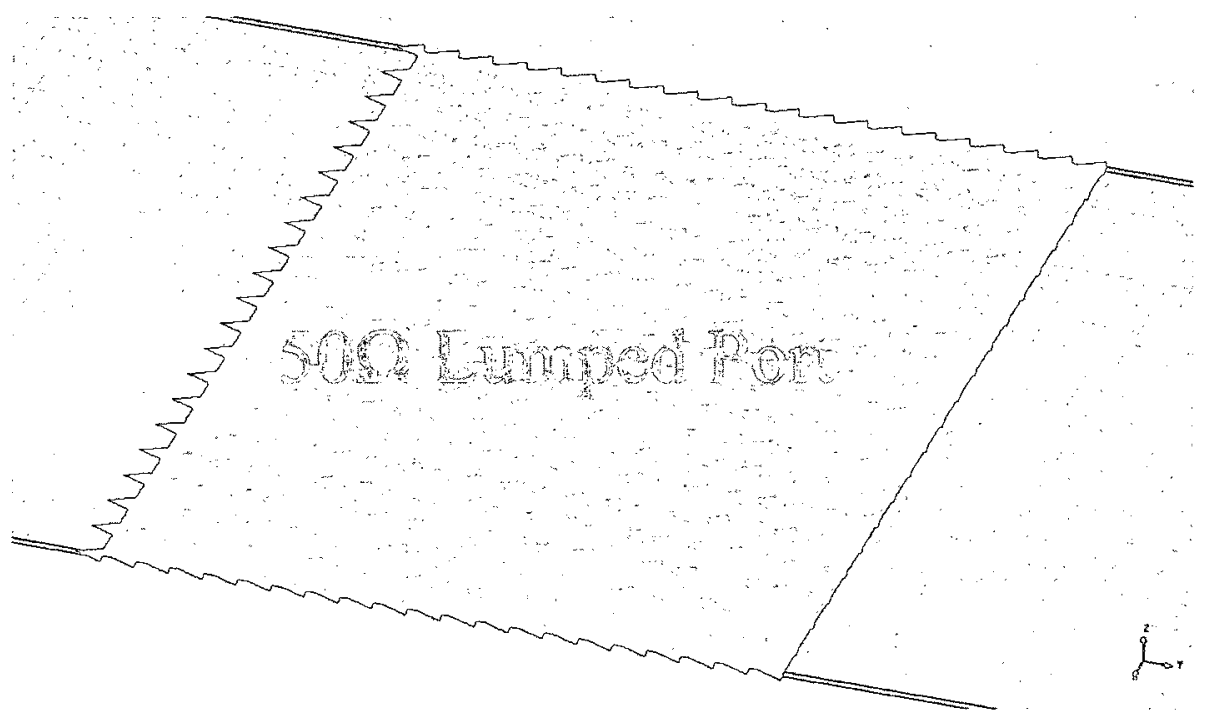

Figure 4.6 Lumped port in HFSS. 
Figure 4.6 shows the Lumped port in HFSS, the length of the port indicates the spacing between the two dipole arms. This space must be well modeled since it affects the impedance of the antenna. Initially the calculated dipole length was used with a port length (spacing between arms) of $1 \mathrm{~mm}$. The design was simulated and then optimized to get the required resonance frequency. Table 4.1 shows the optimized lengths and the spacing between the antenna arms.

Table 4.1 Optimized lengths and arm spacing for the dipole antenna.

\begin{tabular}{|l|c|c|}
\hline \multicolumn{1}{|c|}{ Parameters } & $1.9 \mathrm{GHz}$ & $2.1 \mathrm{GHz}$ \\
\hline length of each arm $(\mathrm{mm})$ & 26.60 & 23.7 \\
\hline width of the arm (mm) & 0.85 \\
\hline space between arms & 0.60 \\
$(\mathrm{~mm})$ & \\
\hline $\mathrm{d}$ of the substrate (mm) & \\
\hline$\varepsilon_{r}$ of the substrate & 1.22 \\
\hline tan $\delta$ of the substrate & \\
\hline
\end{tabular}

Figure 4.7 and Figure 4.8 show the simulated S11 and the input impedance of the $1.9 \mathrm{GHz}$ antenna (26.60 $\mathrm{mm}$ dipole arm). The real part of the impedance was $55 \Omega$ while 
the imaginary was $-j 2.68 \Omega$. The electric field intensity was plotted on the structure as shown in Figure 4.9. It is seen that the highest fields exist in the feed gap and that residual fields are present at the opposite ends, indicating proper dipole operation. The $\mathrm{S} 11$, radiation pattern and antenna impedance for the $2.1 \mathrm{GHz}$ antenna $(23.7 \mathrm{~mm}$ dipole arm) are shown in Figure 4.10, Figure 4.11 and Figure 4.12, respectively.

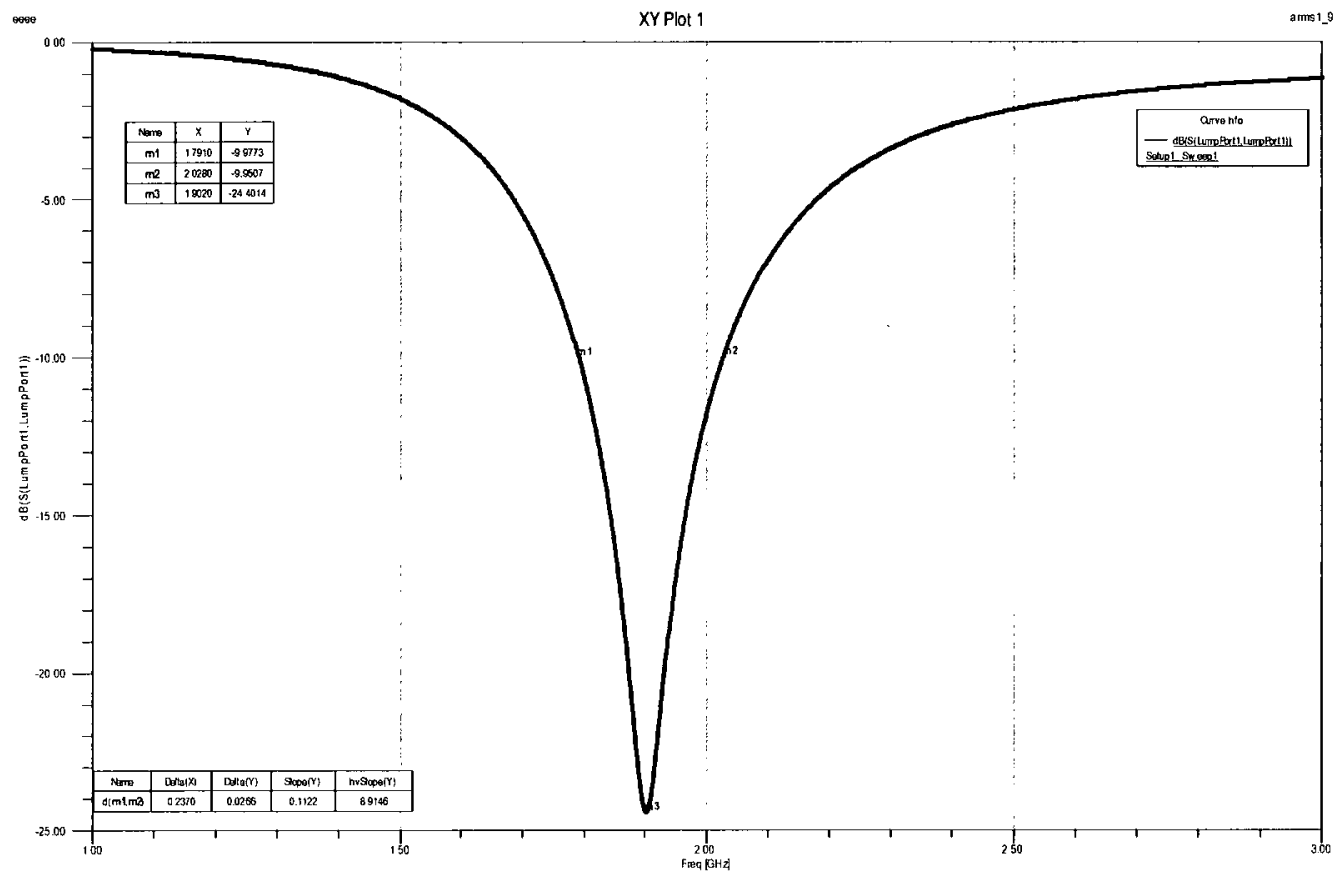

Figure 4.7 Simulated S1 1 of $26.6 \mathrm{~mm}$ dipole (for $1.9 \mathrm{GHz}$ operation). 


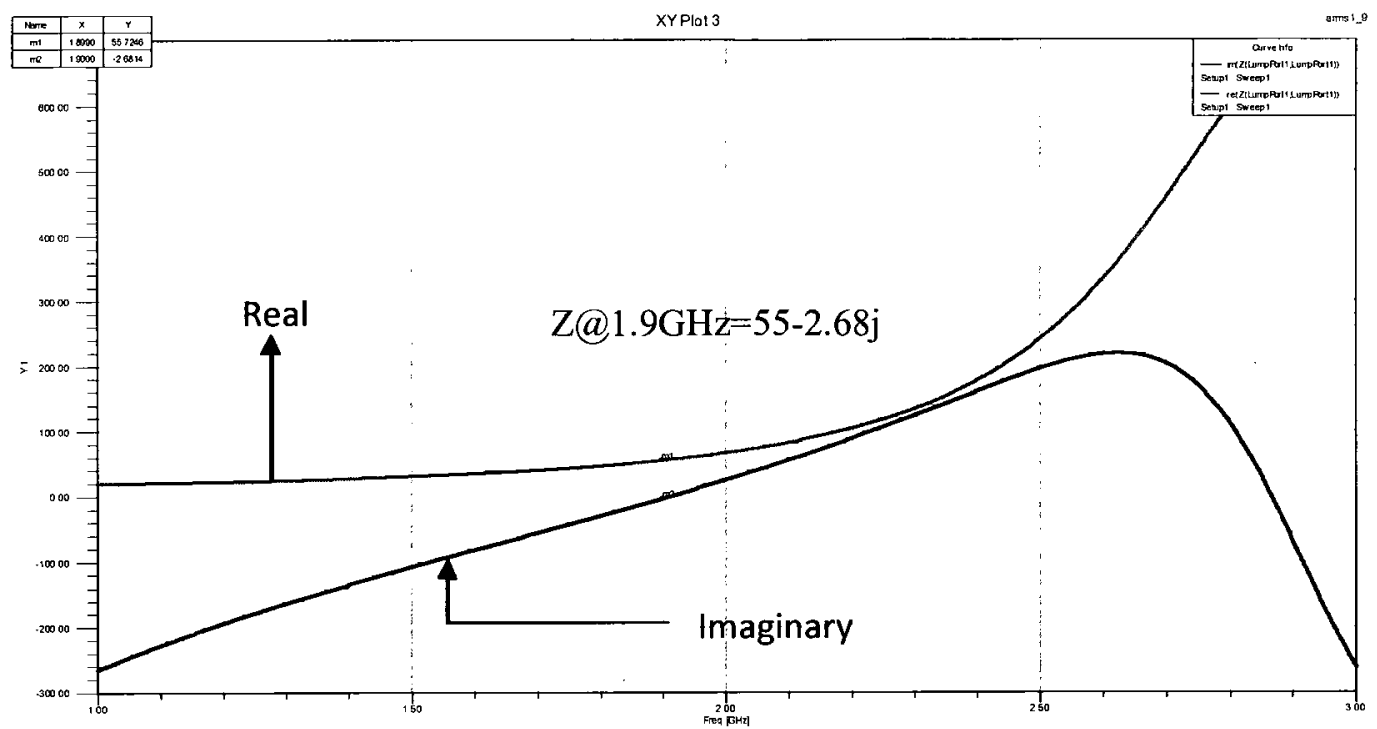

Figure 4.8 Real and imaginary parts of impedance of the $26.6 \mathrm{~mm}$ dipole (for $1.9 \mathrm{GHz}$ operation).

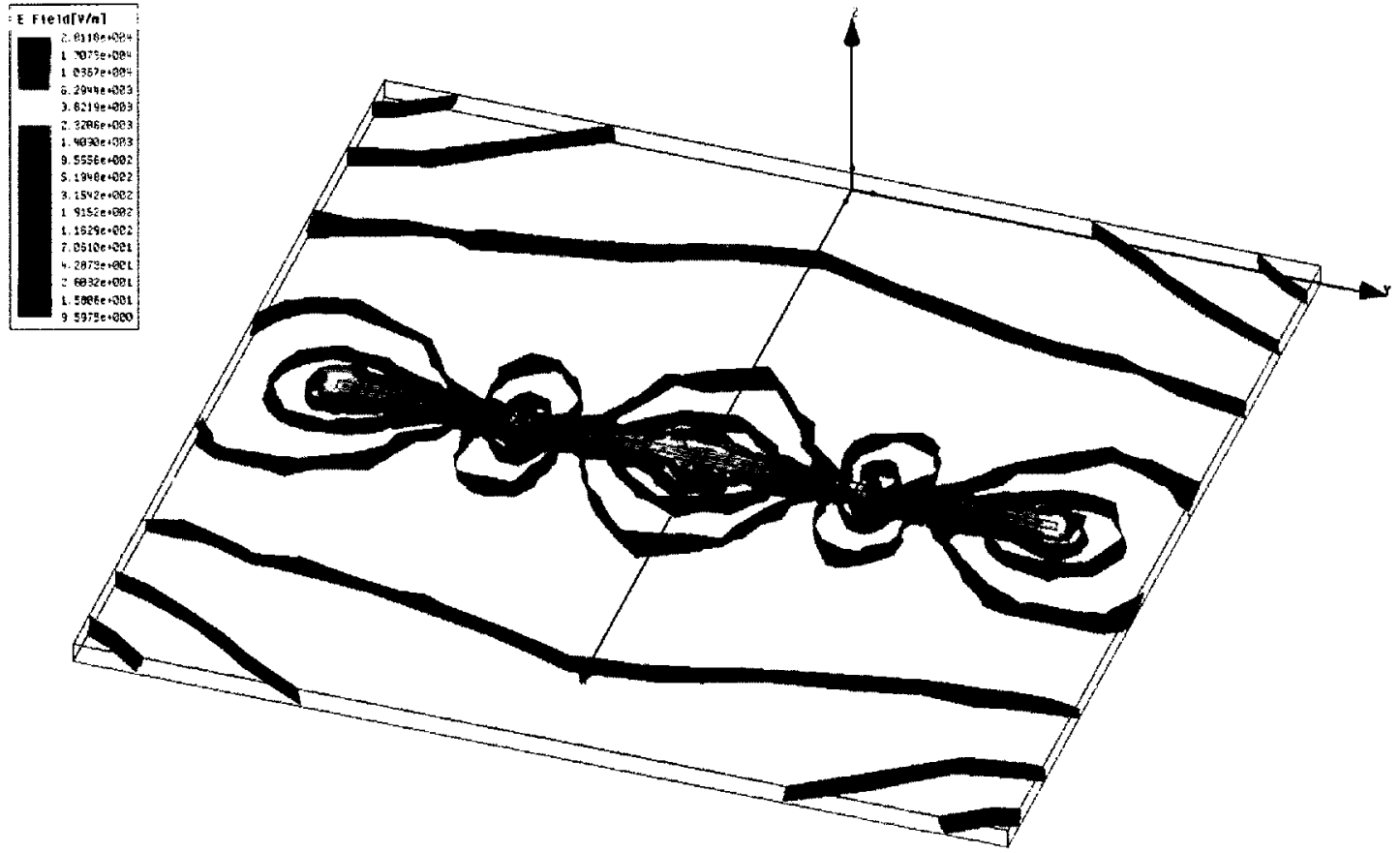

Figure 4.9 Distribution of E-fields for the $26.6 \mathrm{~mm}$ dipole at $1.9 \mathrm{GHz}$ with high coupling at the feed. 


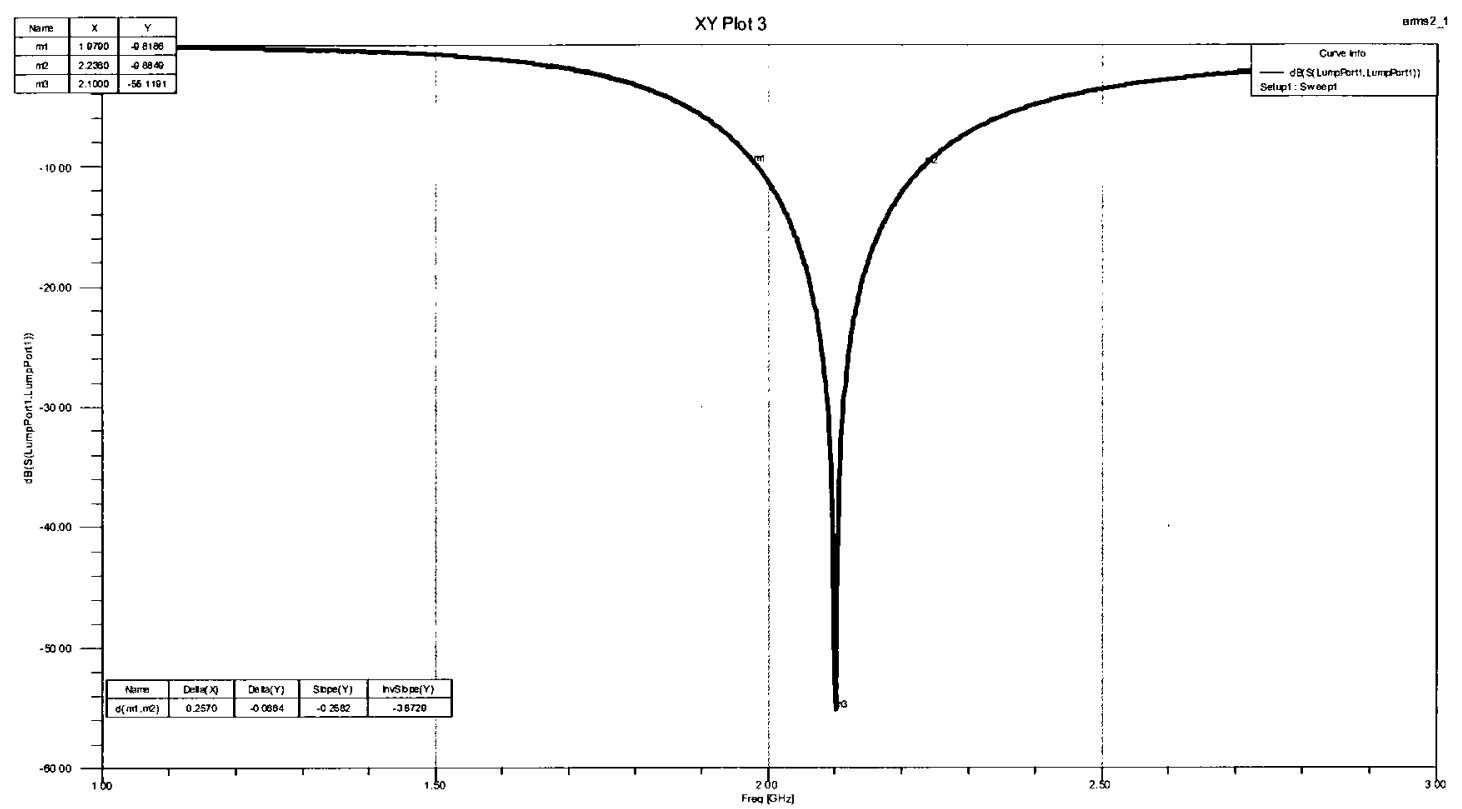

Figure 4.10 Simulated S11 of the $23.7 \mathrm{~mm}$ dipole (for $2.1 \mathrm{GHz}$ operation).
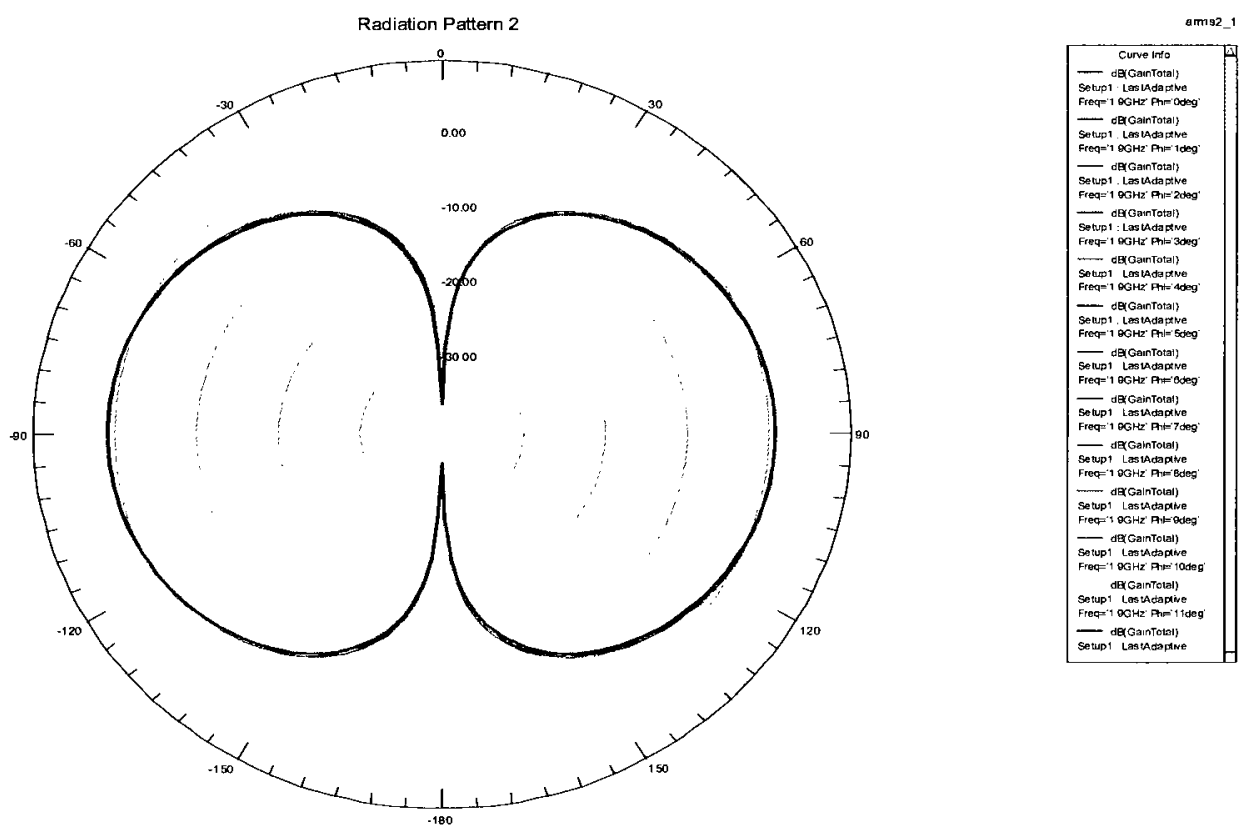

Figure 4.11 Simulated radiation pattern at $2.1 \mathrm{GHz}$ for the $23.77 \mathrm{~mm}$ dipole at E plane . 


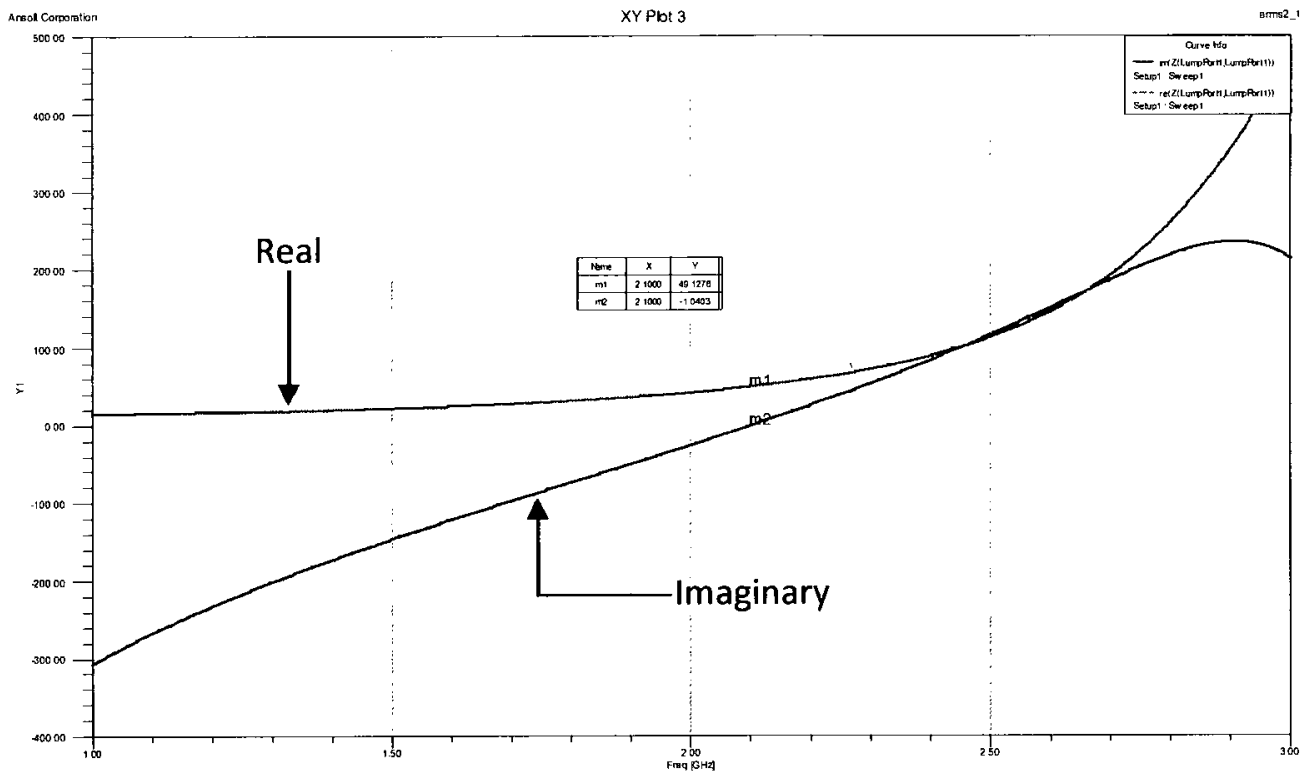

Figure 4.12 Simulated real and imaginary parts of impedance of the $23.7 \mathrm{~mm}$ dipole (for $2.1 \mathrm{GHz}$ operation).

A gap over which the composite polymer is to be deposited was then created along the length of the $2.1 \mathrm{GHz}$ dipole, as seen in Figure 4.13. The small gap was made in a location so that the antenna will resonate at either $2.1 \mathrm{GHz}$ (polymer conducting, effective arm length of $26.6 \mathrm{~mm}$ ) or at $1.9 \mathrm{GHz}$ (polymer non-conducting, effective arm length of $23.7 \mathrm{~mm}$ ). The difference in the two lengths is $2.9 \mathrm{~mm}$, which is too large to fill with only optically-sensitive polymer. The choice of gap size in fact requires careful consideration: if it is too wide, the required polymer illumination area (and required optical power) becomes impractically large; if it is too narrow, then there will be unwanted coupling between the metal strips. The gap was therefore simulated for different gap lengths. It was found that $0.4 \mathrm{~mm}$ was the smallest gap between L1 and L2 that will make the antenna resonate at $2.1 \mathrm{GHz}$ without being affected by the additional nearby strips necessary for $1.9 \mathrm{GHz}$ operation. 
The final dimensions of the tunable dipole antenna are therefore:

$$
\begin{aligned}
& \mathrm{L} 1=23.7 \mathrm{~mm} \\
& \mathrm{~L} 2=2.5 \mathrm{~mm} \\
& \mathrm{G}=0.4 \mathrm{~mm}
\end{aligned}
$$

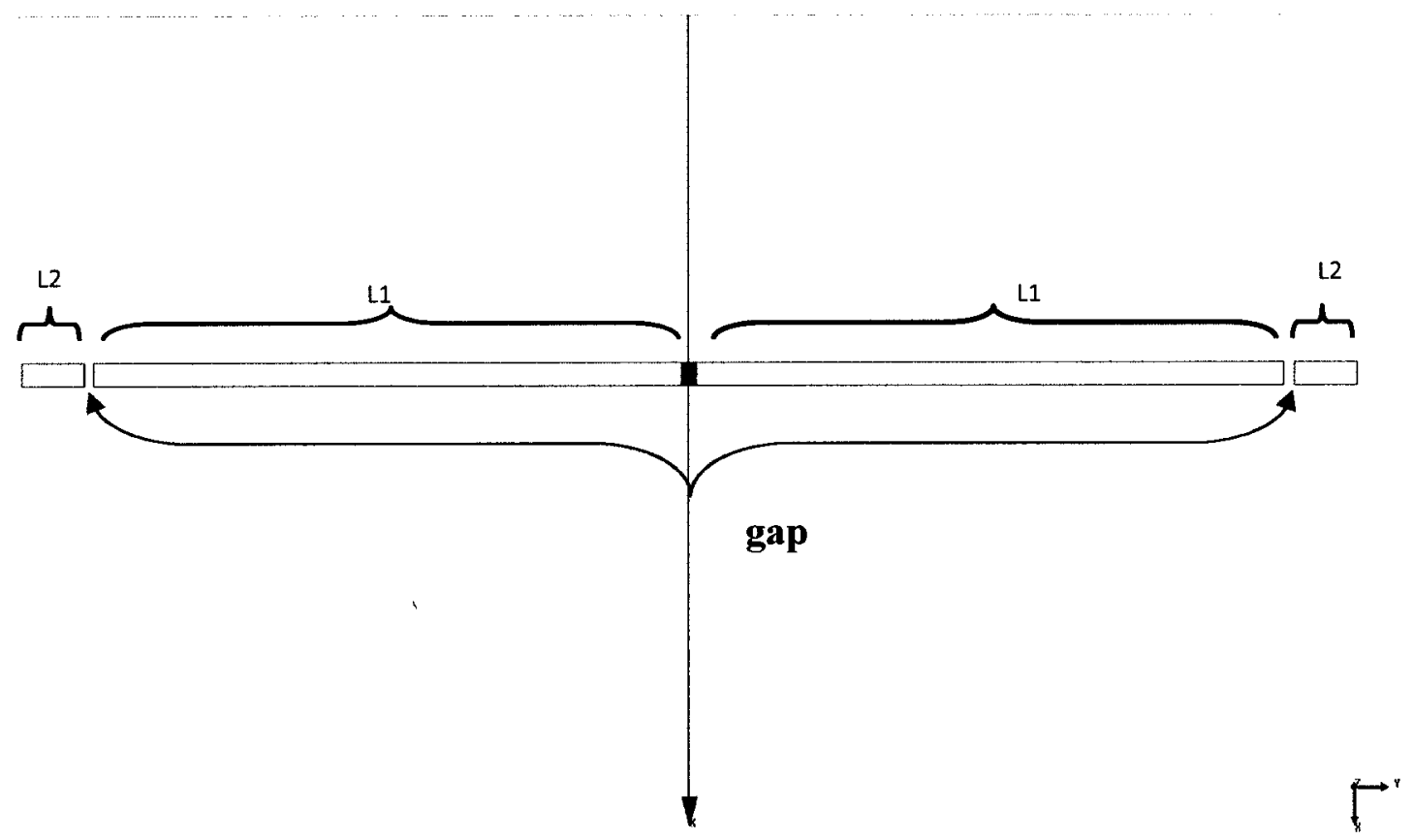

Figure 4.13 The new dipole antenna structure with the gap placed along the dipole arm.

Figure 4.14 shows the input match of the structure with gap length of $0.4 \mathrm{~mm}$, resonating at $2.1 \mathrm{GHz}$. Figure 4.15 shows the E-field plot of the new structure with the gap. It was discovered that there is still small coupling between the main $\operatorname{arm} \mathrm{L}_{1}$ and the 
extended arm $L_{2}$, but not strong enough to shift the resonance frequency away from 2.1 GHz.

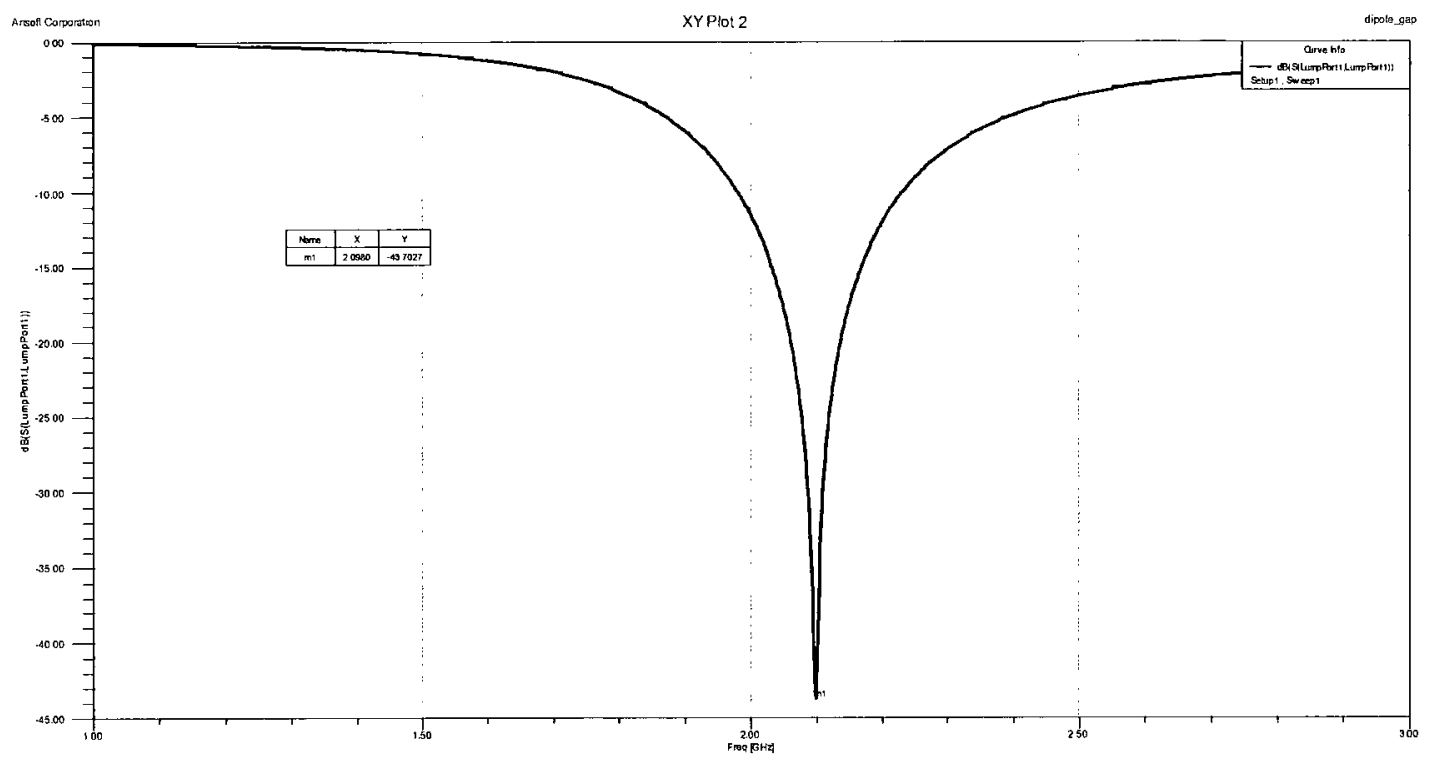

Figure 4.14 Simulated S11 of the segmented dipole with $0.4 \mathrm{~mm}$ gap in each arm.

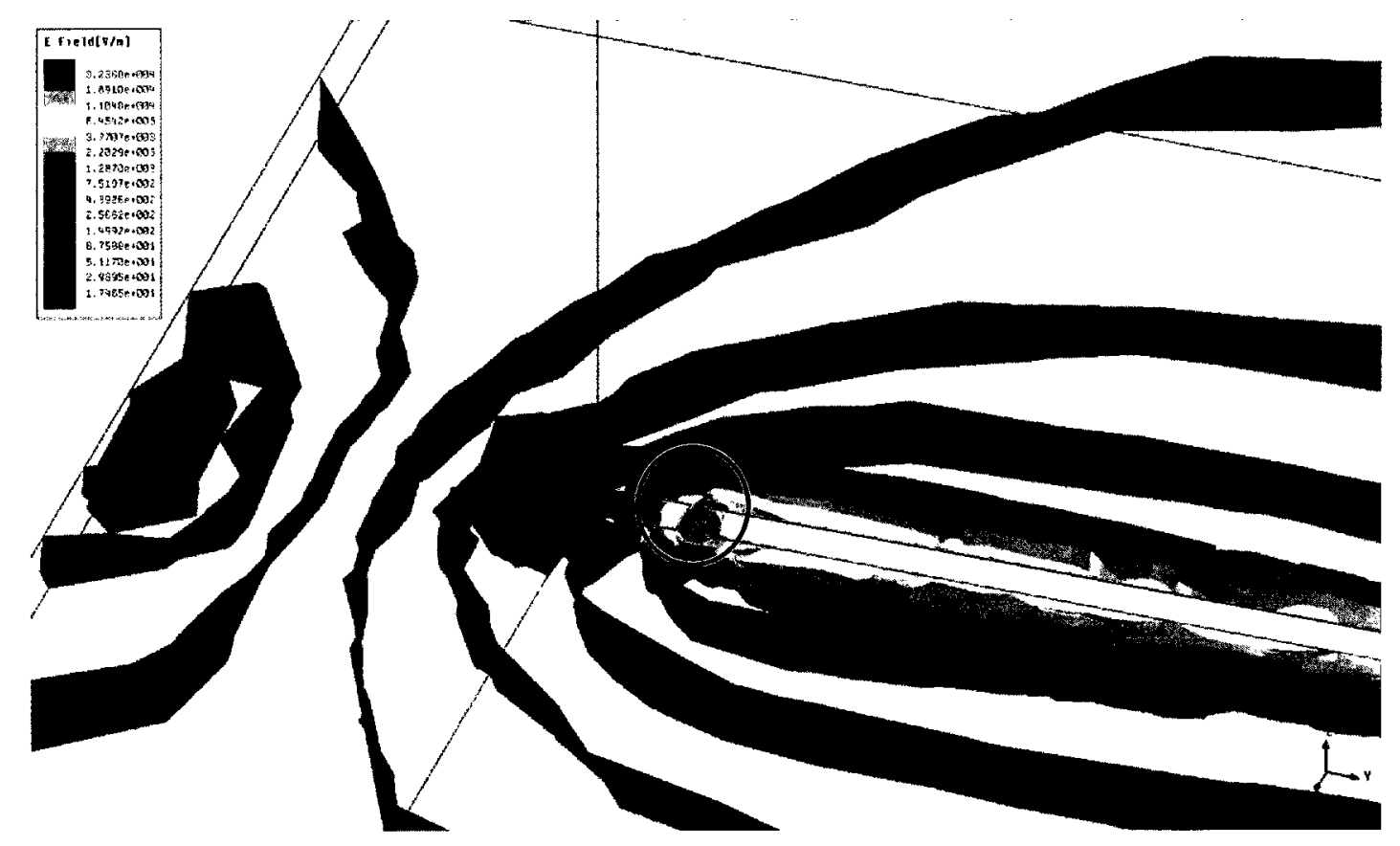

Figure 4.15 E-field plot of the segmented dipole arm showing a small coupling between main $\operatorname{arm} \mathrm{L}_{1}$ and extension $\mathrm{L}_{2}$. 
The photoconductive material was modeled in the gap as shown in Figure 4.16. It has the same thickness as the metal sheet. Conductivity $(\sigma)$ values ranging from insulating $10^{-9}$ $(\Omega \mathrm{m})^{-1}$ to conducting $10^{+5}(\Omega \mathrm{m})^{-1}$ were used for the material and simulated in HFSS to represent all possible material property variations obtainable under optical illumination. Figure 4.17 shows resonances at $1.9 \mathrm{GHz}$ and $2.1 \mathrm{GHz}$, and non-resonant (NR) conditions as the conductivity value was changed over this range.

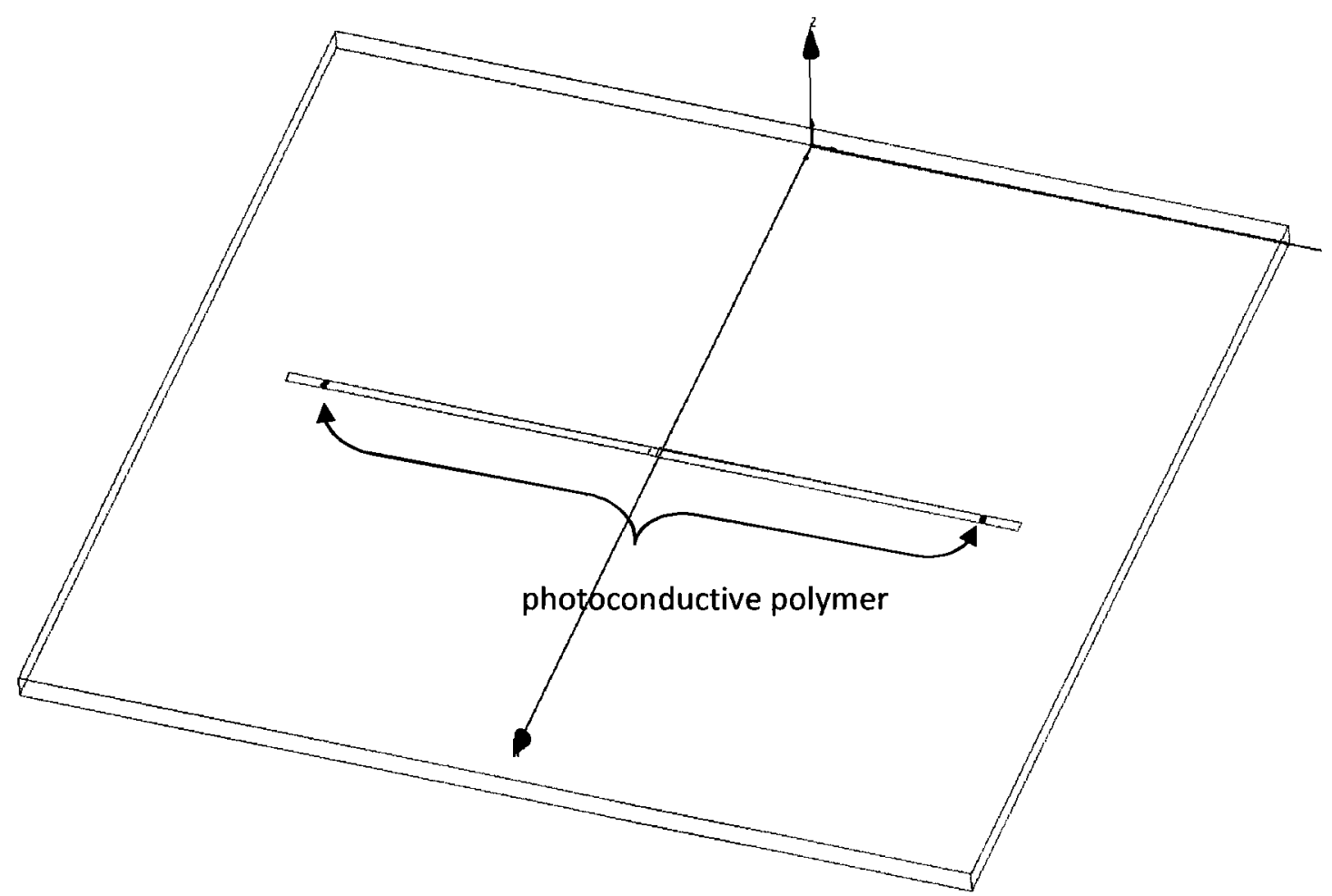

Figure 4.16 Segmented antenna structure with the photoconductive material placed in the gaps. 


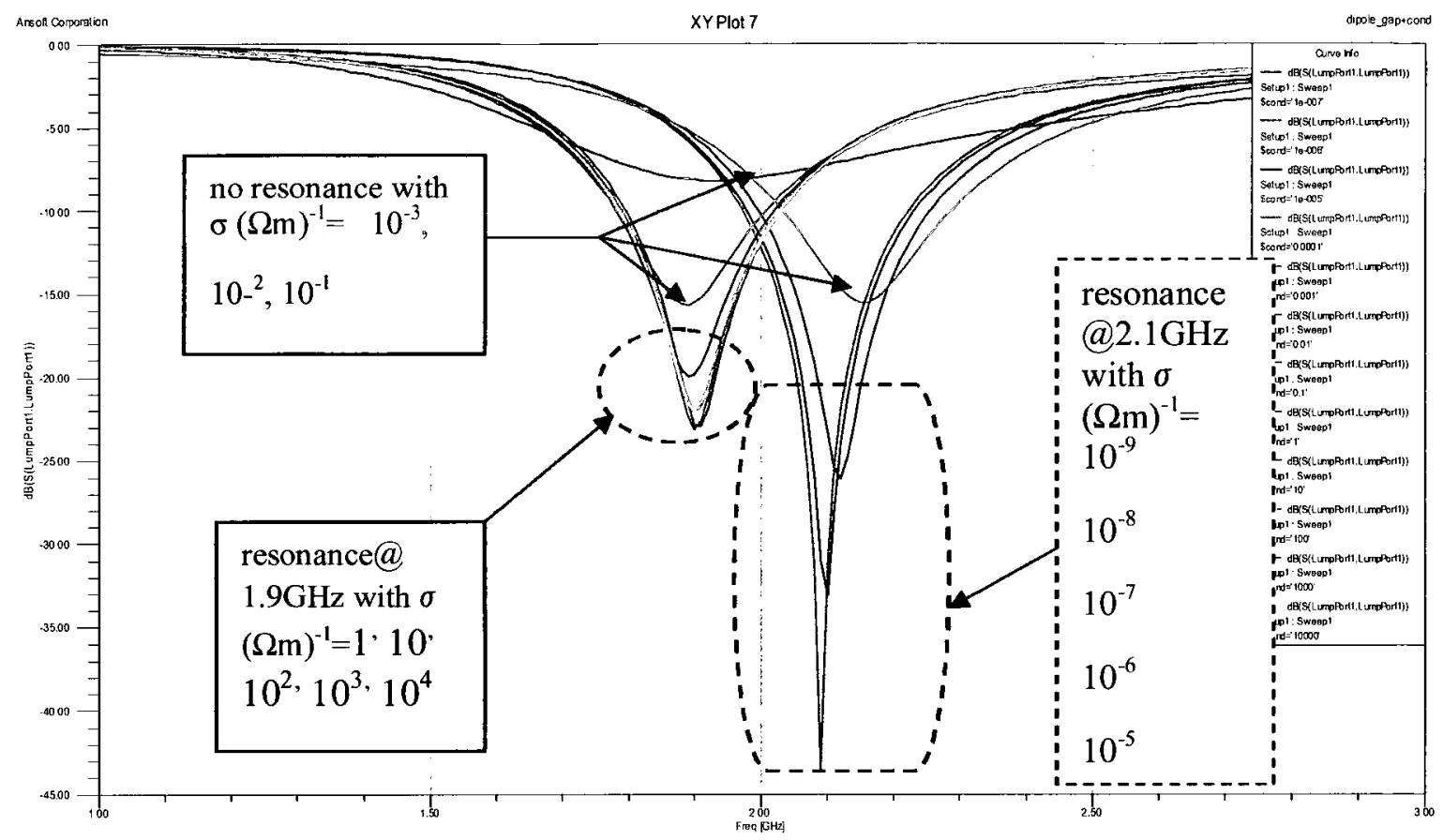

Figure 4.17 Resonance frequency of the antenna with different conductivity values of the CdS composite polymer.

\subsection{Estimation of the Required Polymer Properties.}

It was observed from Figure 4.17 that the resonance was at $2.1 \mathrm{GHz}$ for very low conductivity of $10^{-9}$ to $10^{-4}(\Omega \mathrm{m})^{-1}$ polymer. Here the material can be termed to be an insulator. The light can be assumed to be OFF for the photoconductive polymer. For conductivity between $10-^{3}$ and $10^{-1}(\Omega \mathrm{m})^{-1}$ no resonance occurred and the material was neither a good conductor nor a good insulator. For material conductivity greater than $1(\Omega \mathrm{m})^{-1}$ the resonance frequency changed to $1.9 \mathrm{GHz}$. This is the "LIGHT ON" condition for the photoconductive polymer. It was concluded that conductivity $\mathrm{g} 1(\Omega \mathrm{m})^{-1}$ of the material is good enough to shift the resonance frequency. Table 4.2 shows the conductivity values with correspondent resonant frequency and also the representative 
material type.

The future generations of optically sensitive polymers will require conductivities varying from $10^{-3} \mathrm{~S} / \mathrm{m}$ or lower (sufficiently insulating with light OFF) to $10^{+2} \mathrm{~S} / \mathrm{m}$ or higher (sufficiently conducting with light $\mathrm{ON}$ ) to be useful in this application. 
Table 4.2 Dipole resonance frequency with conductivity and material type for CdS composite in gap

\begin{tabular}{|l|l|l|}
\hline Conductivity value $(\Omega \mathrm{m})^{-1}$ & Material Type & Resonant frequency \\
\hline $10^{-9}$ & Insulator & 2.10 \\
\hline $10^{8}$ & Insulator & 2.10 \\
\hline $10^{-1}$ & Insulator & 2.10 \\
\hline $10^{6}$ & Insulator & 2.10 \\
\hline $10^{5}$ & Insulator & 2.10 \\
\hline $1-^{4}$ & Insulator & 2.10 \\
\hline $10-^{3}$ & semiconductor & $\mathrm{NR}$ \\
\hline $1-^{2}$ & semiconductor & $\mathrm{NR}$ \\
\hline $10^{-1}$ & semiconductor & $\mathrm{NR}$ \\
\hline 1 & Conductor & 1.9 \\
\hline 10 & Conductor & 1.9 \\
\hline $10^{1}$ & Conductor & 1.9 \\
\hline $10^{2}$ & Conductor & 1.9 \\
\hline $10^{3}$ & & 1.9 \\
\hline
\end{tabular}




\subsection{Conclusion}

This chapter presented the preliminary design of an optically tunable dipole antenna for the $1.9 \mathrm{GHz}$ and $2.1 \mathrm{GHz}$ GSM communication bands. A printed dipole having $23.7 \mathrm{~mm}$ arm length and $0.4 \mathrm{~mm}$ gaps filled with photoconducting material, would produce the desired performance. The theoretical results obtained indicate that future polymer material development should aim to achieve conductivities varying from $10^{-3} \mathrm{~S} / \mathrm{m}$ or lower (sufficiently insulating with light OFF) to $10^{+2} \mathrm{~S} / \mathrm{m}$ or higher (sufficiently conducting with light $\mathrm{ON}$ ) in order to be useful in this application. 


\section{Chapter 5}

\section{Conclusion and Future Work}

\subsection{Conclusion}

The characterization and extraction of material properties of polymer containing CdS nanoparticles was done in this thesis. The reflection method was used for the material characterization of planar microwave interdigitated capacitors overlaid with the mixture of polymer containing CdS nanoparticles with $75 \%$ to $25 \%$ ratio by weight. The measured return loss and the S11 on the Smith chart as a function of optical illumination shows that the material was photoconductive. There was an increase in return loss when the light was on for all frequencies and the curve of S11 also moved toward the center of the Smith chart. This was due to polarization loss or conduction loss exhibited by the material under test. For the extraction of material properties, dielectric constant of 4 and loss tangent of 0.004 was obtained with light off, however the dielectric constant remains unchanged for light on while the loss tangent increased to 0.11 . The extraction of the material properties was done by matching the S11 parameters of the fabricated model, lumped element equivalent model and the HFSS fabricated model for each state using commercial availablle software Agilent ADS.

The photoconductive properties of the material were used in the theoretical design of a tunable a dipole antenna for $1900 \mathrm{MHz}$ and $2100 \mathrm{MHz}$ band. The tunable dipole antenna was designed in ANSOFT HFSS a, 3D full-wave electromagnetic field 
simulator. It was concluded that conductivity near $1(\Omega \mathrm{m})^{-1}$ of the material is enough to shift the resonance frequency from $2100 \mathrm{MHZ}$ to $1900 \mathrm{MHz}$ if the photoconductive material was placed along the segmented gap of the antenna arm structure .

\subsection{Future Work.}

An interdigitated capacitor with smaller feature size would have given a better response, but due to the feature size of the David Mann pattern generator, the initial $10 \mu \mathrm{m}$ spacing between the fingers was increased to $12.5 \mu \mathrm{m}$. Also another method of etching would have been preferred. The wet etching method led to further increase in the minimum size feature of the interdigitated capacitor. The test structure also should have been de-embedded to extract the actual capacitance of the IDC. Conductivity measurements of the polymer using the four point probe method should be done in order to determine the actual conductivity as a function of light intensity. The theoretical design tunable antenna should be fabricated and tested to confirm it predicted performance in switching from $1900 \mathrm{MHz}$ to $2100 \mathrm{MHz}$ operation. 


\section{REFERENCES}

[1] B. Boyer, J. Haidar, A. Vilcot, and M. Bouthinon, 'Tunable microwave load based on based Photoinduced plasma in silicon' IEEE Transaction on Microwave Theory and Techniques, vol.45, issue 8, pp. 1362-1367, Aug. 1997.

[2] R.K. Shevgaonkar and S. Shevgaonkar, 'Study of optically controlled microwave devices' International Union of Radio Science: XXLX General Assembly, August 7-16, 2008, Chicago, USA.[online]. Available: http://www.ursi.org/Proceedings/ProcGA05/pdf/D07b.5(01817).pdf [Accessed: May. 17, 2009]

[3] M.R. Chaharmir, J. Shaker, M. Cuhaci and A. Sebak, "Novel Photonically-controlled reflectarray antenna" IEEE Transactions on Antennas and Propagation, vol. 54, no. 4, pp 1134-1142, April 2006.

[4] R.E. Hummel "Electrical properties of materials" in Understanding Materials Science, $2^{\text {nd }}$ ed., New York: Springer, 2005, pp.186-210.

[5] D. Seanor, Electrical Properties of Polymers, New York and London: Academic Pr, Nov. 1982, pp. 116-122.

[6] Y. Wang "Photoconductivity of fullerene" Central research and Development, Du Pont Co, Nature 356, pp 585-587, April 1992.

[7] Y. Chen, et. al, "Researches on the photoconductivity and UV-visible absorption spectra of the first $\mathrm{C}_{60}$ - chemically modifies poly (N-vinlycarbazole)" Polymer bulletin, vol. 36, no. 2 , pp 203-208, Feb. 1996.

[8] J. E. Mark, Ed., Physical properties of polymer handbook, $2^{\text {nd }}$ ed., New York: Springer, 2007, pp. 11-14, 38-40.

[9] A.A. Zaky and R. Hawley, Dielectric Solids, London: Dover, 1970, pp 7-22.

[10] L.F. Chen et al., Microwave Electronics: Measurement and Materials Characterization, NY: Chichester, Wiley 2004. pp. 11-14, 38-40

[11] D.M. Pozar, Microwave Engineering, $3^{\text {rd }}$ ed., New York: Wiley, 2005.pp.9-11, 160-165.

[12] T. Blythe and D. Bloor, Electrical Properties of Polymers, $2^{\text {nd }}$ Ed. New York: Cambridge University press 2005 , pp $38-57$.

[13] A. Petosa, D.J. Roscoe, S. Ittipitiboon and M. Cuhaci "Tunable Dipole Antennas", IEEE Antenna and Propagation, vol. 2, no.5 July 1993. pp 672-675.

[14] A.R. Brown, and G.M. Rebeiz, 'A varactor-tuned RF filter' IEEE Transaction on 
Microwave Theory and Techniques, vol. 48, issue 7, pp. 1157 - 1160, Jul. 2000.

[15] Y. Fukuda, Y. Otani, H. Toyota, and T. Ono, 'Electrical Characterization Techniques of Thin Film Using Metal-Insulator-Metal' Japanese Journal of applied Physics, vol. 46, pp. 6984-6986, 2007.

[16] J.A. Chilton and M.T. Goosey, Special polymers for electronics \& optoelectronics, Chapman \& Hall, London, 1995, pp 23-27, 284-305.

[17] S. Nespurek, V. Cimrova and J. Pfleger, "Charge carrier photogeneration in polymers" Colloid \& Polymer Science, vol. 269, no. 6, pp 556-565, 1991.

[18] T.K. Daubler, I. Glowacki, U. Scherf, J. Ulanski, H.H. Horhold and D. Neher "Photogeneration and transport of charge carriers in hybrid materials of conjugated polymers and dye-sensitive Ti0 $0_{2}$ " Journal of Physics, vol. 86, no. 12, 1999.

[19] S. Tay, et al., "Photorefractive polymer composite operating at the optical communication wavelength of 1550nm" Applied physics letters, vol. 85, no. 20, pp 4561- 4563, 2004

[20] B. Kippelen and N. Peyghambarian, "Photorefractive polymers and their application," polymers for photonics applications II, vol. 161, 2003, pp 87-156.

[21] Y. Yashchyn, and J. Modeski, "Low-cost ferroelectric-ceramic polymer scan antenna," in Proceedings of SBMO/IEEE MTT-S International Conference, 2003, vol.1, pp401-405.

[22] J.H. Schaffner, et al., "Microwave Components with MEMS Switches" $30^{\text {th }}$ European Microwave Conference, 2000.

[23] S. Gevorgian, A. Vorobiev, D. Kuylenstierna, A. Deleniv, S. Abadei, A. Eriks- son, and P. Rundqvist, "Silicon substrate integrated tunable ferroelectric devices for microwave components," Integrated Ferroelectrics, 2004, vol. 66, issue 1, pp. 125-138.

[24] B. Acikel, "High Performance Barium Strontium Titanate Varactor Technology for Low Cost Circuit Applications," Ph.D. dissertation, University of California, Santa Barbara, USA, 2002.

[25] B. Pratsuik, Y. Prokopenko, and Y. Poplayko, "Tunable sphere and cubic dielectric resonator" Microwave, Radar and Wireless Communications, 2008 ,pp 1-4. 
[26] I.D. Robertson and S. Lucyszyn, RFIC and MMIC Design and Technology, $2^{\text {nd }}$ ed., London: Institution of Electrical Engineers, 2001.

[27] Y. Fukuda, Y. Otani, H. Toyota and T. Ono, "Electrical Characterization Techniques of dielectric thin films using metal-insulator-metal structures," Japanese Journal of Applies Physics, vol. 46, no.10b, pp 6984-6986, Oct. 2007.

[28] R. Esfandiari, D.W. Maki, and M. Siracusa, 'Design of Interdigitated Capacitors and Their Application to Gallium Arsenide,' IEEE Transaction on Microwave Theory and Techniques, vol. 31, issue 1, pp 57-64, Jan. 1983.

[29] C. J. Panagamuwa, A. Chauraya and J. C. Vardaxoglou, "Frequency and beam reconfigurable antenna using photoconduction switches", IEEE Transactions on Antennas and Propagation, vol. 54, no. 2, pp. 449-454, February 2006.

[30] N. Tavassolian, G.E. Ponchak, and J. Papapolymerou, "Compact conformal dipole antenna on organic substrate for $2.4 \mathrm{GHz}$ applications" Antennas and Propagation Society International Symposium, July 2008.

[31] Corning 7059 Barium Borosilicate properties: http://www.vinkarola.com/pdf/CorningGlass 7059 Properties.pdf, 2003 [Sept, 8 2008].

[32] R. Venkatesha and P. Przemyslaw, "Cognitive Functionality in Next Generation Wireless Networks: Standardization Efforts" IEEE Communications Magazine, pp. 72-78, April 2008.

[33] Bruce E. Carey et.al "Flexible Frequency Discrimination Subsystems for Reconfigurable Radio Front Ends" EURASIP Journal on wireless communications and Networking, vol. 3pp. 354-363 March 2005.

[34] Private Communication, S. McGarry, Department of Electronics, Carleton University, Ottawa Ontario.

[35] I.M. Campbell, Introduction to Synthetic Polymers, Oxford Science Publications, 196, 1994. 